\title{
DEVELOPMENT OF CYTOCHEMICAL METHODS \\ FOR THE STUDY OF \\ ASCOSPORE WALL BIOGENESIS AND MATURATION
}

\section{By}

DEMARIS E. LUSK

A DISSERTATION PRESENTED TO THE GRADUATE SCHOOL

OF THE UNIVERSITY OF FLORIDA IN PARTIAL FULFILLMENT

OF THE REQUIREMENTS FOR THE DEGREE OF

DOCTOR OF PHILOSOPHY

UNIVERSITY OF FLORIDA 


\section{ACKNOWLEDGEMENTS}

In retrospect, I find that many people have helped me reach my goal to earn a Ph.D. During my tenure as a student at the University of Florida I have studied with all of my committee members: Dr. Henry C. Aldrich, Dr. James Kimbrough, Dr. Walter S. Judd, Dr. James F. Preston, and Dr. Dana Griffin. Each has had a hand in my training and helped to sharpen my mind scientifically.

I have been fortunate to have had several outstanding non-committee mentors. Foremost of this group is Dr. Greg Erdos (Department of Microbiology and Cell Science) who put a considerable amount of time into my training in cytochemical techniques. Dr. Steven Zam (Department of Microbiology Cell Science) and Robin Brigmon (Department of Environmental Engineering Sciences) were responsible for my training in hybridoma technology and methodology. Dr. Ross Brown (Department of Food Science and Human Nutrition) gave me his time for an individualized course on carbohydrate chemistry. Finally, Dr. William Stern guided me whenever I asked for it, and helped to edit my work.

I appreciate the "hands on" help received from two of my peers: Robin Brigmon who on occasion cared for my research hybridomas, and Dr. Mary Davis who helped me to analyze ELISA data statistically.

I have been lucky to have friends with whom I could discuss science, and share knowledge and from whom I could learn. Most notable of this group are Robin Brigmon, Katy Gropp D.V.M. (Department of Physiology), Julia Wendt (Department of 
Microbiology and Cell Science), Audrey Kalehua (Department of Neuroscience), Chi Guang Wu (Department of Plant Pathology), and Dr. Wendy Zomlefer (Department of Botany). Additionally, I wish to thank Gavin Goebel, my sister Vivian Cook, the late Wendy Knowles, and Pamela Handley for their friendship, love, support and encouragement.

I received two very important gifts for use in my research: a culture of Ascodesmis sphaerospora from Dr. Kimbrough, and GS-II lectin-gold from Katy Gropp. My research was supported by a grant from the Gas Research Institute, the University of Florida Interdisciplinary Center for Biotechnology Research Electron Microscopy Core Facility, and the Univerisity of Florida Department of Microbiology and Cell Science. 


\section{TABLE OF CONTENTS}

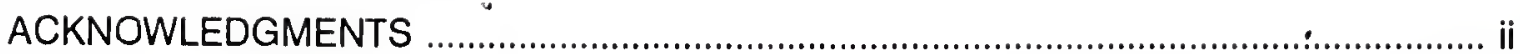

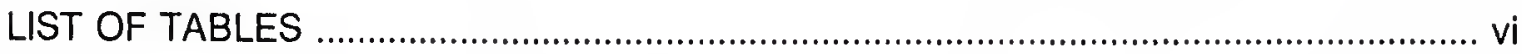

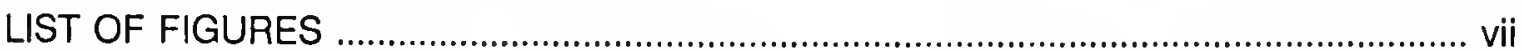

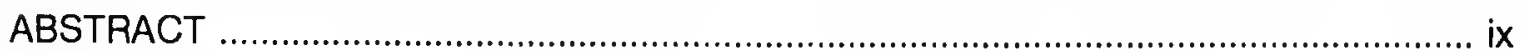

CHAPTERS

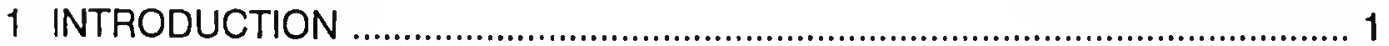

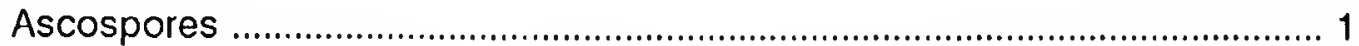

Ascosporogenesis ............................................................................... 3

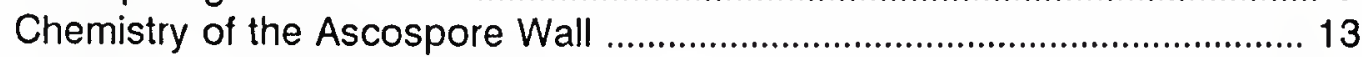

Chemistry of the Hyphal Wall .............................................................. 14

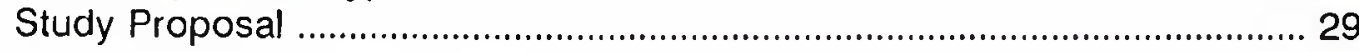

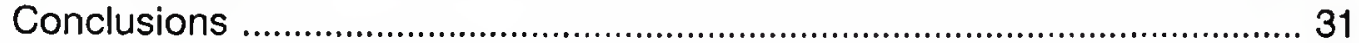

2 STRATEGIES FOR TISSUE PREPARATION AND EMBEDDING .................. 33

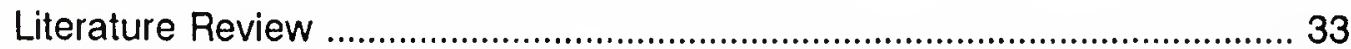

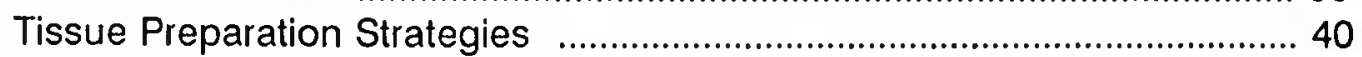

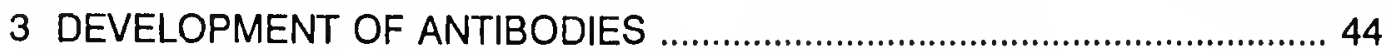

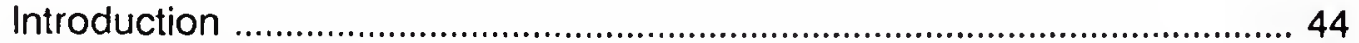

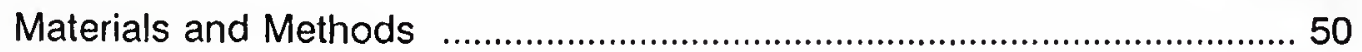

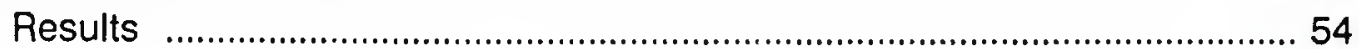

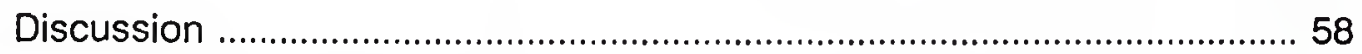

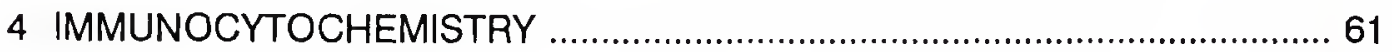

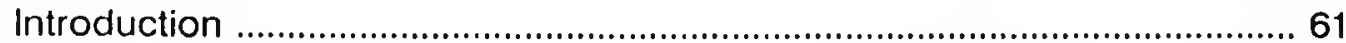

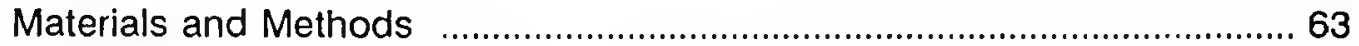

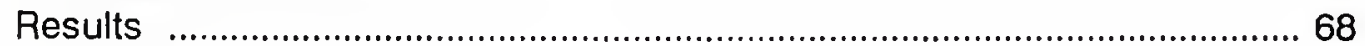

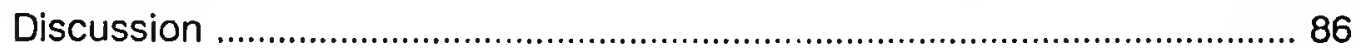




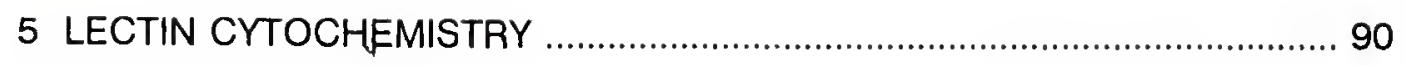

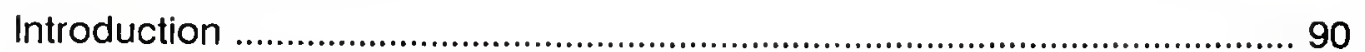

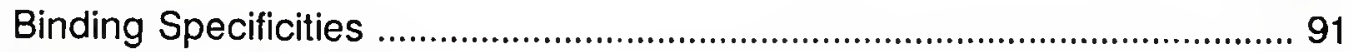

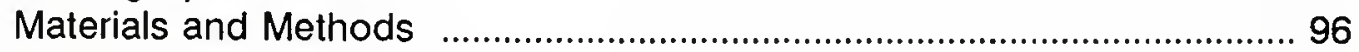

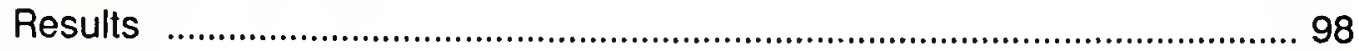

Discussion ..................................................................................... 116

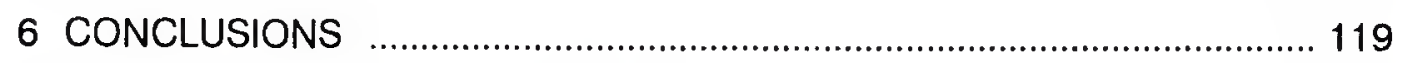

Evaluation of Experimental Methods .......................................................... 119

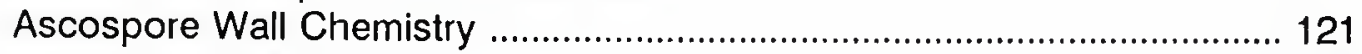

Precursor Tracking ................................................................................. 122

Maturation of the Ascospore Wall ........................................................... 122

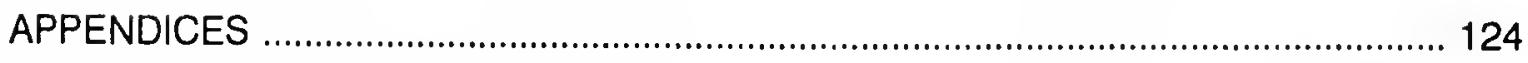

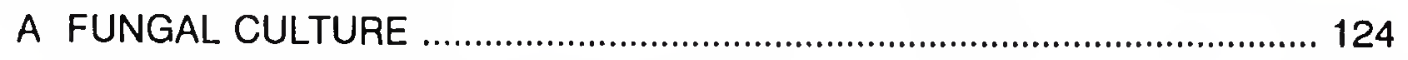

B ISOLATION OF ASCOSPORE WALLS ….............................................. 125

C PROTOCOLS FOR HYBRIDOMA CONSTRUCTION AND CLONING ....... 127

D FREEZING AND THAWING HYBRIDOMA OR SP2-O CELLS ................... 130

E LIGHT BREAK OF ASCOSPORES ........................................................ 132

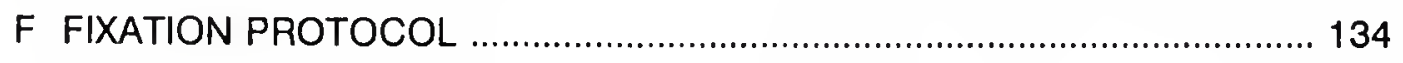

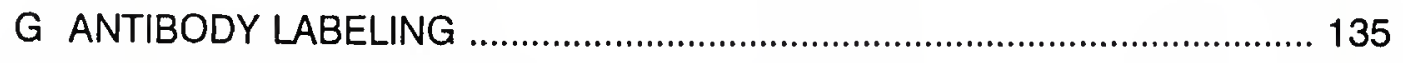

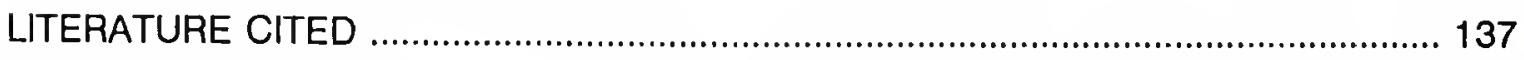

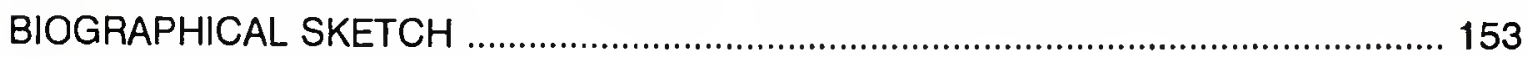




\section{LIST OF TABLES}

Table 3.1. Mean optical densities for buffer wash, substrate, and secondary antibody reatments.

Table 3.2. Least square means comparison of washing vs substrate and antibody / substrate treatment.

Table 3.3. Least square means comparison of interaction of buffer type with treatments.

Table 3.4. Mean optical densities for buffer control, immune mouse and test mouse sera.

Table 4.1. Tissue preparation and embedding. 66

Table 5.1. List of lectins and labeling protocol information. 97

Table 5.2. Comparison of Con A and GS-ll labeling on $\underline{A}$. sphaerospora and binding specificities.

Table 6.1. Comparison of wall labeling patterns. 


\section{LIST OF FIGURES}

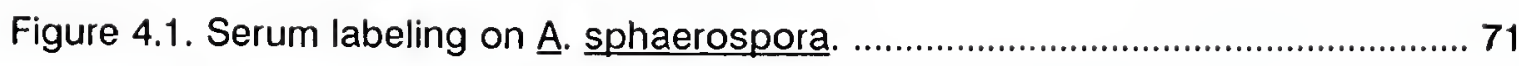

Figure 4.2. Serum labeling and buffer control on A. sphaerospora. .............................. 72

Figure 4.3. 8F11 culture supernatant labeling on $\underline{A}$. sphaerospora. .............................. 72

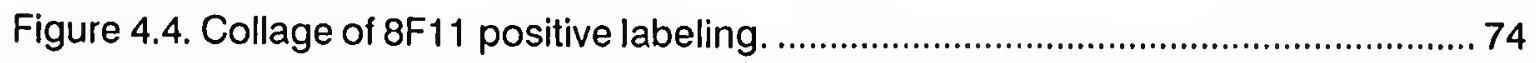

Figure 4.5. Determinant characterization for 8F11 ....................................................... 75

Figure 4.6. Developmental sequence with $8 \mathrm{~F} 11$ labeling. ............................................. 76

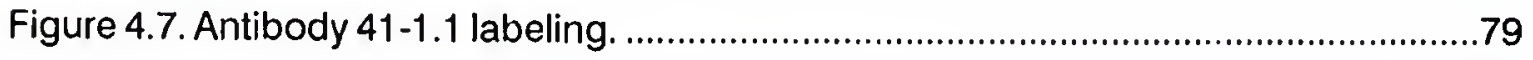

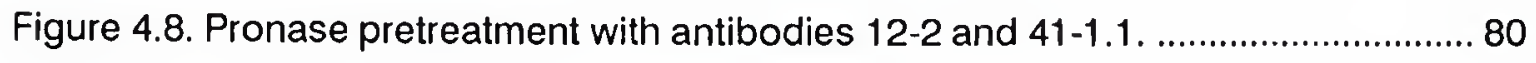

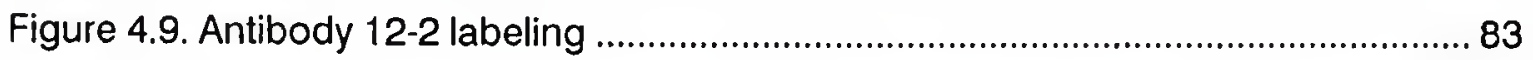

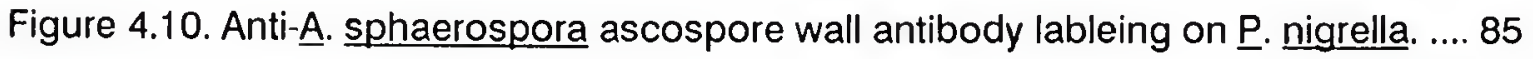

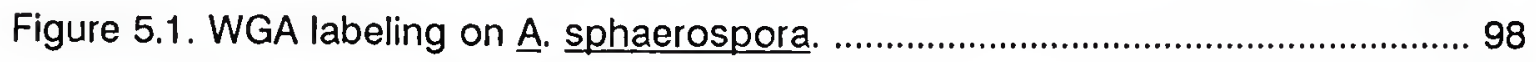

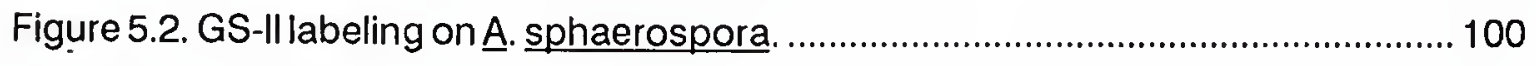

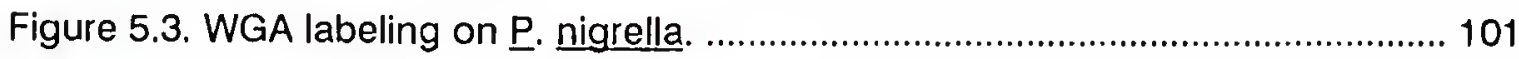

Figure 5.4. GS-II labeling on $\underline{P}$. nigrella. .................................................................... 102

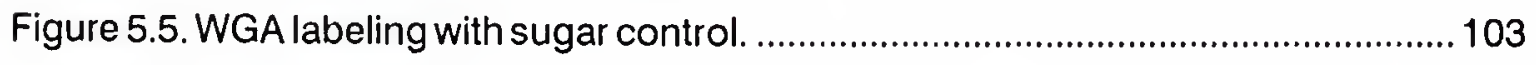

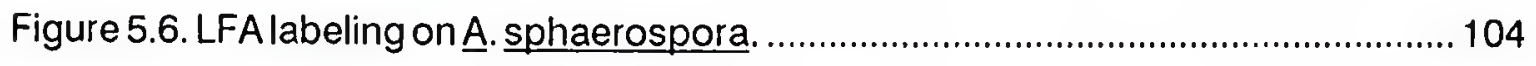

Figure 5.7. LFA labeling on or around spent cells of A. sphaerospora. ......................... 106

Figure 5.8. Con A labeling on $\underline{A}$. sphaerospora......................................................... 109

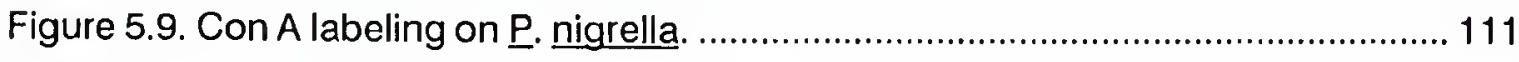


Figure 5.10. Con A labeling with $\alpha$-mannosidase and/or pronase pretreatments. ..... 113

Figure 5.11. Collage of lectin labelings on $\underline{A}$. sphaerospora. ...................................... 115 


\title{
Abstract of Dissertation Presented to the Graduate School of the University of Florida in Partial Fulfillment of the Requirements for the Degree of Doctor of Philosophy \\ DEVELOPMENT OF CYTOCHEMICAL METHODS FOR THE STUDY OF ASCOSPORE WALL BIOGENESIS AND MATURATION
}

\author{
by
}

\section{DEMARIS E. LUSK}

August 1991

Chairman: Dr. Henry C. Aldrich

Major Department: Botany

Detailed morphological studies of the process of ascosporogenesis have been well documented for several species of Ascomycetes. Biogenesis of ascospore wall appears to be a de novo process which occurs between two unit membranes that delimit the ascospore. Although morphological studies have provided a tremendous amount of information about the process, neither biogenesis nor chemical maturation events of these walls can be more than implied via morphology. The goals of this project were to develop cytochemical methods with TEM detection, to improve our understanding of ascospore wall biochemistry and developmental biology, and to provide a foundation of information upon which further studies could be based.

One hybridoma-derived uncloned and two monoclonal antibody preparations against mature ascospore walls of Ascodesmis sphaerospora were developed. The 
uncloned preparation, $8 \mathrm{~F} 11$, has demonstrated a late maturation event by highly specific labeling of the primary wall layer in what appear to be very mature spores. Such an event has never before been demonstrated for ascospores. Monoclonal antibody 41-1.1 clearly demonstrated the presence of a pronase sensitive antigen in the inner region of the primary wall. Monoclonal antibody 12-2 identified an ascospore secondary wall constituent and a cytoplasmic component.

The chemistry of ascospore walls was demonstrated as distinct from vegetative cell walls by the labeling pattern of these antibodies and lectins tested. Con A labeled primary and secondary spore walls and cytoplasmic components. WGA and GS-II lectins labeled ascus walls and vegetative cell walls. GS-II also labeled a cytoplasmic, electron-transparent component. LFA lectin was most specific for an external layer of dead or interacting cells.

The results of this research provide an excellent springboard for further developmental biology, biochemical/molecular structure, and fungal systematics research. Although a probe capable of tracking wall material was not found, these results are encouraging. Isolation and chemical analysis of antigens discovered here would provide insight into the biochemistry of these walls. Morphometric analysis of labeling could provide information about the wall molecular structure. Application of the antibodies and lectins shown here to be cross-reactive with Pseudoplectania nigrella could provide data for use in systematic research of the Pezizales. 


\title{
CHAPTER 1 \\ INTRODUCTION
}

\begin{abstract}
Ascospores
Ascospores are the end product of the meiotic process in Ascomycete fungi. The formation of ascospores has been described as epitomizing the sexual behavior pattern diagnostic of the Ascomycotina (Beckett, 1981). Ascospores are important for dissemination and survival in those species that produce them. As a propagule, they are the sole mechanism for aerial dispersal for those species that do not produce conidia. Airborne fungal spores, especially conidia, along with pollen and dust mites are the most common and potent allergens. Additionally, characteristics of the ascospore have been used by taxonomists since the earliest ascomycete studies. Despite the important position held in the life cycle, the importance of the biological roles, the significance to human health, and the usefulness of their characteristics for taxonomic work, ascospores have received considerably less research attention than hyphae and conidia, especially in the areas of biochemistry and biogenesis.

Early light microscopy studies have provided hypotheses of ascospore origin and development. Of these hypotheses, Harper's (1897) "free-cell formation" has been shown via ultrastructural studies to be correct. Studies of mature ascospore morphology via light microscopy (e.g., LeGal, 1947, 1951) have been a starting point for electron microscopy studies, as well as having provided invaluable data for taxonomic application. In the area of cell biology, ascospore ontogeny (ascosporogenesis) has
\end{abstract}


interested researchers because it represents an unusual type of cytokinesis and cell differentiation.

Ultrastructural studies of ascosporogenesis came into vogue around the early 1960's, apparently culminated in Beckett's (1981) synthesis on the subject, and continue today. In that paper Beckett stated that the origin of wall materials, either as precursor or assembled units, was unclear. Much more is known about chemistry and synthetic machinery for hyphal wall constituents than for ascospore wall constituents. Synthesis of hyphal wall components can occur either in situ or within the cell. In addition to those potential synthesis sites, synthesis of ascospore wall components may also occur in the ascus cytoplasm (epiplasm) that surrounds the developing spore. There is some morphological evidence suggesting that that could in fact be the case for some wall components.

The very fact that ascospores are formed by the "free-cell" process within a walled cell makes them difficult to access for biochemical and biosynthesis study during development. Isolation of ascospores at various stages of development for these types of studies would be a more feasible pursuit if the ratio of spores per ascus, which is typically $8: 1$, were greater. Yet, the availability of ascospores for post-embedding ultrastructure study has been demonstrated over and over again in the many publications on the morphological aspects of ascosporogenesis. Following the trend of post-embedding TEM study, and additionally testing various cytochemical reagents and techniques, could provide the most expedient route to valuable chemical and biogenesis information.

Just such a post-embedding cytochemical route has been pursued in this study. The application of these techniques has provided data about the chemistry and biology 
of ascospores that will improve our understanding of the biological processes involved. This work has also provided a foundation of data upon which further work in the areas of cell biology, developmental biology, and systematics can be based.

\section{Ascosporogenesis}

Introduction

In general, for ascomycetes, the process of meiotic spore (ascospore) production follows a pattern. First there is production of a dikaryotic ascus initial from ascogenous hyphae, karyogamy, meiosis with concurrent production of spore delimiting membranes (SDMs) often in the form of an ascus vesicle (Reeves, 1967; Carroll, 1967; Rosing, 1982; Mims et al., 1990), then a post-meiotic mitotic nuclear division producing $8(1 n)$ nuclei, next an envelopment of the in nuclei via constriction of the ascus vesicle Oi otherwise, and finally ascospore wall formation between the SDMs concurrent with maturation of the sporoplasm and vacuolation of the ascus cytoplasm (epiplasm). Additionally, there may be further mitotic divisions of the $1 \mathrm{n}$ nuclei after the intial 8 nuclei have been delimited (Gibson \& Kimbrough, 1988a, 1988b; Kimbrough et al., 1990). In Beckett's (1981) review of ascospore formation literature, he stated that there are two points of universal agreement amongst ascospore studies; those are "1) Nucleate

portions of the cytoplasm are delimited by an envelope of 2 unit membranes. 2) Ascospore wall material is deposited between these 2 unit membranes which separate as the spore matures."

\section{Wall Nomenclature and Pattern of Wall Development}

Once the spore delimiting membranes are in place around the nuclei, a wall 
forms between them. The outer membrane is displaced from the spore plasma membrane as the wall develops (Mims et al., 1990). No standardization of wall layer terminology was proposed until Merkus (1973) and Beckett (1981) made efforts to that effect. The wall material is laid down in two stages; in the first stage the primary wall is laid down, and in the second stage a second layer is sometimes formed between the primary wall and the outer delimiting membrane (e.g., Merkus, 1973; Gibson \& Kimbrough, 1988a, b; Kimbrough et al., 1990). Hohl and Streit (1975) did not find this order of stepwise development in the wall of Neurospora lineolata. They found that after the primary wall was laid down a secondary wall was formed to the inside, between the primary wall and the spore plasma membrane (or inner delimiting membrane). This seems to be the less common of the two methods. In both cases the second layer deposited was called the secondary wall (Merkus, 1973; Hohl \& Streit, 1975). The outer delimiting membrane loosens, forming the so called "perisporal sac" prior to deposition of secondary wall material.

Typically, periclinal (parallel to the wall inner surface) bands between the primary and secondary wall layers are evident in micrographs of mature spores. Merkus (1973) called these bands the epispore wall. Merkus' wall nomenclature seems complete, clear, adequately descriptive, and efficient. Beckett (1981), in an effort to reduce the confusion of wall nomenclature added to the confusion by defining the secondary wall as "all subsequent wall material that is formed, either by modification of the primary wall or by addition to it. ..." It is clear that his secondary wall includes Merkus' epispore wall. Merkus' wall nomenclature as just described is used through this work. 


\section{Pre-wall Formation Events}

Although some authors discuss crozier formation and development of the ascus initial (e.g., Reeves, 1967; Zickler \& Simonet, 1980; Rosing, 1982) and a few discuss karyogamy as part of ascospore ontogeny (Leung \& Williams, 1976), it is much easier to find information on the post-nuclear fusion processes of ascospore ontogeny (e.g., Carroll, 1967; Hohl \& Streit, 1975; Merkus, 1976; Dyby \& Kimbrough, 1987). At the

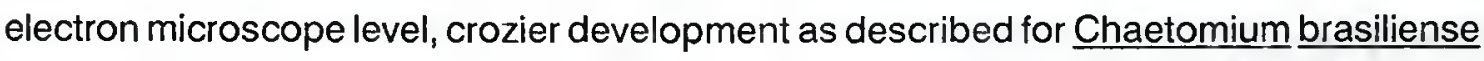
(Rosing, 1982), Myxotrichum deflexum (Rosing, 1985), and Pyronema domesticum (Reeves, 1967) follows the stylized description usually taught as basic. Reeves (1967) found young asci of $\mathrm{P}$. domesticum with fusion nuclei to be rich in "long strands of endoplasmic reticulum" and that basal vacuolation had been initiated. Leung \& Williams (1976) have provided a detailed description of the meiotic and post-meiotic mitotic divisions in the asci of Pyricularia oryzae. There seem to be no striking abnormalities in those divisions as described. Unfortunately, they gave no information on other cellular activities that occur simultaneously with those divisions. Zickler and Simonet (1980) found in their experiments with sporulation deficient mutants of Podospora anserina that any disturbance in the strict orientation of post-meiotic mitosis spindles leads to irregular distribution of nuclei and afterward in the distribution of the ascospore. They further stated that such disturbance is often associated with variation in the final number of ascospores formed.

Over the years many suggestions for the origin of spore delimiting membranes have been made. Beckett (1981) stated that all of the proposed methods of SDM formation could be accommodated by the endo-membrane concept of Morre, Mollenhauer, and Bracker (1971). In that same paper Beckett provided a table that 
summarized the research to that date on the origin of these membranes. Structures implicated in the formation of SDMs include: the ascus plasma membrane, mesosomes, myelin figures, cisternae of endoplasmic reticulum, endomembrane vesicles, and the nuclear envelope.

Ascospore initiation appears to be dependent on the position of spore delimiting membrane in relation to the haploid ascus nuclei. Two fundamentally different patterns of spore initiation have been found. With a few exceptions, the Hemiascomycetes are characterized by the direct envelopment of individual nuclei by membranes formed in association with spindle pole bodies, while Euascomycetes form a discontinuous membrane cylinder around the periphery of the ascus. This cylinder has two layers of unit membrane and is the ascus vesicle. Zickler and Simonet (1980) observed ascus vesicle formation in Podospora asernia even in the absence of live nuclei and concluded that initiation and formation of ascus vesicles were independent of the nuclear divisions and/or presence of spindle plaques. The ascus vesicle invaginates, giving rise to the spore delimiting membrane. Typically, each nucleus present, and the adjacent cytoplasm, are surrounded by the delimiting membrane and develop into ascospores.

During these early phases of ascospore ontogeny changes in the epiplasm have also been observed. In many Pezizalian fungi, Merkus $(1975,1976)$ noted the development of "globular structures." Formation of these globular structures can begin in the pre-meiotic ascus and continue through the spore delimiting stages. She speculated that these are food reserves and stated that they do not seem to play a role in the formation of walls (Merkus, 1975). A system of vacuoles at the ascus bases exists, and an apical system of vacuoles begins forming around the period of the second meiotic division (Reeves, 1967). Niyo and coworkers (1986) noted the presence 
of vacuoles, ER, and lipid bodies in young asci. Microtubules are often noted in asci before ascospore delimitation (Reeves, 1967; Beckett, 1981; Rosing, 1982, 1985; Dyby \& Kimbrough, 1987).

\section{The Primary Wall}

The primary wall formation is first evident in micrographs by a slight separation between the inner and outer delimiting membranes. The delimiting membranes remain appressed to the developing primary wall until it has apparently completed the biosynthesis process (Merkus, 1973, 1974, 1975, 1976; Kimbrough \& Gibson, 1990). At the time of apparent completion, the outer delimiting membrane loosens signaling the onset of secondary wall formation.

The appearance of the primary wall in electron micrographs is typically described as electron-translucent or electron-transparent. In recent studies of mature spores (with evident secondary wall and epispore layers), the primary walls have been shown to have some electron-density (Kimbrough et al., 1990). Fibrillar orientation of the primary wall in at least the case of Geopyxis carbonaria has been observed and described as anticlinal (perpendicular to the wall inner surface) (Kimbrough \& Gibson, 1990).

The exact origin of the primary wall material of ascospores remains to be determined, and probably varies amongst the taxa. Reeves (1967) and Rosing (1982) suggested ER that lies in close proximity to the spore plasma membrane as a possibility. Rosing, in that same article, noted the appearance, increase in number, and fusion of dark granules between the spore delimiting membranes in Chaetomium brasiliense and suggested that thóse membranes actually synthesized the granules. Merkus (1976) suggested that spore plasma membrane plays a role in the synthesis of 
primary wall material. These suggestions are supported by Beckett's (1981) concluding remark that "both spore plasm membrane and investing membrane play a role in regulating wall formation in young ascospore initials." In Merkus' ascospore wall studies $(1973,1974,1975,1976)$, she ruled out dictyosomes as a source and minimized the role of lomasomes as a source of wall material. Reeves (1967) found few lomasomes in Pyronema domesticum asci. This seems to agree with Merkus' minimization. It has additionally been suggested that small vacuoles originating in the sporoplasm may be involved with primary wall synthesis (Kimbrough \& Gibson, 1990; Wu \& Kimbrough, 1991a, 1991b).

Merkus $(1973,1975)$ found that the dimensions of the primary wall layer varied depending upon the fixative used. In further regard to ascospore shape she stated that "the ascospores are rounded off before the primary wall is formed" in some species and that "the ascospores round off during primary wall development" in other species. More recently the primary wall of Gyromitra esculenta was said to confer the characteristic shape seen in mature spores (Gibson \& Kimbrough, 1988b). It is unfortunate that these types of data are not always noted because these data could be a useful taxonomic characteristic. On the other hand, this type of deformation could be artifactural and freeze fixation studies should preceed use of these data for taxonomy.

\section{The Secondary Wall}

The loosening of the outer delimiting membrane forming the perisporal sac signals the onset of secondary wall formation. In a few cases secondary wall formation has been found to begin prior to completion of the primary wall (Merkus, 1976). With few exceptions (e.g., Neurospora lineolata, Hohl \& Streit, 1975), the secondary wall 
forms to the outside of the primary wall, between that wall layer and the outer delimiting membrane. Undifferentiated material, sometimes described as fibrillar (Gibson \& Kimbrough, 1988b) or floccose (Kimbrough \& Gibson, 1990), apparently accumulates in the perisporal sac and then condenses onto the primary or epispore wall layer to form the secondary wall (Merkus, 1976). Beckett (1981) concluded that "there is no common pattern of development for the secondary wall formation." Certainly with the diversity of ascospore ornamentation found in members of this class there can be little doubt to the truth in that statement. Merkus (1976) outlines seven different developmental groups within the Pezizales alone.

Synthesis of secondary wall materials, either as precursor or final macromolecule, could occur within the sporoplasm or at the spore plasma membrane, at the outer delimiting membrane, or in the epiplasm. Gibson \& Kimbrough (1988a) supposed sporoplasm to be the primary or only source of material for the secondary wall. In support of this supposition they argued that the epiplasm is isolated from the developing wall whereas the sporoplasm remains in close contact. Despite this argument, the sporoplasm as the sole or even primary source of secondary wall material seems unlikely as these materials would have to traverse the existing primary wall. Merkus (1976) felt it was unlikely that the sporoplasm has a function in secondary wall formation and that the investing membrane might have an active role. Based on structural similarities of components within the epiplasm and the secondary wall, Merkus (1976) found it highly probable that parts of the epiplasm are incorporated into the secondary wall. Wu and Kimbrough (1991a, 1991b) provided morphological evidence for diffusion, or movement otherwise, of materials from the epiplasm into the perisporal sac. They proposed that these materials are involved in wall formation. Bellemer and 
Melendez-Howell (1976) also suggested an active role on the part of the epiplasm.

Mechanisms controlling deposition and structure of the ascospore wall seem unclear. Beckett (1981) presumed that the spore nucleus plays a major role in controlling wall deposition and architecture. While the spore nucleus undoubtedly plays such a role for the deposition of primary wall, and for secondary wall formed interior to the primary wall (e.g., Neurospora lineolata), the situation is less clear for those fungi in which the secondary wall forms to the outside of the primary wall. The question of control of secondary wall formation is especially interesting as final form of ornamentation is 1) due to this external wall layer and 2) is often diagnostic at the species or genus level of fungi within the Pezizales.

\section{The Epispore Wall}

The epispore wall as seen in micrographs appears to be a periclinal band, or more typically bands, of varing electron density. It is located between the primary and secondary wall layers.

The timing of differentiation and source of material differentiated into this wall layer are apparently variable. Differentiation of this layer could commence 1) after the primary wall is formed but before secondary wall deposition begins, 2) during the deposition of secondary wall material, or 3) after the secondary wall is complete. Kimbrough \& Gibson (1988a) reported development of the epispore layer prior to the deposition of secondary wall material for Helvella acetabulum. The bulk of available data supports the differentiation of epispore layer(s) during deposition of secondary wall

materials (in 브. macropus and $\underline{H}$. elastica, Gibson \& Kimbrough, 1988a; in Gyromitra esculenta, Gibson \& Kimbrough, 1988b; Dyby \& Kimbrough, 1987; in Geopyxis 
carbonaria, Kimbrough \& Gibson, 1990; Kimbrough et al., 1990; in Ascobolus immersus, and $\underline{A}$. stictoideus, Wu \& Kimbrough, 1991a \& b). No reports reviewed suggested that differentiation of the epispore wall layer commenced after complete formation of the secondary wall. It is obvious from the figures in the reviewed articles that differentiation of the epispore layer(s) continues through the development of the secondary wall layer and that epispore differentiation may not be complete until after the secondary wall is apparently fully formed and mature.

Epispore wall constituents could be derived from the primary wall, secondary wall, or laid down as new material prior to the deposition of secondary wall material. Merkus $(1975,1976)$ described the primary wall as differentiating into the epispore and an endospore layer. While it is clear that she felt the parent material of the epispore to be primary wall constituents as originally formed, more recent articles present evidence for synthesis of new materials for this layer (in Helvella acetabulum, Gibson \& Kimbrough, 1988a; in Ascobolus immersus, and A. stictoideus, Wu \& Kimbrough 1991a \& b). In Helvella macropus the epispore was described as being evident soon after secondary wall deposition began, and in $\underline{H}$. elastica it was evident at the time secondary wall deposition is evident (Gibson \& Kimbrough, 1988a). Morphological evidence is insufficient to determine the derivation of epispore wall materials. It is possible that the epispore wall is an amalgamation of secondary and primary wall material modified in situ by enzymes present in the wall or perisporal sac.

\section{Ascopore Maturation}

The appearance of ascospores during the initial phases of development is distinctly different from that of a mature spore. This is the case for both sporoplasm and 
the spore wall. In electron micrographs the sporoplasm is initially packed with cytoplasmic components, such as mitochondria and ribosomes (e.g., Dyby \& Kimbrough, 1987; Kimbrough et al., 1990), that are indicative of high levels of activity. At the time they are delimited, ascospores are typically uninucleate. In the Helvellaceae further mitotic nuclear divisions occur so that the mature spore is multinucleate (Gibson \& Kimbrough, 1988a, 1988b). Sometimes lipid droplets develop or coalesce during the development and maturation processes (e.g., Gibson \& Kimbrough, 1988a, 1988b; Kimbrough et al., 1990). At about the time the epispore wall layers are forming, the sporoplasm appears to condense (Kimbrough et al., 1990). Most strikingly, the membranes of the sporoplasm take on a negative appearance as compared to earlier stages. In what appears to be the most mature spore state while still in the ascus, the sporoplasm is typically missing from the section. This most probably indicates poor infiltration and/or polymerization of the resin. This problem is likely to be the result of changes in the spore wall that seal it from the external environment.

The primary and secondary wall layers are apparently constructed sequentially. The primary wall as it appears at the time the perisporal sac forms has been called mature (Gibson \& Kimbrough, 1988b). This wall layer would not actually be mature if in fact the primary wall undergoes further change before the spore is expelled. Merkus' (1976) hypothesis regarding the differentiation of epispore wall from the primary wall implied such immaturity of the primary wall. Slight staining differences observed (Kimbrough et al., 1990) between the just formed primary wall and the primary wall of mature spores are also suggestive of post-formation changes within this wall layer.

The appearence of the epispore wall changes from a single layer to several layers in the most mature spores observed (e.g., Gibson \& Kimbrough, 1988a; Kimbrough et al., 1990). 
The appearance of the secondary wall changes as deposition progresses, especially when ornaments are formed. Sometimes, as the secondary wall develops differential staining of fibrillar material occurs (Kimbrough et al., 1990) and/or electrontranslucent lacunae (Kimbrough et al., 1990; Kimbrough \& Gibson, 1990) are evident in developing ornaments and wall thickenings.

In conclusion, possible maturation processes within the wall could produce 1) a change in the staining properties of the primary wall, 2) layering of the epispore, 3) differential staining of the secondary wall, and 4) a change in the permeability of the wall.

\section{Chemistry of Ascospore Wall}

Very little information on the chemical composition, or nature, of ascospore wall layers is available. The only information found on the chemistry of ascospores of nonyeast species is based on cytochemical experimentation primarily with silver periodate stain. Silver proteinate stain demonstrates the presence of periodate sensitive carbohydrates. Periodate sensitive carbohydrates are those that possess residues with vicinal diols. Glucans, mannans, and galactans with (1-3) linkages are insensitive to periodate and will not stain with with the silver proteinate staining procedure. Likewise chitin, because of the $\mathrm{N}$-acetyl substitution on carbon 2 , is insensitive to silver periodate. Sensitive pyranosyls would have (1-4) or (1-6) linkages and be unsubstituted. Based on the negative results of silver proteinate staining experiments, Dyby \& Kimbrough (1987) concluded that the primary wall of those fungi studied (Peziza spp.) is primarily composed of (1-3) glucan rather than chitin or other polysaccharides. Similar staining 
and conclusions were drawn for Geopyxis carbonaria (Kimbrough \& Gibson, 1990). Gibson and Kimbrough found the primary walls of Gyromitra esculenta (1988b) and Helvella spp. (1988a) to have some affinity for silver proteinate and they suggested the presence of chitin. These conclusions are incorrect in being both more specific than, and at variance with known carbohydrate sensitivities for periodate.

The outer edge of the secondary wall of Peziza spp., and the inner band of the epispore wall stained positively with silver proteinate (Dyby and Kimbrough, 1987). They speculated that the secondary wall ornaments consisted of lipids, protein, glycoprotein, and possibly chitin. In Geopyxis carbonaria (Kimbrough \& Gibson, 1990) and Gyromitra esculenta (Gibson \& Kimbrough, 1988b), there was no evident staining by silver proteinate in the secondary wall layers. Merkus (1973) felt that the secondary wall was formed via deposition of membranous fragments in a homogeneous matrix.

No work specifically on biochemistry of non-yeast ascospores appeared in a recent text on the subject of fungal wall biochemistry (Kuhn et al., 1990). A great deal more is known about hyphal walls than ascospore walls. Research on the structure, biochemistry, synthesis, and even genetics of hyphal walls is available.

\section{Chemistry of the Hyphal Wall}

\section{Functions of the Fungal Wall}

The cell walls of fungi function in every aspect of fungal life. Fungal morphology can vary to meet functional needs by a change in wall construction (Bartnicki-Garcia, 1968). These cell walls provide a structural barrier that is resistant to lysis by competing microflora or host defenses, prevents disruption of the protoplast by free water, and maintains cellular form. A variety of enzymes have been found in hyphal walls. The 
walls are the site of recognition systems (e.g., self-self and self-host) and mediate adherence. They undoubtedly help prevent desiccation, but may additionally act as a filter and ion exchanger (Reiss, 1986). The many functional aspects and dynamic nature of cell walls have prompted some researchers to recognize cell walls as organelles (Mauseth, 1988).

\section{Wall Chemistry}

Hyphal walls have been reported to be $80 \%-90 \%$ polysaccharide (Farkas, 1979 ; Zonneveld, 1971; Bartnicki-Garcia, 1968). This characteristic is in common with grampositive bacterial and plant cell walls (Peberdy, 1990). Various glucans (Wessels, 1986; Zonneveld, 1971), chitin (Wessels, 1986; Bartnicki-Garcia, 1968), chitosan (Mol \& Wessels, 1987), other homo- and heterpolysaccharides, glycoproteins (Gorin, 1985; Johnston, 1965), and peptido-polysaccharides (Gander, 1974) make up the carbohydrate fraction of hyphal walls. These polysaccharides are composed of amino sugars, hexoses, hexuronic acids, methyl pentoses, and pentoses (Farkas, 1979). Bartnicki-Garcia (1968) stated that "at least 11 monosaccharides" are reported to occur in hyphal walls; but only D-glucose, $\mathrm{N}$-acetyl-glucosamine, D-mannose, D-galactose and D-galactosamine are consistently found in the Ascomycetes, with the latter two sugars being more-or-less characteristic of this class of fungi. On the basis of their presumed function and physical form, cell wall components can be divided into two major categories: skeletal and matrix. Additionally, a gel-like (or glycocalyx) layer surrounding hyphae has been described (Wessels, 1986).

Skeletal elements are crystalline or microfibrillar in form, and consist primarily of chitin, and/or crystalline beta-glucans $(B(1-3)$ linked homopolymer; Farkas, 1979). It is 
important to note that some researchers report protein(s) as always being associated with chitin, and further, that this association is in a regular or crystalline fashion (Neville, 1975; Blackwell, 1982). However, Rudall (1969), on whose information Neville and Blackwell base this stated association, reported a protein-chitin association for the crystalline chitin of crustacean, insect, and spider cuticles, but that glucan(s) of $B(1-3)$ and $B(1-6)$ linkages are the principal protein-associated substance(s) in fungi. Glucans of these same linkages, although with a higher degree of $B(1-6)$ branching, probably make up the gel-like layer that surrounds the hyphae (Wessels, 1986; Peberdy, 1990). The matrix is then the remainder of wall components; amorphous homo- and heteropolysaccharides, glyco-conjugates, proteins, and lipids or lipo-conjugates.

\section{Survey of Methods}

Current knowledge about the architecture and chemistry of hyphal walls is founded in three basic research methods. These are 1) degradation (extraction, digestion) followed by chemical analysis and/or shadow casting TEM of the surface, 2) localization via cytochemistry and transmission electron microscopy techniques, and 3) immunological studies. Additionally, morphological studies, especially those examining changes associated with altered nutritional or environmental conditions, have contributed to current understanding of these walls.

Degradation of walls appears to be accomplished most often by chemical (alkali, acid, etc.) extraction, but some investigators report the use of enzyme digestions. In general, after wall isolation and any desired preparatory steps (e.g., treatment with boiling diethyl ether then diethyl ether-ethanol-HCl for removal of lipids, Zonneveld, 1971 ; or treatment with hot phenol and water, $9: 1 \mathrm{v} / \mathrm{v}$, for removal of RNA and protein 
impurities, Johnston, 1965), chemical extractions begin with hot water or/then mild alkali (e.g., $5 \% \mathrm{KOH}$ ), followed by acid hydrolysis of the soluble fraction(s). More severe alkali and acid treatments are then applied to the initially insoluble residue to further fractionate the wall components. Between each step there is commonly a separation of supernatant from residue and wash(es) of the residue.

A major portion of fungal cell walls are soluble in hot water, phenol, and/or alkali. At least two fungal polysaccharides, lichenin $(a B(1-4)$ and $B(1-3)$ linked glucopyranose polymer) and nigeran (a glucopyranose polymer with alternating $\alpha(1-3)$ and $\alpha(1-4)$ linkages) are soluble in hot water. The latter is partially characterized by its solubility in water according to Aronson (1981). Wessels (1986) describes glucans with $B(1-3)$ and $B(1-6)$ as being "more or less" soluble in water. Hearn and coworkers (1989) studied only the water soluble fraction of Aspergillus fumigatus mycelia (including cytoplasm) and found predominantly galactomannans and glucans.

Cell wall outer layers are "as a rule" soluble in dilute alkali according to Wessels (1986). Often extraction procedures begin with alkali, or with hot water, as pointed out previously. Some glucans are soluble in dilute alkali but not in hot water. The differences in glucan structure associated with hot water solubility/insolubility appear to be slight. For example, pseudonigeran (a glucopyranose polymer of consecutive $\alpha(1-3)$ with interspersed $\alpha(1-4)$ linkages) is not soluble in hot water but is soluble in alkali, whereas nigeran (a glucopyranose polymer of alternating $\alpha(1-3)$ and $\alpha(1-4)$ linkages) is characterized by its water solubility (Gorin, \& Spencer, 1968). Additionally, Wessels (1986) pointed out that water soluble $B-(1-3)-B-(1-6)$ glucans have longer (1-6)-B-linked branches than those that are water-insoluble/alkali-soluble, although some of these glucans remain insoluble under either of these conditions. In their comparison of 
polysaccharides obtained from water extraction and those of alkali extraction, Hearn and coworkers (1989) reported "marked differences in the contents of non-reducing endunits of $\alpha$-D-Man(p) and B-D-Gal(f)." These differences are primarily number of units per side chain.

Mol and Wessels (1987) described "most" yeast wall fractionations as beginning with a "rigorous" alkali step to remove mannans and proteins. Zonneveld (1971) found a considerable portion of the wall ( $22 \%$ dry weight of complete wall) in this fraction. Galactomannans (e.g., Gorin, 1985) and other heteropolysacchrides (e.g., Johnston, 1965) and glycoprotein conjugates (e.g., Mahadevan \& Tatum, 1967) are commonly found in both alkali and water (Hearn et al., 1989) fractions. Acid hydrolysis is the final step before quantitative analysis of either of these fractions. Zonneveld (1971) used $2 \%$ hydrochloric acid at $100^{\circ} \mathrm{C}$ for an hour to hydrolyze these fractions. Mahadevan and Tatum (1965) initially used 3N hydrochloric acid to hydrolyze the carbohydrates, then did a second treatment with $6 \mathrm{~N}$ hydrochloric acid to hydrolyze proteins.

Treatment of the alkaline-insoluble fraction with hydrochloric or sulfuric acid (e.g., $40 \% \mathrm{H}_{2} \mathrm{SO}_{4}(\mathrm{v} / \mathrm{v})$ at $4^{\circ} \mathrm{C}$ for $18 \mathrm{hr}$, then diluted and boiled $3 \mathrm{hr}$ ) is thought to hydrolyze all the remaining glycosidic bonds, except chitin, leaving chitin as a final residue (Zonneveld, 1971). Nitrous acid is also commonly used. It is said to specifically attack non-acetylated glucosamine residues and depolymerize glucosamine-containing polymers (Stagg \& Feather, 1973; Mol \& Wessels, 1987; Davis \& Bartnicki-Garcia, 1984).

Enzymes have been useful in carbohydrate degradation/dissection of whole walls, and/or wall fractions for component analysis, elucidation of glycosidic bond type, and localization. Mahadevan and Tatum (1965) used crude enzyme complexes from snail gut (known to contain chitinase, carbohydrases, and proteases) and Aspergillus 
niger (known to contain cellulase) for degradation of cell walls and various wall fractions produced by chemical treatment. These results were then compared with the chemical hydrolysis data for their conclusions regarding the importance of various wall constituents in maintaining the wild-type colonial morphology in Neurospora crassa. Novaes-Ledieu and Mendoza (1981) used $B(1-3)$-glucanase, isolated from Rhizopus arrhizus, to confirm the presence of predominantly $B(1-3)$ linkages in a glucan of the alkali-insoluble fraction. Mol and Wessels (1987) used chitinase from Serratia marcescens to establish a glucan-glucosamine link and thus the presence of glucosaminoglycan in the walls of Saccharomyces cerevisiae. Examples of enzyme localization uses are discussed later.

Various analytical methods are used to ascertain molecular structure, hydrolysate composition, linkage information, and other relevant data. Various chromatographic/ electrophoretic (e.g., thin-laver, Zonneveld, 1971; thin-layer and HPLC, Briza et al., 1986; gas-chromatography, Stagg \& Feather, 1973; SDS-PAGE, Hearn et al., 1989), colorimetric/spectrophotometric (e.g., Mol \& Wessels, 1987; Novaes-Ledieu \& Mendoza, 1981; Zonneveld, 1971, 1972; Mahadevan \& Tatum, 1965, 1967), optical-rotation analysis (e.g., Zonneveld, 1971; Johnston, 1965), infrared spectrometric (e.g., Briza et al., 1988; Novaes-Ledieu \& Mendoza, 1981), and various NMR (e.g., GLC-MS, Hearn et al., 1989; NMR, Briza et al., 1986, 1988; C-n.m.r., Gorin \& lacomini, 1984) methods have been used to determine hydrolysate composition and linkage information. Paper chromatography (immobility of polymer/mobility of primed residue) has even been used to monitor chitosan synthesis (Davis \& Bartnicki-Garcia, 1984). X-ray crystallography, or diffraction (e.g., Rudall, 1969; Blackwell, 1982) has been used for determining the 
structure of relatively insoluble residues. This technique has been used to verify the presence of such structures as crystalline chitin.

Localization of wall components via light and electron microscopy techniques provides visual information on which to base models of wall structures. Fluorescence (light) microscopy using autofluorescence (e.g., Briza et al., 1986), fluorescent stains (e.g., Briza et al., 1988), and fluorescent-labelled conjugates (e.g., Briza et al., 1988) has been used to determine presence and in some cases (such as yeast bud scar) location of inner and outer wall layers. Sequential enzyme digestions followed by shadow casting TEM at each step has provided extensive insight regarding wall architecture (Hunsley \& Burnett, 1970; Burnett, 1979). TEM of specimens prepared only for morphology (e.g., Dute et al., 1989) provides general information on which initial hypotheses and further studies can be based. TEM of sections labelled with goldconjugated lectins and enzymes has, in some cases, resulted in evidence of various wall components residing within specific wall layers (Benhamou, 1988, 1989). Some lectins and their binding specificities are given in chapter 5 .

Two immunological strategies have been employed for analysis and identification of wall components. The so called "blind" approach uses whole fungi, isolated wall fragments or fractions (e.g., Young and Larsh, 1982) and the direct approach, which employs pure antigen as immunogen (e.g., Green et al., 1980). The blind approach has the advantages of requiring less effort in preparation of immunogen, and the produced monoclonals can then be used to isolate the antigenic molecules in relatively pure form for further analysis. Through these methods mural mannan, galactomannan, and protein antigens have been isolated (Reiss, 1986). These methods will be discussed in greater detail in chapter 3. 
fungal wall morphology (Burnett, 1979; Zonneveld, 1971). In combination with other preparatory and analytical methods, this approach can be put to use in wall studies. An example of such a study is Zonneveld's (1973) substitution of the glucose analog, 2-deoxy-glucose, for glucose to determine the role(s) of $\alpha(1-3)$ glucan in vegetative growth and sexual morphogenesis.

\section{The Carbohydrates}

As previously stated, hyphal walls are mainly composed of various carbohydrates, including chitin. The presence of chitin in ascomycete hyphal walls was established over 20 years ago (Aronson, 1965; Bartnicki-Garcia, 1968). More recently chitin was said to be "the most characteristic component of fungal walls" (Wessels, 1986). It accounts for a significant portion of the wall in some fungi (e.g., about $10 \%$ in Neurospora crassa, Burnett, 1979; and 9-13\% in Aspergillus niger, Johnson, 1965). The presence of chitin in conidia and ascospores is highly probable, but neither so well, nor ubiquitously, established. However, the occurrence of chitin in crustaceans, insects, and spiders, as well as fungal hyphae, prompted Rees (1977) to suggest that this polymer may be "more abundant in nature than cellulose."

Chitin is a $\mathrm{B}-(1-4)$ linked polymer of $\mathrm{N}$-acetylglucosamine. Although chitin is usually considered to be a homopolymer, non-acetylated residues may occur (Rudall, 1969; Wessels, 1986). Crystallization occurs when single chitin polymers pack, or pile, side-by-side and form numerous, regular, inter-polymer $\mathrm{CO}--\mathrm{NH}$ hydrogen bonds (Rudall, 1969; Rees, 1977). Three crystalline forms of chitin $\left(\alpha-, B-\right.$ - and $\left.\gamma_{-}\right)$are known (Rudall, 1969). The B-form is made up of chains piled in parallel orientation to one another while the $\alpha$-form is of antiparallel orientation, and the $\gamma$-form (Fig. 8) has both 
parallel and antiparallel polymer components. The $\alpha$-form is the most stable (Rudall, 1969), and the form present in fungal chitin (Rudall, 1969; Wessels, 1986).

Rudall (1969) describes fungal chitin as "spirally wound fibrils." An alternate term for Rudall's fibril is microfibril, and this latter term appears to be more widely used. More recent researchers find the relationship between crystallinity and microfibrillar structure not so clear-cut (Wessels, 1986). In fact, according to Wessels (1986), associated Bglucan may prevent "formation of perfect crystallites of chitin." In fungal hyphae these microfibrils are interwoven forming a rigid web which is capable of retaining its shape even after removal of matrix materials (Burnett, 1979). This led Burnett (1979) to conclude that chitin performs "a genuine skeletal function." It is important to recognize that chitin may not be the major contributor of mechanical strength and stability for all fungi that are considered to be Ascomycetes. It has been suggested that in Saccharomyces cerevisiae a portion of the chitin present is not found in crystalline form, and that crystalline chitin may not be the primary element of mechanical strength in this fungus (Mol \& Wessels, 1987).

Complete deacetylation of chitin polymers produces homopolymers of glucosamine, or chitosan. There may be a range of deacetylated polymers from chitin to chitosan present in fungal walls (Rudall, 1969; Mol \& Wessels, 1987). Studies have shown biological deacetylation of chitin to be the mode of chitosan formation (e.g., Davis \& Bartnicki-Garcia, 1984). Incomplete deacetylation may cause imperfections in the crystalline structure and allow water penetration of the resultant pseudo-chitin (Rudall, 1969).

Chitosan has been found in the walls of Zygomycetes (Bartnicki-Garcia, 1968), non-reproductive and non-lamellae fruit-body cells of the Basidiomycete species 


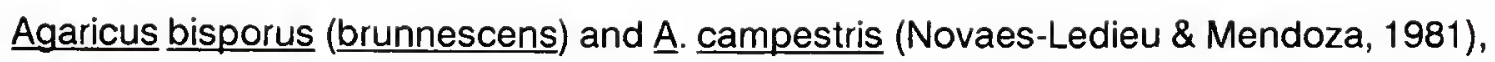
Sacchromyces cerevisiae cells in early stationary growth phase (Mol \& Wessels, 1987), and the ascospore walls of yeast strain AP3 (Briza et al., 1988). In terms of taxonomic groups in which chitosan can be found, this polymer is probably more widespread than early reviews indicate (e.g., Bartnicki-Garcia, 1968), but it may be restricted in the type of cell in which it occurs.

The glucans (D-glucopyranosyl polymers) are also important in terms of their abundance and function in hyphal walls. Up to $25 \%(w / w)$ of Neurospora crassa walls are composed of glucan (Burnett, 1979). The glucans known from ascomycete walls include $\beta(1-3), \beta(1-6), \beta(1-3)-\beta(1-6), \alpha(1-3), \alpha(1-3)-\alpha(1-4)$ linked, and possibly $\alpha(1-4)$ linked D-glucopyranosyl.

Although the presence of cellulose ( $B(1-4)$-D-glucopyranosyl) in the cell walls is typical for some fungi such as the Oomycetes (Bartnicki-Garcia, 1968), it is characteristically absent in Ascomycetes. Within the Ascomycetes the presence of cellulose has only been documented in species of the non-Pezizalian ascomycetes Europhium and Ophiostoma (Aronson, 1981). Chitin and $B(1-3)$ linked glucans provide the mechanical support for fungal cells that cellulose does for higher plant walls.

Pure $B(1-3)$ glucan, or those polymers with infrequent $B(1-6)$ linkages, can crystallize into microfibrils (Burnett, 1979). The extent to which $\beta(1-3)-\beta(1-6)$ glucans can crystallize seems to be dependent on the frequency of $B(1-6)$ branches (Burnett, 1979). Glucans of this type with a high frequency of $B(1-6)$ linkages are presumably more amorphous than those with a low frequency. Amorphous molecules are generally considered to be matrix components. This type of mixed linkage glucan has been found in notable quantities in alkali-insoluble wall fractions of Sacchromyces cerevisiae 
(Mol \& Wessels, 1987), associated with chitin (Wessels, 1986; Rudall, 1969) and in Aspergillus niger (Stagg \& Feather, 1973).

Zonneveld (1971) has shown the presence of $\alpha(1-3)$-glucopyranosyl in Aspergillus nidulans, and demonstrated its importance in the fructification elsewhere (Zonneveld, 1973). These $\alpha-(1-3)$ glucans are generally considered to be linear (Aronson, 1981). In a earlier study of $\underline{A}$. niger Johnston (1965) reported a wall fraction of predominantly $\alpha-(1-3)$ linked glucose residues. This glucan was found in the alkalisoluble fraction (S-glucan; Zonneveld, 1971), implying that this too is a matrix component. Wessels (1986) indicated that $\alpha-(1-3)$-D-glucan occurred in the alkaline soluble fraction of both Ascomycete and Basidiomycete walls. This glucan has been shown to have a characteristic rodlet-form in the outer wall region of the Basidiomycete Schizophyllum commune, but at least for Neurospora crassa, no evidence of this form has been found (Burnett, 1979). Rodlet structures have also been demonstrated by freeze fracture techniques in the condial walls of Scopulariopsis brevicaulis (Cole \& Aldrich, 1971) and teliospore walls of Neovossia horrida (Nawaz \& Hess, 1987). Although no chemical data were given for those teliospores (Nawaz \& Hess, 1987), rodlets in conidial walls are described as proteinaceous (Hashimoto et al., 1976).

The term "mycodextran" was coined by Dox and Neidig (1914) for the glucan of alternating $\alpha(1-3)$ and $\alpha(1-4)$ linkages they isolated from Penicillium expansum. This glucan now goes by the name nigeran. Johnston (1965) found this glucan in the hyphal walls of $\underline{A}$. niger. Based on Johnston's data, Gorin (1968) reported this component to represent $26-42 \%$ of the total wall, Aronson (1981) reported $4-6 \%$, and by this author's rough calculation from that data, 10\%. For $\underline{A}$. nidulans Zonneveld (1971) reported that few, if any $\alpha(1-4)$ glycosidic linkages exist. This large discrepancy between species may 
be actual, or it may be due to culture conditions, or methodology. Gorin (1968) found that $\underline{\mathrm{A}}$ niger grown with starch rather than glucose as the primary carbon source had predominantly (87\%) $\alpha(1-3)$ linkages (pseudonigeran). Gorin (1968) also stated, apparently contrary to Johnston's (1965) written opinion, that pseudonigeran was the glucan present in $\underline{A}$. niger rather than both nigeran and pseudonigeran because neither were soluble in hot water. Pseudonigeran is thought to be more widespread taxonomically than nigeran (Aronson, 1981). Zonneveld $(1972,1973)$ found $\alpha(1-4)$ linked glucose residues in the alkali-insoluble fraction along with $B(1-3), B(1-6)$, mannose-galactose polymers, and chitin. Horikoshi and lida (1964) reported a glucan of $\alpha(1-3)$ and $\alpha(1-4)$ linked residues, but gave no indication of the proportions of these linkages within the polymer. Aronson (1981) stated that $\alpha(1-4)$ linkages between glucans to heteropolysaccharides (e.g., B-glucan-galactomannorhamnan in Fusicoccum amygdali) "are unquesionably significant" as they knit various polysaccharides into larger wall complexes. No reports of a consecutively $\alpha(1-4)$ linked glucan were found in this literature search and review.

Mannose is commonly found in fungal wall digestions (Bartnicki-Garcia, 1968). Apparently homopolymers occur, but mannose is more often described as a constituent of heteropolysaccharides and glycoprotein conjugates. Yeast mannan has been described as having an $\alpha-D-(1-6)$ backbone, and $\alpha-D-(1-3)$ and $\alpha-D-(1-2)$ branches (Gorin, 1968) of two to five residues (Reiss, 1986). Farkas (1979) described yeast mannan as a glycoprotein with 2 distinct carbohydrate moieties; one with $\alpha$-D-(1-6) backbone and $\alpha-D-(1-3)$ linked branches, the other with only $\alpha-(1-2)$ linkages. Trichosporon aculeatum has a branched mannan in which all the linkages of yeast mannan exist, but more than 5 consecutive $\chi-D-(1-2)$ linkages were never found (Gorin, 
1968). In Candida albicans cell wall mannans with $\alpha-D-(1-2)$ and $\alpha-D-(1-6)$ linkages are major antigens (Gorin, 1968; Reiss, 1986). Unlike the previous mannan, these antigenic mannans have furanosyl, as well as pyranosyl residues (Gorin, 1968).

Galactose, like mannose, is commonly found in fungal walls, but in this case is neither present in all fungi, nor even all Ascomycetes. Both furanosyl and pyranosyl residues occur in galactan homopolymers (Gorin, 1968), and heteropolysaccharides (Gorin, 1985). Apparently galactose is more abundant in heteropolysaccharides. Galactocarolose is an example of galactan from Penicillium charlesii. Gorin (1968) described this molecule as a linear oligomer (9-10 residues) of $\alpha$-D-(1-5)-galactofuranose (Gorin, 1968). Galactocarolose has also been described as a degradation product of peptidophospho-galactomannans (Salt \& Gander, 1985; Preston \& Gander, 1968).

Phosphorylated residues of both galactose and mannose have been found in fungal walls (Gorin, 1968). These residues, and 2-amino-2-deoxy-D-galactose, have been described as occurring as components of "exocellular" polymers (Gorin, 1968). The exact position and role in (or outside) the wall is unclear.

\section{Wall Proteins and Glycoproteins}

Proteins are an obvious component within the wall since amino acids are commonly found in wall fractionations (Gorin, 1985; Novaes-Ledieu, \& Mendoza, 1981; Zonneveld, 1971; Johnston, 1965; Mahadevan, \& Tatum, 1965). Wall proteins occur both glyco-conjugated (Hearn, et al., 1989; Salt, \& Gander, 1985; Aronson, 1981), and apparently unconjugated (Farkas, 1979). Rosenberger (1976) found fungal walls to be $10-15 \%$ protein after extensive washings and considered this protein to be a structural component. Glycoprotein in the wall may be a component in a supra-molecule capable 
of sealing in unbound wall materials (Farkas, 1979). Mural glycoproteins may participate in cell-cell recognition, cell dfferentiation, and mating (Tanner, 1990).

Farkas (1979), Reiss (1986) and Kuhn \& Trinci (1990) described the wall as the location of a number of enzymes. In hyphae, some of the mural enzymes undoubtedly play a role in the provision of nutrients (Kuhn \& Trinci, 1990). Mural enzymes fall into two major categories; the proteinases and $B(1-3)$ glucanases (Reiss, 1986). Other enzymes known to occur murally are invertase, acid phosphatase (Farkas, 1979; Reiss, $1990)$ and $B(1-4) x y l a n a s e$ (Notario et al., 1979).

A mannan-protein complex has been described as the matrix component in yeasts (Peberdy, 1990). Aronson (1981) provided another example in that some 10\% of Pyricularia oryzae wall was said to be "proteohetero-glycan." When purified, this molecule was determined to be $91 \%$ carbohydrate and $9 \%$ protein. The polysaccharide portion had an $\alpha-(1-6)$ mannopyranosyl main chain with (1-2) linked glucomannan or galactomannan side chains (Aronson, 1981).

Wall Lipids

Bartnicki-Garcia (1968) presented evidence supporting lipid(s) as a bona fide wall component. Cell walls of Aspergillus niger have been reported to be $2-7 \%$ lipid (Johnston, 1965). No further information was found on its relationship(s) with other wall components, conjugate partner(s), or roles within the wall.

\section{Locations of Synthesis Enzymes}

Various enzymes have been isolated which are involved in the synthesis of wall components. Publications on these enzymes began appearing in 1957 with Glaser and 
Brown's (1957) description of chitin synthesis in fungi. The bulk of chitin synthetase has since been found to be attached to the plasma membrane (Duran et al., 1975; Kang et al., 1985). Furthermore, isolated intact membranes have been shown to synthesize chitin on the external face of those membranes in vivo (Cabib et al., 1983).

Chitosan synthesis has been characterized as a chitin deacetylation process (Davis \& Bartnicki-Garcia, 1984). Interestingly, only $37 \%$ of the chitin deacetylase was associated with the extracellular fraction. The remainer was associated with the particulate (14\%) and soluble $20000 \mathrm{~g}$ supernatant (49\%) fractions (Araki \& Ito, 1975).

The other structural carbohydrate known to occur in fungi is $B(1-3)$ glucans. $B(1$ 3)glucan synthase has, like chitin synthetase, been found to be a membrane bound enzyme. Further, it has been described as an integral, trans-plasma membrane enzyme (in Neurospora crassa, Hrmova et al., 1989; in Mucor rouxii, Fevre et al., 1990; Peberdy, 1990). Activity of $B(1-3)$ glucan synthase has also been found in association with both endoplasmic reticulum and plasma membrane fractions (in, Saprolegnia monoica, Fevre, 1984).

Glycosyl transferases would also be involved in construction of wall carbohydrates. These enzymes might be expected to occur in the cytosol and indeed the mannosyltransferases have been found in the cytosolic particulate fraction of Cryptococcus laurentii (Schutzbach \& Ankel, 1972).

The occurrence of glycoproteins in the wall has been previously mentioned. Tanner (1990) described glycoproteins as occurring only in special cellular compartments including the cell wall, and organelles involved in glycoprotein systhesis, i.e., endoplasmic reticulum, Golgi complex, and secretory vesicles. Mannoprotein formation in yeasts has long been thought to be a process involving much or all of the endomembrane system (Farkas, 1979). 


\section{Study Proposal}

\section{Hypotheses}

Very little is known about the chemistry, biosynthesis, or maturation process of ascospore walls. The bulk of fungal research in these areas has focused on hyphae. This may be due in part to the fact that the developing ascospore is difficult to access in comparison to hyphae. Yet, this type of research would add greatly to our understanding of the biology of this group of organisms.

The most fundamental questions are that of chemistry and biosynthesis of ascospore walls and their constituent layers. Toward answering such questions some researchers have published a limited amount of cytochemical data. Those experiments have provided infomation of a general, non-specific nature. Nevertheless, it is important to make assumptions and/or hypotheses about the specific chemical nature so that appropriate experimental designs may be created. Thus, it is necessary in this case to apply the information available on hyphae to develop hypotheses. The original study proposal used available information to just such an end.

Skeletal elements in hyphae consist primarily of chitin and/or B(1-3)glucan (Farkas, 1979). It not inconceivable that some mannans could play a strucural role. Thus, it was hypothesized that structural elements of ascospores are most likely to be chitin and/or $B(1-3)$ glucan and less likely to be mannan. This hypothesis is supported by the fact that the synthesis enzymes for chitin and $B(1-3)$ glucan have been found to be located in plasma membranes (Duran et al., 1975; Kang et al., 1985; Hrmova et al., 1989; Fevre et al., 1990). Further, there is strong evidence indicating that the spore delimiting membranes are derived from the ascus plasma membrane (Mims, 1990).

Due to the potential diversity of matrix constituents no hypothesis regarding 
specific conponents was put forward in the original proposal. Although, a hypothesis of general similarity (i.e., Ho: these wall systems will have some shared components) was forwarded. In terms of classes of molecules, it is likely that proteins and glycoproteins are generated at or in the endomembrane system in either the epiplasm or sporoplasm of ascospores. Further, it is also probable that some matrix components arrive at the delimiting membranes in vesicles of the endomembrane system.

As no structure similar to ascospore secondary walls has been described for hyphae, no hypotheses for common constituents could be proposed. Morphological evidence seems to indicate that at least the major components of this wall layer are synthesized at the outer delimiting membrane or in the epiplasm. Based on morphological evidence for the vesicular epiplasm origin of secondary wall components and highly probable endomembrane orgin of some matrix components it was hypothesized that given the appropriate probe, it would be possible to track wall materials not synthesized in situ. This hypothesis is not directly testable and therefore was only a secondary goal of this research.

Maturation events in the ascospore walls undoubtly occur. Minimally, such an event is required to fulfil the sealing function necessary for survival of the spore. It was hypothesized that maturation events would be documentable using the proposed cytochemical techniques. Again, this hypothesis is not directly testable and therefore was considered to be a secondary goal of this research.

Using the chemical and biosynthesis information available on hyphae it was possible to select commercially available probes to test the chemical similarity hypotheses. Monoclonal antibodies developed against either hyphal or ascospore walls could be used for the same purpose. Anti-ascospore wall antibodies were of particular interest as they could also provide evidence for unique chemistry of the spore wall. 
Materials and Methods

Due to the repetitious nature of developing protocols, and the immunological requirement for large quantities of antigen relatively free of contaminating wall materials, the research organism must 1) produce ascocarps readily in culture, 2) sporulate prolifically, and 3) not produce conidia. Ascodesmis sphaerospora meets these criteria, was available, and was thus proposed for use and used as the research organism.

Development of cytochemical techniques and protocols specific for elucidation of biochemical and biosynthesis (biogenesis) information for ascospores was the primary goal of this research. Basic technology for such work (cytochemical stains; carbohydrate, lectin, enzyme, and immuno-, cytochemistry; and use of secondary probes) was outlined by Aldrich and Todd (1986). More specific information on these techniques was also readily available and is reviewed in chapters 2,4 , and 5 . Carbohydrates are an obvious target of this research and thus lectin and immunocytochemical techinques were proposed as the initial and primary focus of the techniques research. Use of enzyme-digestion and enzyme-probe techniques was also proposed as a third line of techniques research.

Production of anti-spore wall antibodies was seen as necessary for successful completion of this project. Technology for preparation of monoclonal antibodies from mice spleen (and other sources) is well described in the literature and is reviewed in chapter 3.

\section{$\underline{\text { Conclusions }}$}

As proposed, this study was seen to have the potential to produce data that could increase our knowledge of the chemistry and our understanding of the biology 
of ascosporogenesis. The procedures developed would be applicable to other fungi and had the potential for addressing other biological questions. Thus, as proposed, it was felt that this work had great potential for provision of a foundation of data for future research on the biology of Ascomycete fungi. 


\section{CHAPTER 2 \\ STRATEGIES FOR \\ TISSUE PREPARATION AND EMBEDDING}

\section{Literature Review}

Introduction

Perhaps one of the most difficult steps of any long-term experimental project is the preparation of material for experiments that are temporally far removed. This can be a critical problem for cytochemical experiments where tissue may only be available on rare occasions, or in limited amounts. The fixation and resin embedding of tissue immortalizes it, but also changes it irreversibly. Pre-embedding experiments are sometimes the most appropriate route. The possibility of pre-embedding experiments which exists for some tissues are out of the question here because of the impermeable nature of cell walls.

The success of cytochemical experimention such as proposed for this study, is relatively dependent on the condition of target molecules. If the changes incurred during tissue processing significantly alter potential target molecules, then cytochemical experiments to detect such molecules can, and probably will, be rendered ineffective (e.g., Craig \& Goodchild, 1982; Eldred et al., 1983; Erdos \& Whitaker, 1983; Hardham, 1985). Bendayan (1989b) reported that the tissue components should retain their 3dimensional configuration in order to be recognized by enzyme probes. The ascospore constituents that are the potential target molecules include carbohydrates, proteins and glycoproteins. It is important therefore to understand how tissue processing might affect 
these molecules specifically prior to the actual tissue processing and cytochemical experimentation.

Tissue processing involves fixation of the material, sometimes a secondary fixation, dehydration, infiltration of a resin, and polymerization of that resin. Significant changes at the molecular level can occur during any of these processing steps. Each of these steps, including typically used reagents and potential resultant molecular changes are reviewed below. The extent to which tissue processing alters the biological configuration of macromolecules varies (Bendayan, 1989a). Therefore, one must develop fixation and dehydration protocols and chose an embedding medium optimal for the cytochemical probe, and more specifically for its target molecule.

\section{Fixation}

The goal of fixation is to kill and stabilize cell structures. This should be done rapidly so that a minimum of autolytic (postmortem) damage occurs. Fixation of biological material is often done in two steps. The primary fixation is most typically done with glutaraldehyde, and/or formaldehyde and/or acrolein. The secondary fixation is done with osmium tetroxide after the primary fixation and buffer washes.

Glutaraldehyde, or a mixture of glutaraldehyde and formaldehyde, is probably the most commonly used primary fixative for electron microscopy. Glutaraldehyde is a dialdehyde and very effectively stabilizes proteins via irreversible cross-linking. Hayat (1981) stated that no other fixative has surpassed the ability of glutaraldehyde to crosslink proteins and preserve tissue proteins for electron microscopy. This fixative introduces both intra- and intermolecular cross-links in proteins but is unable to crosslink low concentrations of proteins (Hayat, 1981, 1986). Glutaraldehyde reacts with the 
$€$-amino group of lysine, $\mathrm{N}$-terminal amino groups, $\alpha$-amino groups of free amino acids, protein associated DNA, and the $1^{\circ}$ amino groups of ethanolamine containing phospholipids (Hayat, 1986; Sternberger, 1986). Most lipids (other than phospholipids), myelin, and glycoproteins are not fixed by glutaraldehyde (Hayat, 1986). Glycoproteins are said to be "immobilized" by glutaraldehyde. Glutaraldehyde is not thought to interact with carbohydrates (McLean and Nakane, 1974). For good morphological preservation of biological material primary fixation with $2 \%-3 \%$ glutaraldehyde $(\mathrm{v} / \mathrm{V})$ in buffer for $1-2$ $\mathrm{hr}$ at $4^{\circ} \mathrm{C}$ or room temperature is usually adequate. Low concentrations of glutaraldehyde are recommended for immunocytochemistry (especially with monoclonai antibodies, Beesley, 1989) and enzyme cytochemistry (Bendayan, 1989a) since retention of biological configuration can be altered by this fixative. Loss of antigenicity or receptor integrity during dehydration and infiltration may be reduced by glutaraldehyde (Craig \& Goodchild, 1982). DeWaele and coworkers (1983) reported that some glutaraldehyde in the fixative solution enhances the permeablility of the cell surface membranes. This would be particularly beneficial for pre-embedding experiments. The concentration of glutaraldehyde in the fixative solution could be less relevant when the receptor site is carbohydrate in nature.

Formaldehyde can also be used as the sole primary fixative but this is not recommended for good ultrastructural preservation (Hayat, 1981, 1986). Unlike glutaraldehyde, it is a mono-aldehyde and its reactions with proteins and other cellular components are at least partly reversible. It penetrates tissue rapidly and in that respect is superior to glutaraldehyde. Cross-linking of protein is slow with formaldehyde (Hayat, 1986). It reacts with free amino groups, hydroxyl, caroxyl, sulfhydryl, and peptide bonds. Formaldehyde is a poor fixative for lipids and actually degrades some types 
of lipids (Hayat, 1986). If only this fixative is used, lipids may be extracted during dehydration.

Acrolein is a monoaldehyde which can be used as a fixative. It is an extremely reactive, flammable, volatile, and toxic (respiratory, ocular mucosa, and skin irritant) reagent (Hayat, 1981). It reacts rapidly with free amino groups and is superior to formaldehyde for cross-linking protein (Hayat, 1986). This aldehyde is bifunctional by virtue of its double bond. It also reacts with carboxyl, imidazol, and substrates that bear sulfhydryl or thiol groups and is thought to react with fatty acids (Hayat, 1981 \& 1986).

Mixtures of aldehydes are recommended (Hayat, 1986) because they often produce superior ultrastructure preservation.

Secondary fixation with osmium tetroxide is commonly used for routine morphological work. Osmium tetroxide has two major advantages for morphological work; 1 ) it is a heavy metal salt and imparts contrast to those molecules and structures it stabilizes, and 2) it stabilizes unsaturated fatty acids by oxidizing the available double bonds (Hayat, 1986). Thus, osmium tetroxide is the fixative of choice for stabilizing and visualizing membranes. In addition to its action on lipids, it also cross-links proteins to a small degree (Hayat, 1986). Osmium tetroxide is said to denature the $\alpha$-helix regions of membrane proteins (Lenard \& Singer, 1968).

\section{Additives to Primary Fix}

Additives to the primary fixative solution such as picric acid (Stefanini et al., 1967; Dae et al., 1982) periodate-lysine (Hixson et al., 1981; McLean and Nakane, 1974: Pollard et al., 1987), and tannic acid (Stirling, 1989) have been recommended to improve morphology without loss of antigenic or binding site receptivity (Stirling, 1990). 


\section{Dehydration}

Dehydration is a requirement for proper infiltration and polymerization of plastic resins. While the epoxy resins are hydrophobic and will not tolerate any water, the acrylic resins are water tolerant (Newman, 1987). The dehydrant should be compatible with the resin, inert to biological material, and should not denature molecular components (Stirling, 1990). Ethanol has been reported to fulfill these requirements (Carlemalm et al., 1982), yet lipid extraction (Weibull et al., 1983) and dimensional changes (Boyde et al., 1977) have also been reported to occur when ethanol concentrations exceed $70 \%$. Specimens for ultrastructure study typically employ epoxy resins and are dehydrated in ethanol series through $100 \%$ followed by acetone washes. Acetone may also be used with the acrylic Lowicryl resins. Kellenberger and coworkers (1987) reported freeze-substitution experiments where $3 \%$ glutaraldehyde in acetone and infiltration with acetone diluted Lowicryl were used. At low temperatures extraction does not appear to be a problem. Conversely, acetone should be avoided when the acrylic resin LR White is employed as this solvent may interfere with the polymerization process (Stirling, 1990). When LR White resin is to be used dehydration through only $70 \%$ ethanol has been recommended to avoid the detrimental effect of higher concentrations (Newman \& Jasani, 1984; Newman, 1987; Newman \& Hobot, 1987).

\section{Resins and Polymerization}

As early as 1962 it was suggested that the media could exert a "differential effect by differences in the way in which they combine with reactive groups of proteins and nucleic acids, and possibly by differences in the penetrability of the insoluble polymers by the enzymes" (Leduc \& Bernhard, 1962). The two problems related to resins are 1) 
preservation of binding site receptivity (antigenicity) within the tissue and 2) steric hindrance of the probe (Causton, 1984). These problems demand close attention to the chemical reactivity of cured resin, the curing process itself and to the degree of crosslinking achieved during the curing process. The success of EM detection also requires the resin be stable in an electron beam. Causton (1984) recommended epoxy crosslinked systems or cross-linked hydrophilic acrylics for best results and greatest flexibility of technique.

Another potential problem discussed by Newman and Hobot (1987) is that of extraction of tissues by the resins. Polymerization by chemical acceleration of the resin was the solution they suggested and demonstrated (Newman \& Hobot, 1987). The rate of diffusion of the accelerator into the tissue is an obvious limiting factor.

Araldite, Epon, and Spurr are the epoxy resins used for electron microscopy. They all have the advantage of being stable in the beam and the disadvantages of a high degree of cross-linking not only with resin components but also with peptide groups, and of being hydrophobic. An additional disadvantage of Araldite is that the component, diglycidyl ether of bisphenol $A$, is a large molecule and has a slow rate of diffusion into tissue (Causton, 1984). Epon and Spurr resins are less viscous than Araldite and provide improved diffusion properties. Spurr resin has the highest rate of diffusion of all these epoxy resins (Causton, 1984).

Similar to glutaraldehyde, cross-linking of resin to peptide groups may disrupt specific receptor requirements of the molecular probes. Such cross-linking may also alter the way in which a section is cleaved from the block and thus alter the amount of surface area available for cytochemical interaction with the tissue. Kellenberger and coworkers (1987) have shown the relief of Epon sections to be smoother than that of 
Lowicryl sections. They further suggested that the cleavage where co-polymerization does not exist will follow the interfaces between resin and proteins whereas the cleavage will preferentially not follow such interfaces where co-polymerization does exist. Essentially, a cleavage which follows the resin/protein interface is preferable because binding sites are laid open (Kellenberger et al., 1987).

The characteristic hydrophobicity is imparted to these resins by alkane $\left(\mathrm{RCH}_{3}\right)$ side chains (Causton, 1984). Newman and Jasani (1984) described the epoxies as impermeable to aqueous solutions at neutral $\mathrm{pH}$ and thus antibodies are isolated from the antigens by a hydrophobic barrier. Treatment with oxidizing agents such as hydrogen peroxide, periodic acid (periodate) or potassium permanganate produces hydrophilic groups, thus distroying the hydrophobic barrior. These treatments may also oxidize target molecules and therefore are best avoided (Causton, 1984; Newman \& Jasani, 1984).

The acrylic resins are the Lowicryls (K4M, HM20) and LR White. The great advantage these resins have over the epoxy resins is that they are hydrophilic (Newman, 1987). Thus hydration sensitive receptor sites are more likely to be retained, the need for the potentially detrimental oxidation treatment is supposedly eliminated and the mildest curing conditions can be chosen (Causton, 1984).

Newman and Hobot (1987) reported that these hydrophilic resins swell in aqueous solution and that this swelling is dependent on the degree of cross-linking. They further postulate, as Kellenberger and coworkers (1987) did for Lowicryl section "relief", that this swelling may improve receptor site accessibility.

Lowicryls can be cured with UV-light as well as with chemical accelerators. They are very mobile at low temperatures and thus infiltration and polymerization can be 
done at low temperatures. Although ultrastructural preservation is improved by low temperature methods, Newman (1987) pointed out that this does not automatically imply improved preservation of antigenicity. Causton (1984) stated that Lowicryl "has no special features that make it especially suited to electron microscopy."

LR White resin can be cured with UV-light, heat, and chemical accelerators (Newman, 1987). Newman and Jasani (1984) reported that best results for postembedding cytochemistry were obtained with this resin when it had a slow $\left(50^{\circ} \mathrm{C}\right)$ heat cure. Later, Newman and Hobot (1987) described catalytic polymerization at room temperature and at $0^{\circ} \mathrm{C}$ to be a further improvement. This work was done with human pituitary and rat kidney tissue, not a tissue with cell walls where the rate of penetration of the accelerator would be a more critical factor. Newman and Hobot (1987) reported gelling of chemically accelerated resin within approximately 7 minutes. It is doubtful that the accelerator could completely infiltrate both ascus and ascospore walls that rapidly.

\section{Tissue Preparation Strategies}

Introduction

The cytochemical study proposed in chapter 1 requires use of post-embedding methods. The principal probes proposed for use in this study were antibodies, lectins and possibly enzymes; the potential target molecules were protein, glycoprotein, and carbohydrate in nature. It is clear from the preceding literature review that tissue processing and embedding inevitably causes a reduction in the receptivity of some binding sites due to loss of or damage to tissue elements. The trade off between morphology and labelability has long been recognized. In fact, the issue was resolved by Leduc and Bernard (1962) via acceptance of artifacts and poor morphology for the 
contribution to our knowledge of ultrastructural chemistry their experiments could provide. Similar acceptance of poor morphology was proposed as a starting place for a study.

\section{Fixation}

The choice of fixative can be critical, especially for use of protein binding probes. Antibody and enzyme probes are used for detection of protein and glycoprotein molecules. To some extent it may be possible to increase an antibody's ability to recognize a glutaraldehyde fixed molecule by light fixation of the immunogen prior to its use. Light fixation in this case would be fixation with $0.5 \%$ glutaraldehyde for 30 minutes on ice. It is then possible to use tissues fixed with at least $0.5 \%$ glutaraldehyde, and possibly up to $2 \%$ glutaraldehyde (Erdos, personal communication) with those antibodies. Unfortunately, for use enzyme probes a lowered concentration or no glutaraldehyde in the fixative solution is typically required. Generally, a combination of glutaraldehyde and formaldehyde is recommended for post-embedding cytochemistry (e.g., $0.1 \%-1 \%$ glutaraldehyde with $2 \%-4 \%$ formaldehyde, Stirling, 1990; Roth, 1983; DeWaele et al., 1983). Acrolein, or mixes with acrolein were not recommended in any of the literature reviewed here. Use of osmium tetroxide post-fixation is not recommended in general where post-embedding cytochemistry is to be used because of its adverse effect on antigenicity and receptor site reactivity (Bendayan, 1989b; Stirling, 1990). When osmium tetroxide is used it is recommended to pre-treat sections with a saturated solution of periodate (Bendayan \& Zollinger, 1983; Bendayan 1984a, 1984b, 1989a, 1989b). This treatment, in turn, could damage some carbohydrates and oxidize alkanes. Stirling (1990) recommended preparing tissue with a number of 
different fixations. Following the recommendations of Erdos (personal communication) and Stirling (1990), the following preparations were proposed as an adequate start-up system:

1) Fixation of the immunogen as previously described, and embedding an alioquot of this preparation for TEM use.

2) Fixation of lightly broken spores that have not been fractionated and retain some cytoplasm with $0.5 \%$ glutaraldehyde and $4 \%$ formaldehyde.

3) Fixation of ascocarps with several combinations of glutaraldehyde and formaldehyde including: $0 \%$ glutaraldehyde with $4 \%$ formaldehyde, $0.5 \%$ with $4 \%$, $1 \%$ with $2 \%-4 \%$, and $2 \%$ with $2 \%$.

4) Fixation of ascocarps with $2 \%$ glutaraldehyde and $2 \%$ formaldehyde then post-fixed with osmium tetroxide (for comparative morphology).

Use of additive(s) to the fixatives was omitted from this plan. It was felt that the various fixative mixtures proposed would provide enough variation for initial screening of probes and testing of protocols.

\section{$\underline{\text { Resins and Dehydration }}$}

Lowicryl K4M, LR White, Spurr, and Epon resins were available for this study. Lowicryl K4M with low temperature infiltration and polymerization provides the greatest advantages for post-embedding cytochemical experimentation. Unfortunately, the experimental organism has brown spores which are impenetrable to UV radiation for polymerization. Chemical acceleration in a low temperature environment is possible with both K4M and LR White, but local temperatures may be variable and could potentially exceed an acceptable limit. Additionally, the cytoplasm of the spore may not obtain an 
adequate amount of accerator to polymerize properly. LR White polymerized in a 50$60^{\circ} \mathrm{C}$ oven thus appeared to be the best choice for this work. The potential for heat damage to potential binding sites was recognized, and accepted as part of the cytochemial reagent screening procedures.

LR White will tolerate up to $12 \%$ water in the tissues and still polymerize (Stirling, 1989). Dehydration through $95 \%$ alcohol is therefore not necessary. So as not to push the limits of the resin to a critical point, and keeping in mind that the stock alcohols used for dehydration may contain slightly less alcohol than the label suggests due to evaporation, dehydration through $95 \%$ alcohol (ethanol) was proposed.

Newman and Hobot (1987) recommended a rather short infiltration period with several changes of fresh $100 \%$ resin to avoid or reduce extraction. This recommendation was not followed because of the diffusion limits potentially imposed by the cell walls. A series of dilutions in $95 \%$ ethanol followed by several changes of $100 \%$ resin were proposed for the infiltration process.

Spurr resin rather than Epon was proposed for use with samples prepared for morphological study. Spurr resin is less viscous than Epon and therefore can infiltrate tissues with greater ease than Epon. Although Epon provides better morphology, for fungi and other other organisms with heavy cell walls, infiltration is the more critical factor. Spurr resin will not polymerize properly if water is present in the tissue, and therefore tissues used for this purpose needed to be dehydrated through ethanol and acetone before the infiltration process began. 


\section{CHAPTER 3 \\ DEVELOPMENT OF ANTIBODIES}

\section{$\underline{\text { Introduction }}$}

\section{Antibodies}

Antibodies, or immunoglobulins, are glycoproteins that make up the fraction of blood plasma called gamma globulin. Immunoglobulins are produced when a chemical, or chemicals, recognized as foreign is present in the body. It is part of the immune response. The specific chemical an antibody is made against and will bind to is called an antigen. That part of the antigen molecule which is actually bound by the antibody is the antigenic determinant or epitope and is typically 5-7 residues of a polymer (Goding, 1986). A single foreign molecule can have several antigenic sites. For example, lysozyme has 8 predominant antigenic sites (Sercarz et al., 1974). The binding of an antibody to its target epitope on the antigen is highly specific.

In their classic paper, Kohler and Milstein (1975) introduced a way to construct hybrid B-lymphocyte/myeloma cells (hybridomas) which can make antibodies. All of the antibodies produced by a single hybridoma clone have the same amino acid sequence and hence have the same binding properties (Edwards, 1981). These are called monoclonal antibodies. They can be selected for a predefined specificity and thus have become a valuable laboratory tool, although they have not diminished the need for polyclonal antibodies.

Antiserum developed against an antigen typically contains antibodies to a 
number of antigenic determinants on that target antigen. These antibodies are not derived from a single genotype of B-lymphocyte and are therefore called polyclonal antibodies.

As laboratory tools, there are pros and cons to both polyclonal and monoclonal antibodies. When an antigen is purifiable, polyclonal antibodies are often preferred. They will provide a precise identification of their target antigen whereas monoclonal antibodies are unable to distinguish between a group of different molecules which all bear the appropriate antigenic determinant (Edwards, 1981). Additionally, development of polyclonal antibodies requires much less work than development of monoclonals. A great deal of time spent "cell farming" and preforming hundreds or even thousands of tests is typically required to develop a usable monoclonal hybridoma cell line and antibody preparation (Goding, 1986). Conversely, if an antigen is not purifiable, or is unknown at the onset of experiments, monoclonal antibodies make the identification, assay, marking and purification of that antigen possible (Edwards, 1981). For immunocytochemical experimentation the best polyclonal antiserum tends to be inferior to monoclonal antibodies in terms of unwanted background (Mason et al., 1983).

\section{Immunogens}

When whole cells or isolated cell walls are used as immunogen, there are many different potentially antigenic molecules present. Typically, in a molecularly diverse immunogen some of the molecules present will be more antigenic than other molecules present. The term "immunodominant" is sometimes used to describe this phenomenon (Mason et al., 1983). This greater antigenicity, or immunodominance, results in a stronger response to these molecules. Therefore, one cannot assume that antibodies 
will be produced against a particular molecule of interest if several other molecules are presented at the same time. On the other hand, if very little is known about a chemically complex system, like the ascospore walls in the present study, any information gained by this so called "blind approach" (Mason et al., 1983) can increase our knowledge of the chemistry and biology of the system. In fact, the blind approach has been promoted as a valuable tool for cytochemical research in cases where little is known about the chemistry of a system (Sternberger, 1986). For the study of fungal antigens, Reiss (1986) promoted the use of whole cells and/or wall fragments as immunogen.

\section{Fungi and Fungal Walls as Antigens}

In a recent review of fungal infections, fungi are described as poor antigens (Khardori, 1989). Host non-specific and innate defense mechanisms such as intact skin, mucus membranes, indigenous microbial flora, and the fungicidal activity of certain cell types are apparently of greater importance than antibodies in protection against opportunistic fungal infections (Khardori, 1989). The status (health) of the host rather than the pathogenic properties of the fungus influence contraction and severity of fungal diseases (Khadori, 1989). Reiss (1986) further specified chronic fungal infections as the result of defects in immunoregulation controlled by thymic functions.

Despite this low antigenicity, there are a number of reports, particularly in the medical literature of monoclonal antibody development against fungal antigens (e.g., for Telletia sp., Banowetz et al., 1984; for Ophiostoma ulma, Benhamou \& Ouellette, 1986; for Phytophthora cinnamomi, Hardham et al., 1985, 1986; for Candida albicans, Brawner \& Cutler, 1986a, 1986b; Hopwood et al., 1986; Hospenthal et al., 1988; for Candida

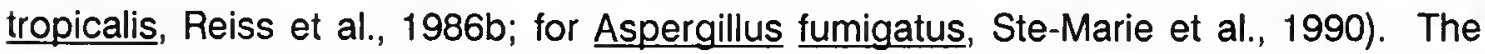


specific antigens and/or antigenic determinants reported for fungi include: peptido-Lfucomannan (Miyazaki et al., 1980), a high molecular weight glycoprotein of Phytophthora cinnamomi (Guber \& Hardham, 1988), Candida tropicalis mannan (Reiss et al., 1986b), oligogalactoside side chains and mannopyranosyl side chains of a Aspergillus fumigatus galactomannan (Ste-Marie et al., 1990), and M-protein of histoplasmin from Histoplasma capsulatum (Reiss et al., 1986a). The major surface antigens of fungi are thought to be mannans because; 1) Con A lectin agglutination of

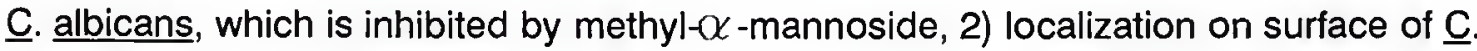
albicans by the silver proteinate method, 3) ultrastructural localization with Con A on surface of Sporothrix schenckii, 4) chemical analysis after digestion of Histoplasma capsulatum walls with various glucanases, and 5) mannans were detected in fractions

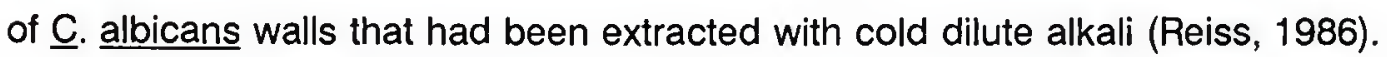

\section{Production}

Information and discussion on the production of monoclonal antibodies is abundant and easily found in immunology text books (e.g., McMichael \& Fabre, 1982; Goding, 1986), review articles (e.g., Edwards, 1981; Mason et al., 1983), and articles pertaining to specific antigens (e.g., Reiss et al., 1986a, 1986b; Ste-Marie et al., 1990). At this point in time too much information is available to adequately review the subject as a whole, and thus only a few references shall be discussed.

Two immunization processes, in vitro and in vivo, are currently used to develop antibody producing cell lines. The in vitro techniques for development of antibody were first deomonstrated by Mishell and coworkers (1967). Basically, these techniques differ from the in vivo techniques by immunization of non-immune B-lymphocytes (B-cells) in 
culture rather than immunization of a mouse (or other mammal). The in vitro method is preferable when antigen is limited (Pardue et al., 1983), or a weak antigen is of interest (Pardue et al., 1983; Borrebeck \& Moller, 1986; Brams et al., 1987). For this study these advantages were not sufficient to warrant the extra time required to learn the techniques or additional time spent developing a specific protocol and "cell farming."

The in vivo method requires that mice be immunized. When whole cells or cell fragments are of interest, $1-5 \times 10^{6}$ cells or parts per immunization is recommended (Bastin et al., 1982; Mason et al., 1983). There is diversity in the literature as to the most appropriate immunization schedule (Prabhakar et al, 1984). A final intraperitoneal or intravenous immunization 3 days prior to removal of the spleen is the most universally accepted procedure (Prabhakar et al., 1984).

After mice have been immunized for a sufficient period of time their serum can be tested for the presence of antibodies against the antigen of interest. If such antibodies are present, a fusion of spleen derived B-lymphocytes and a appropriate myeloma cell type can be made to produce hybridoma cells. Fusion of the cells can be accomplished using Sendai virus (Kohler \& Milstein, 1975), or with polyethyleneglycol (PEG; Mason et al., 1983; Prabhakar et al., 1984). During the fusion process it is possible for B-cell/B-cell and myeloma/myeloma fusions to occur. Some cells may remain unfused. Selective media are used to prevent these unwanted cell types from growing and perhaps overgrowing the hybridomas (Mason et al., 1983). Although Mason and co-workers (1983) described the process of cell fusion as being inefficient in that only a small minority of cells undergo fusion, fusions can yield hundreds to thousands of individual hybrid cell lines (Edwards, 1981). Of the cell lines produced by a fusion only about $10 \%$ produce antibody to the antigen used to immunize the mouse (Edwards, 1981). 
Once colonies of hybridomas begin to expand rapidly or fill about $1 / 2$ of any size well, the culture supernatant can be tested for the presence of antibodies. Several assays have been described for detection of antibodies in hybridoma culture supernatant including radioimmunoassay (RIA), enzyme-linked-immunosorbent-assay (ELISA) and immunofluorescence (FA). The choice of assay has been described as "extremely crucial" because the assay can greatly affect the selection of antibodies with different specificities (Prabhakar et al., 1984).

\section{ELISA}

ELISA is a commonly used assay for detection of antibodies in hybridoma culture supernatant. It has the advantage over RIA's in not requiring any radioactive reagents. It usually requires less preparative effort than cytochemical methods such as the FA.

The ELISA is based on the premise that an immunoreagent (e.g., antibody, antigen) can be immobilized on a carrier surface while retaining its activity or capicity for binding (Voller \& Bidwell, 1980). Typically the process requires adsorption of the relevant antigen to wells of plastic microtiter plates, incubation with the test samples, incubation with an enzyme-labeled antibody which is directed against the antibody in the test sample (e.g., goat-anti-mouse antibody), incubation with the appropriate enzyme substrate, then stopping and photometric determination of the reaction (Voller \& Bidwell, 1980).

\section{Antibody Containing Products}

The antibody-containing products are serum, ascites fluid, and hybridoma culture supernatant. Immune-mouse blood is collected at the time a sacrifice is made. This 
serum provides a positive control while serum from a non-immune, or normal, mouse provides negative controls for both ELISA and EM screenings of hybridoma culture supernatants.

Hybridoma culture supernatant contains a sufficient quantity of antibody (5$25 \mu \mathrm{g} / \mathrm{ml}$; Edwards, 1981) to not only allow ELISA screening, but also be a useful source for cytochemistry.

Ascites fluid is produced by planting hybridoma cells in the intra-peritoneal cavity of a live mouse. There they typically grow, divide and promote production of fluid (ascites) which has a high titre of antibody $(0.1-1 \mathrm{mg} / \mathrm{ml}$; Edwards, 1981). In addition to the antibody of interest, ascites fluid will contain a number of non-specific serum immunoglobulins which can produce background staining in immunocytochemical experiments (Mason et al., 1983). Based on the Mason's arguement, ascites will not be used in this project.

\section{Materials and Methods}

\section{Fungal Cultures}

Cultures of Ascodesmis sphaerospora (culture \#260) were kindly donated by Dr. J.W. Kimbrough. Cultures were grown on corn meal/malt extract/yeast extract (CMMY) medium. No unusual treatment or growth conditions were required, although petri plates were sealed with parafilm so that moisture would condense on the lids and trap expelled ascospores. The exact formula for CMMY and growth conditions are given in Appendix A. Cultures were allowed to sporulate for 1 to 3 weeks before the ascospores were collected and processed. 
Isolation of Immunogen

Ascospores that collected in the condensation on the lids were swept together with a rubber policeman and transferred to flask with a Pasteur pipet. The spores were allowed to settle to the bottom and the excess fluid removed. The spores were then broken in a Braun homogenizer and separated from the cytoplasmic components by centrifugation over a steep sucrose gradient. The spore fragments were washed several times, fixed with $0.5 \%$ glutaraldehyde and $1 \%$ formaldehyde, washed several times more with buffer (cacodylate once, then PBS) before they were used as immunogen. Details of the entire process are given in Appendix B.

The concentration of wall fragments per $\mathrm{ml}$ was determined by making three 10 fold serial dilutions, then counting fragments on a hemacytometer. Antigen was prepared twice. The first preparation contained approximately $4.5 \times 10^{8}$ parts per $\mathrm{ml}$ and the second contained about $7 \times 10^{8}$ parts per $\mathrm{ml}$. Mice were given approximately 2-3.5 $\times 10^{7}$ parts per immunization.

\section{Immunization}

Two sets of mice were immunized. From the first set of 4 , a single mouse was sacrificed after two months of regular immunization (once every other week) and a final boost three days prior as described in Appendix C. A second mouse was sacrificed after that initial two months, a 3 month break, and another 2 months of regular immunization and pre-sacrifice boost. The other mice in this set died due to unforseen circumstances. When these were lost, immunization of another set was begun immediately so that mice would be available whenever needed. 
Only one mouse was used from the second set of 3 . Its immunization schedule was similar to that of the second mouse from the first set.

Hybridoma Production and Cloning

The complete protocol used for hybridoma production and cloning, including materials, is given in Appendix C. A total of 3 fusions were performed.

\section{Feeder Cells}

Use of feeder cells (which can be peritoneal exudate cells, thymocytes or B-cells of a normal mouse) is recommended especially with when transferring hybridomas to a larger volume or cloning (Prabhakar et al., 1984; Goding, 1986). Thymocyte and/or B-cells were used for these purposes here. The thymus and/or spleen was removed from young mice and pushed through a metal mesh screen. They were then diluted to approximately $10^{6}$ cells per $\mathrm{ml}$ in appropriate media and either plated out at $100 \mu \mathrm{l}$ per well of a 96-well plate or placed in a sterile growth flask and cultured as for hybridomas.

\section{ELISA}

The indirect-method as outlined by Voller and Bidwell (1980) and was used with alterations as needed for this antigen/antibody system. Those alterations were: 1) the antigen was dried down onto the plate in a $37^{\circ} \mathrm{C}$ oven overnight, 2) test samples contained mouse antibody rather than human, 3$)$ both PBS and tris $(0.02 \mathrm{M}) /$ high salt $(0.5 \mathrm{M}) /$ tween $(0.1 \% \mathrm{v} / \mathrm{v} ; \mathrm{THST})$ antibody buffering systems were tried, 4$)$ the secondary enzyme labeled antibody was alkaline-phosphatase-goat-anti-mouse lgG/lgM specific (Jackson Laboratory), and 5) the enzyme substrate was p-nitrophenylphosphate. Plates 
were read on a SKT Labinstruments EasyReader SF Plus microtiter plate reader using a $405 \mathrm{~nm}$ filter.

It became apparent after several screenings that the background on the assays done was unacceptably high. Two experiments were designed and run to demonstrate this statistically. The first experiment run was without a primary antibody and tested both substrate alone and secondary antibody with subsequent substrate step. These variables were nested within a buffer wash trial comparing PBS with THST. The second experiment compared buffer negative controls, immune-mouse serum and normal-mouse serum. SAS statistical analysis of this data was done using PC SAS version 6.03 (SAS institure Inc.) program, on an IBM PS 2 computer.

\section{EM Screening}

EM screening methods are given in Appendix $F$, and are discussed in chapter 4.

\section{Collection and Storage of Products}

Immune-mouse blood was collected at the time spleen was removed. Heparin was added to prevent coaggulation. The blood was heated to $60^{\circ} \mathrm{C}$ and held at that temperature for 30 minutes to inactivate serum proteases and other enzymes. The cells were removed by centrifugation (Dynac centrifuge, speed setting 90-100, for 30 minutes). Serum was pipeted off and further diluted with (1M) PBS with $1 \% \mathrm{w} / \mathrm{v}$ sodium azide for a final dilution of $1 / 10$. Serum was then frozen and stored at $-80^{\circ} \mathrm{C}$. Normal mouse serum was handled in exactly the same manner.

When small volumes of culture supernatant were harvested but not used 
immediately, the supernatant was stored in microfuge tubes at either $4^{\circ} \mathrm{C},-20^{\circ} \mathrm{C}$, or $80^{\circ} \mathrm{C}$ depending on the projected time of use. Several of these went through several freeze/thaw cycles and were damaged.

Hybridoma cells were removed from large volumes by centrifugation (Dynac centrifuge, speed setting 5 , for $8-10$ minutes). Sodium azide was added $(0.1 \% \mathrm{w} / \mathrm{v})$ and then the supernatant was aliquoted, frozen and stored at $-80^{\circ} \mathrm{C}$.

The protocol for preparation and freezing of hybridomas in given in Appendix D.

\section{Results}

\section{Immunogen}

It should be noted that the concentrations (fragment particles/ml) determined using the hemacytometer for wall fragments per $\mathrm{ml}$ are not highly reliable. The reasons are: 1) The shape of fragments was very inconsistent and some of them may have been smaller than can be resolved on the light microscope when using a hemacytometer. 2) They were additionally diluted by sticking to plasticware, glassware, and each other, hence reducing the apparent count.

\section{Immunization}

The second and third fusions used mice that had an extended immunization regime. These mice had greatly enlarged spleens.

\section{Hybridoma Production and Cloning}

Three fusions were preformed. The first fusion required $4-96-$ well plates and the second and third required 9 plates each. The increase in plates required per fusion 
was most likely due to an increase in the number of cells per spleen. Additionally, the B-cells were removed from the spleen by the syringe method (Appendix $C$, method 2) in the last two fusions. This is the more gentle way to release the B-cells and survival of B-cells was probably improved.

All 3 fusions had a high hybridoma recovery rate. Between $70 \%-90 \%$ of the wells had viable hyridomas after 2 weeks of feeding with selective media. A majority of those tested positive with ELISA testing.

Over 100 mixed cell cultures from fusions were screened using EM techniques. Of these cultures six were targeted for expansion and coloning.

\section{Products}

Three highly useful antibody-containing culture supernatants were identified and proven in EM screening. It was possible to clone only 2 of the three. The third was lost in the first expansion into a 24-well plate.

Hybridoma cells from over 100 mixed cell cultures and several vials all of the cloned cell lines were frozen for future use.

\section{ELISA}

SAS data is given in tables 3.1-3.4. Optical densities of the 3 treatments 1) buffer washes only, 2) substrate treatment, and 3) both secondary and substrate treatments are compared using log-transformation of raw data and the least-square mean test in table 3.2. These data demonstrate that the optical density of the substrate only treatment was significantly different from that of the buffer washes. Further, this analysis shows that the optical density when secondary antibody treatment was included was 
significantly different from the substrate only treatment. It is evident from the means based on raw data (table 3.1) that these significant differences are due to increasing optical density. This indicates that a statistically significant increase in background optical density occurs at each of these later steps in the ELISA assay protocol.

Table 3.1 Mean optical densities for buffer wash, substrate, and secondary antibody treatments.

\begin{tabular}{|c|c|c|c|c|c|}
\hline$\frac{\text { Trtm. }}{\text { PBS }}$ & N Obs. & Mean & Std. Dev. & $\begin{array}{l}\text { Tab. } 3.2 \\
\text { LS \# } \\
\end{array}$ & $\begin{array}{l}\text { Tab. } 3.3 \\
\text { LS \# }\end{array}$ \\
\hline $\begin{array}{l}w / 2^{\circ} A B \\
w / \text { sub. }\end{array}$ & 8 & 0.5035 & 0.0782 & 1 & 1 \\
\hline $\begin{array}{l}\text { PBS } \\
\text { w/o } 2^{\circ} A B \\
\text { w/o sub. }\end{array}$ & 8 & 0.0489 & 0.0034 & 2 & 2 \\
\hline $\begin{array}{l}\text { PBS } \\
\text { w/o } 2^{\circ} A B \\
\text { w/ sub. }\end{array}$ & 8 & 0.0764 & 0.0018 & 3 & 3 \\
\hline $\begin{array}{l}\text { THST } \\
\text { w/ } 2^{\circ} A B \\
\text { w/ sub. }\end{array}$ & 8 & 0.3030 & 0.0718 & 1 & 4 \\
\hline $\begin{array}{l}\text { THST } \\
\text { w/o } 2^{\circ} A B \\
\text { w/o sub. }\end{array}$ & 8 & 0.0558 & 0.0079 & 2 & 5 \\
\hline $\begin{array}{l}\text { THST } \\
\text { w/o } 2^{\circ} A B \\
\text { w/ sub. }\end{array}$ & 8 & 0.0896 & 0.0093 & 3 & 6 \\
\hline $\begin{array}{l}\text { sub., subst } \\
2^{\circ} \mathrm{AB} \text {, secc } \\
\text { Tab., table } \\
\text { LS \#, least } \\
\text { w/, with } \\
\text { w/o, withou }\end{array}$ & $\begin{array}{l}\text { ary antik } \\
\text { dare me }\end{array}$ & nber & & & \\
\hline
\end{tabular}


Table 3.2. Least square means comparison of washing vs substrate and antibody/ substrate treatment. (Data log transformed; $x<0.05$ indicates a significant difference.)

$$
\begin{aligned}
& \operatorname{Pr}>|T| \text { HO: LSMEAN (i)=LSMEAN (j) } \\
& \begin{array}{lrrr}
i / j & 1 & 2 & 3 \\
1 & . & 0.0001 & 0.0001 \\
2 & 0.0001 & . & 0.0001 \\
3 & 0.0001 & 0.0001 & .
\end{array}
\end{aligned}
$$

Table 3.3. Least square means comparison of interaction of buffer type with treatments. (Data log transformed; $x<0.05$ indicates a significant difference.)

$$
\operatorname{Pr}>|T| \text { HO: LSMEAN }(i)=\operatorname{LSMEAN}(j)
$$

$\begin{array}{lrrrrrrr}\mathrm{i} / \mathrm{j} & 1 & 2 & 3 & 4 & 5 & 6 \\ 1 & . & 0.0001 & 0.0001 & 0.0001 & 0.0001 & 0.0001 \\ 2 & 0.0001 & . & 0.0001 & 0.0001 & 0.0636 & 0.0001 \\ 3 & 0.0001 & 0.0001 & . & 0.0001 & 0.0001 & 0.0228 \\ 4 & 0.0001 & 0.0001 & 0.0001 & . & 0.0001 & 0.0001 \\ 5 & 0.0001 & 0.0636 & 0.0001 & 0.0001 & . & 0.0001 \\ 6 & 0.0001 & 0.0001 & 0.0228 & 0.0001 & 0.0001 & .\end{array}$

The type of buffer used for washing also affects the amount of background optical density. As would be expected, there was no statistically significant difference in the optical densities of the two buffer controls (table 3.3, LS\# 2 vs 5). On the other hand, when antibody was tested, there was a statistically significant difference in optical density readings between the PBS and THST buffer washes (table 3.3 , LS\# 1 vs 4). From the raw data means (table 3.1: 0.5035 vs 0.3030 ) it is apparent that THST buffer washes reduced the background in the system.

The mean optical densities of the sera are given in table 3.4. The high standard deviations of the serum means are the result of pooling data from $1 / 500$ and $1 / 1000$ serum dilutions. The mean optical densities for normal-mouse serum in both buffer 
wash systems were high enough to be considered positive for anti-wall antibodies. Each of those means are over 1.5 standard deviation units greater than the buffer control (which did have the secondary antibody treatment).

Table 3.4: $\quad$ Mean optical densities for buffer control, immune mouse and test mouse sera.

\begin{tabular}{llll} 
Trtm. & N Obs. & Mean & Std. Dev. \\
\cline { 2 - 2 } & & & \\
PBS & 4 & 0.3692 & 0.0391 \\
PBS & 4 & 2.4285 & 0.1749 \\
IM & & & \\
PBS & 4 & 1.0942 & 0.3609 \\
NM & & & \\
THST & 4 & 0.3518 & 0.0350 \\
THST & & & 0.3359 \\
THST & 4 & 2.0472 & \\
IM & & & 0.2314 \\
THST & 4 & 0.7628 & \\
NM & & & \\
IM = immune mouse & & & \\
NM = normal mouse & & &
\end{tabular}

\section{Discussion}

\section{Hybridoma Production}

The great success of these fusions in terms of hybridoma recovery and apparent production of anti-fungal antibodies (via ELISA testing), especially the second fusion, was overwhelming and many lines were lost to poor management and inexperience. 
All 3 of the antibody preparations used came from the second fusion. The third fusion was done primarily in an effort to reproduce antibody 8 F11. The effort was apparently unsuccessful but it also provided an opportunity to try a different management system. In the first 2 fusions ELISA testing began as soon as hybridoma colonies filled $1 / 4$ to $1 / 2$ a well in the 96 well plates and those wells which tested positive were immediately expanded and cloned. In the third fusion, after an intial growth period, cells from 8 wells were transferred into a single well of a 24 well plate and allowed to expand before testing. After $2-5$ days growth in the 24 well plate, $100 \mu l$ of culture supernatant was harvested for testing and the cells were frozen. This method required about 3-4 weeks of growth with only $10-20 \mathrm{hr}$ of labor a week to take cells from fusion to freezer, vs 2-3 months of $40-60 \mathrm{hr}$ per week labor of the previous method required. The supernatant could then be stored and tested at a convienent time. After testing, cells could be brought out of the freezer in small numbers, cultured, retested, expanded, and cloned at a convenient time. Athough time has not permitted further work with the cells from the third fusion, they are available.

\section{ELISA}

Several problems were encountered with the ELISA system for this antigen. The wall fragments are heavy and sticky which made preparing the plates difficult and time consuming. These factors also made the particle count per well unreliable. Background from the secondary antibody-enzyme conjugate was sufficient to make some negative results appear positive or hide low concentrations of antibody that might be expected from a colony which is just establishing itself. Normal-mouse serum also appeared to contain reactive antibodies with this system, whereas in the EM screening, no significant 
labeling occurred. For these reasons the ELISA was found to be not only a great deal of trouble but an ineffective assay system for this antigen.

Mason and coworkers (1983) and Sternberger (1986) expressed a preference for EM screening of hybridoma culture supernatants when the final use is to be immunocytochemistry. Mason and coworkers (1983) based their preference on the arguements that 1) monoclonal antibodies which react strongly in one assay procedure do not always give satisfactory results in another unrelated assay system, and that 2) the results from immunocytochemical techniques are inherently more informative (providing not only $+/$ - results, but specific background and localization data). Based on these opinions, arguements and experience with the ELISA, any future screening for anti-ascospore antibodies will be done using cytochemical techniques. It is further suggested that cytochemical techniques be used when screening for antibodies against any fungal wall system if the antigen is wall fragments and the intended final use is immunocytochemical. Assessment of the value of the labeling information then becomes a part of the screening process. 


\section{CHAPTER 4 \\ IMMUNOCYTOCHEMISTRY}

\section{Introduction}

\section{Brief History of Immunocytochemistry}

The practice of cellular localization began in the 1830's with Raspail's "microchemistry," or chemical analysis in combination with microscopic examination (Raspail, 1830). The immunological approach in histochemistry (light level cell chemistry) was introduced by Coons and coworkers (1941). They used fluorescent conjugated antibodies to identify sites of antigen-antibody reaction at the light microscopic level. Development of an electron-dense marker was necessary for immuno-labeling to be applied to electron microscopy (immuno-cytochemistry). Singer (1959) introduced the use of ferritin as an electron-dense marker. Nakane and Pierce (1966) described the application of horse-radish-peroxidase (HRP) and diaminobenzidine (DAB) reaction to histochemistry. Immunogold techniques, and use of gold as as electron-dense marker for electron microscopy were introduced by Faulk and Taylor (1971) and later by Romano and coworkers (1974). Lectin-gold techiques for microscopy were described in articles such as Roth (1983). The avidin-biotin-gold system (Tolson et al., 1981) and enzyme-gold techniques (e.g., Bendayan, 1981, 1982) were also described in the early 1980's. In the past 20 years histochemistry has progressed from the use of stains which are capable of identifying classes of molecules such as deoxyribonucleic acids to the use of probes and techniques which are highly 
specific for particular substrates and that can demonstrate subcellular location. Causton (1984) described immunocytochemistry as potentially being the most demading of all the staining techniques.

$\underline{\text { Immunolabeling of Fungi }}$

Several publications have used immunocytochemistry to examine fungi. Localization of ligninperoxidase in Phanerochaete chrysosporium is reported by Daniel and coworkers (1989). Ste-Marie and colleagues (1990) report development of 2 antiAspergillus fumigatus monoclonal antibodies. The first, MAb1, labeled the inner cell wall of hyphae and conidia, and intracellular membranes. The second, MAb40, bound hyphal and conidial walls more diffusely and intracellular membranes less intensely. This second antibody was also found to recognize the cell walls of Candida albicans serotype A. Brawner and Cutler (1986b) demonstrated variable expression of cell

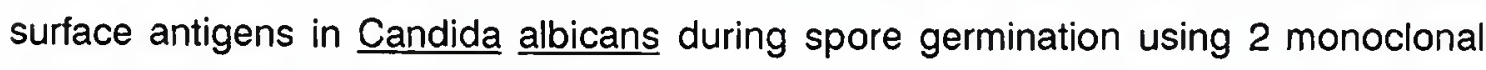
antibodies (H9 and $\mathrm{C6}$ ). Phytophthora cinnamoni zoospore encystment was found to be induced by specific lectin and antibody binding to the cell surafce (Gubler \& Hardham, 1988). Undoubtedly, more publications exist, particularly in the medical literature. Reiss (1986) described localization studies as an important step subsequent to the development of antibodies and characterization of their determinants. His work has primarily been in the field of medical mycology.

\section{Charaterization of Antigenic Determinants}

Most naturally occurring antigens are proteins and carbohydrates including glycoproteins and glycolipids (Goding, 1986). In any case, some idea of the nature of 
the determinant is desirable. A number of simple tests have been used with ELISA, Western blots, and thin layer chromatography. These include heat treatment, proteinase treatment (notably pronase and trypsin), and periodate treatment (Goding, 1986). Proteins are typically sensitive to proteinase and heat but not periodate, while the converse typically is true for carbohydrates. Yet these tests are not absolutely diagnostic since some proteins resist digestion by proteinases and some carbohydrates are insensitive to periodate. Additionally, the amino acids tyrosine, tryptophan and methionine may react with periodate (Geoghegan et al., 1982; Yamasaki et al., 1982). Periodate has successfully been used as a pretreatment for antibody labeling on sections of osmocated tissue (Bendayan \& Zollinger, 1983). These authors demonstrated improved labeling with this pretreatment, but it should be noted that the antigens of interest were proteinaceous.

\section{Materials and Methods}

\section{Experimental Organism}

The choice of Ascodesmis sphaerospora as the experimental organism was explained in chapter 1. Conditions under which it was grown and spores harvested were given in chapter 3 . For electron microscopy both ascospores and apothecia were harvested and prepared for study. Spores were collected in the same manner as for preparation of immunogen but were handled differently thereafter as explained below. Apothecia were monitered for development and harvested just after spores were noticed in the water droplets on the petri dish lid; usually 10-14 days after inoculation. At this point it was thought that most of the ascospore developmental stages would be represented, yet the culture was relatively young and active. 


\section{Tissue Preparation}

Ascospores were prepared for electron microscopy by an inital fixation step and then "gently" breaking them with vortex and glass beads followed by another fixation step, dehydration, and infiltration. The detailed protocol is given in Appendix $E$.

A general protocol for fixation, dehydration, infiltration, embedding and infiltration of apothecia is given in Appendix F. Blocks of agar (approx., $0.5 \mathrm{~cm} \times 1 \mathrm{~cm}-2 \mathrm{~cm} \times$ $0.25 \mathrm{~cm}-0.5 \mathrm{~cm}$ ) were cut from cultures of sporulating $\underline{A}$. sphaerospora and prepared. Additionally, pelleted apothecia were prepared by flooding plates with the various reagents up to $75 \%$ or $95 \%$ ethanol step of dehydration. At this point apothecia were scraped off of the agar and treated as a suspension and pelleted between every step thereafter.

Table 4.1 demonstrates the specific variations in fixation, dehydration, and resin used to prepare material for electron microscopy.

Pseudoplectania nigrella, used for comparitive work was collected in the Oregon coastal range in March, 1990. Sections of apothecial tissue were fixed for one hour on ice in the field immediately upon collection. One set of tissue samples was fixed with $2 \%$ glutaraldehyde and $2 \%$ formaldehyde (block $225-\mathrm{A}$ ). This set was later split, and half was post-fixed with osmium tetroxide (block 225-A). Another set of tissue samples was fixed with $1 \%$ glutaraldehyde and $2 \%$ paraformaldehyde (block $225-\mathrm{B}$ ). Tissue samples not post-fixed were embedded in LR White (blocks 225- A \& A'). Dehydration and further processing was as in the protocol given in Appendix F. Post-fixed tissue was embedded in Spurr resin. Sections for EM labeling experiments were cut from block 225-B. 


\section{Sectioning}

Pale gold to silver $(70-90 \mathrm{~nm})$ sections were cut on a RMC MT6000-XL microtome or a LKB 8800 ultramicrotome III. For cytochemical experiments sections were placed on formvar (0.25\%-0.3\% powder w/v in ethylene dichloride) coated 75 or 100 mesh nickel grids. Formvar coated 75 mesh copper grids were used for morphological study.

\section{The Antibodies}

The development and cloning of the three antibodies tested were the subject of chapter 3. The antibodies used for immunolabeling were in the hybridoma culture supernatant. Culture supernatants were diluted $3 / 4,1 / 2$ and $1 / 4$ in either PBS or THST buffer for labeling experiments. The three antibodies primarily used will be hereafter referred to as $8 \mathrm{~F} 11,12-2$, and $41-1.1$. The latter two are monoclonal.

Normal-mouse and immune-mouse serums, and PBS and THST buffers were used as controls.

\section{Experimental Immunocytochemistry}

Several general types of experiments were performed: screening of hybridoma culture supernatants, testing of positive and negative serum controls, monoclonal labeling with special attention given to finding developmental sequences, determinant characterization, and determinant unmasking.

A general protocol, with special notes for determinant and unmasking steps, is given in Appendix E. This general protocol was established as effective by experimenting with positive and negative serum control on sections cut from various 
Table 4.1: Tissue preparation and embedding.

BLOCK NUMBER

\begin{tabular}{|c|c|c|c|c|c|c|c|}
\hline & 1 & SP & 1 & 2 & 3 & 4 & 5 \\
\hline Immunogen & $x$ & & & & & & \\
\hline Spores (LB) & & $x$ & & & & & \\
\hline AC undisturbed & & & $x$ & $x$ & $x$ & $x$ & $\mathrm{x}$ \\
\hline \multicolumn{8}{|l|}{$\mathrm{AC}$ pelleted } \\
\hline $30 \mathrm{~min} .1^{\circ} \mathrm{fix}$ & $\mathrm{x}$ & & $x$ & & $x$ & & \\
\hline $45 \min .1^{\circ}$ fix & & $x$ & & & & & \\
\hline $60 \min .1^{\circ}$ fix & & & & $x$ & & $x$ & $x$ \\
\hline $0 \% \mathrm{G} / 4 \% \mathrm{~F}$ & & & $x$ & $x$ & & & \\
\hline $0.5 \%$ G / 0\% F & $x$ & & & & & & \\
\hline $0.5 \% \mathrm{G} / 2 \% \mathrm{~F}$ & & $x$ & & & & & \\
\hline \multicolumn{8}{|l|}{$0.5 \% \mathrm{G} / 4 \% \mathrm{~F}$} \\
\hline $1 \% \mathrm{G} / 2 \% \mathrm{~F}$ & & & & & $\mathrm{x}$ & $x$ & \\
\hline \multicolumn{8}{|l|}{$1 \% \mathrm{G} / 3-4 \% \mathrm{~F}$} \\
\hline $2 \% \mathrm{G} / 2 \% \mathrm{~F}$ & & & & & & & $x$ \\
\hline OsO4 & & & & & & & $\mathrm{x}$ \\
\hline $95 \% \mathrm{EtOH}$ & $x$ & $x$ & $x$ & $\mathrm{x}$ & $\mathrm{x}$ & $x$ & \\
\hline Acetone & & & & & & & $x$ \\
\hline LR White & $x$ & $x$ & $x$ & $x$ & $x$ & $x$ & \\
\hline Spurr's & & & & & & & $x$ \\
\hline
\end{tabular}
LB, lightly broken
$A C$, ascocarp
G, glutaraldehyde
$F$, formaldehyde 
Table 4.1 continued.

BLOCK NUMBER

\begin{tabular}{|c|c|c|c|c|c|c|c|}
\hline & 11 & 12 & 13 & 14 & 15 & 16 & 26 \\
\hline \multicolumn{8}{|l|}{ Immunogen } \\
\hline \multicolumn{8}{|l|}{ Spores (LB) } \\
\hline \multicolumn{8}{|l|}{ AC undisturbed } \\
\hline AC pelleted & $x$ & $x$ & $x$ & $x$ & $x$ & $x$ & $x$ \\
\hline $30 \mathrm{~min} .1^{\circ} \mathrm{fix}$ & $x$ & & $x$ & & & & \\
\hline \multicolumn{8}{|l|}{$45 \min .1^{\circ} \mathrm{fix}$} \\
\hline $60 \min .1^{\circ}$ fix & & $x$ & & $x$ & $x$ & $x$ & $x$ \\
\hline \multicolumn{8}{|l|}{$0 \% \mathrm{G} / 4 \% \mathrm{~F}$} \\
\hline \multicolumn{8}{|l|}{$0.5 \% \mathrm{G} / 0 \% \mathrm{~F}$} \\
\hline \multicolumn{8}{|l|}{$0.5 \% \mathrm{G} / 2 \% \mathrm{~F}$} \\
\hline $0.5 \%$ G / $4 \% \mathrm{~F}$ & $x$ & $x$ & & & & & \\
\hline \multicolumn{8}{|l|}{$1 \% \mathrm{G} / 2 \% \mathrm{~F}$} \\
\hline $1 \% \mathrm{G} / 3-4 \% \mathrm{~F}$ & & & $x$ & $x$ & & & \\
\hline $2 \% \mathrm{G} / 2 \% \mathrm{~F}$ & & & & & $x$ & $x$ & $x$ \\
\hline $\mathrm{OsO} 4$ & & & & & & $x$ & $x$ \\
\hline $95 \%$ EtOH & $x$ & $x$ & $x$ & $x$ & $x$ & & $x$ \\
\hline Acetone & & & & & & $x$ & \\
\hline LR White & $x$ & $x$ & $x$ & $x$ & $x$ & & $x$ \\
\hline Spurr's & & & & & & $x$ & \\
\hline
\end{tabular}

blocks with $1 / 100,1 / 1000$ and $1 / 10,000$ serum dilutions. All of the experiments more or less follow that protocol with major differences being the particular blocks (tissue creparation) used.

Sections used for screening of hybridoma culture supernatants were cut from the SP block. This block was chosen for this purpose because the material was prepared 
most like the immunogen ( block), yet the wall sturucture is less disrupted and it retains cytoplasm so that cross-reactivity could be monitored. Further, because this bolck is a pellet of spores less trimming and facing was required than was necessary for the apothecial blocks, thus reducing time and effort required to section.

Initial experiments with monoclonal antibodies were done using sections from blocks 4,14 and 15.

Determinant and unmasking experiments were also done using sections from a variety of blocks, but most typically from the SP block to save time in preparing sections. These experiments required a pretreatment of sections with saturated periodate for 30 to 60 minutes at room temperature. Alternatively, tissues in section were digested with $1 \%(\mathrm{w} / \mathrm{v})$ pronase in PBS for 60 minutes.

Specific deviations from the general protocol and origin of sections are given in the individual figure captions and noted in the results section where appropriate.

\section{Evaluation of Labeling}

All evaluations of labeling are qualitative rather than quantitative. Qualitative evaluation is sufficient for gross determination of specificity, background, and labeling density.

\section{$\underline{\text { Results }}$}

\section{Serum Labeling}

Immune-mouse serum labeled all parts of the ascospore wall, from the spore plasma membrane edge to the furtherest tip of secondary wall ornament (figs. 4.1A \& 4.2B). Ascus and vegetative cell walls were labeled to a much lesser extent (fig.4.2A). 
Additionally, sporoplasm, epiplasm (ascus cytoplasm), and vegetative cell cytoplasm components were specifically labeled. Conversely, normal-mouse serum did not specifically label any part of the fungus, and the background labeling was minimal (fig. 4.1C). The buffer negative control also had minimal background labeling (fig. 4.2B).

\section{Antibody Screening}

Between 200 and 300 culture supernatant screenings were done during the processes of identification and cloning of anti-wall antibody-producing hybridomas. Not only were $8 F 11,12-2$ and 41-1.1 identified and used, but 5 other monoclonal lines from culture 12 and 2 others from culture 41-1 were identified. Enough culture supernatants from these later lines exist for further testing with them when desired.

None of these screenings were done with periodate- or pronase-pretreated sections. It is now obvious from the pretreatment results with antibodies 12 and 41 (figs. $4.7,4.8 \& 4.9$ ), both cloned and uncloned, that some of the supernatants that had only scanty but apparently specific labeling may have actually been quite good if the sections had been pretreated.

\section{Antibody 8 F11}

Although not a monocional, antibody $8 \mathrm{~F} 11$ performed as specifically on sections as the monoclonals similarly tested. It labeled the primary wall and sporoplasmic vesicles (fig. 4.3A). Cell wall labelling was typically restricted to the outer $2 / 3$ to $3 / 4$ of this wall layer (figs. $4.3 \mathrm{~A}, 4.4 \mathrm{~A} \& \mathrm{~B}$ ). From the experiments performed it is impossible to determine if the wall and vesicle labeling are the result of the same antibody. Demonstration of identical antibody labeling on the cell wall and vesicles could be 


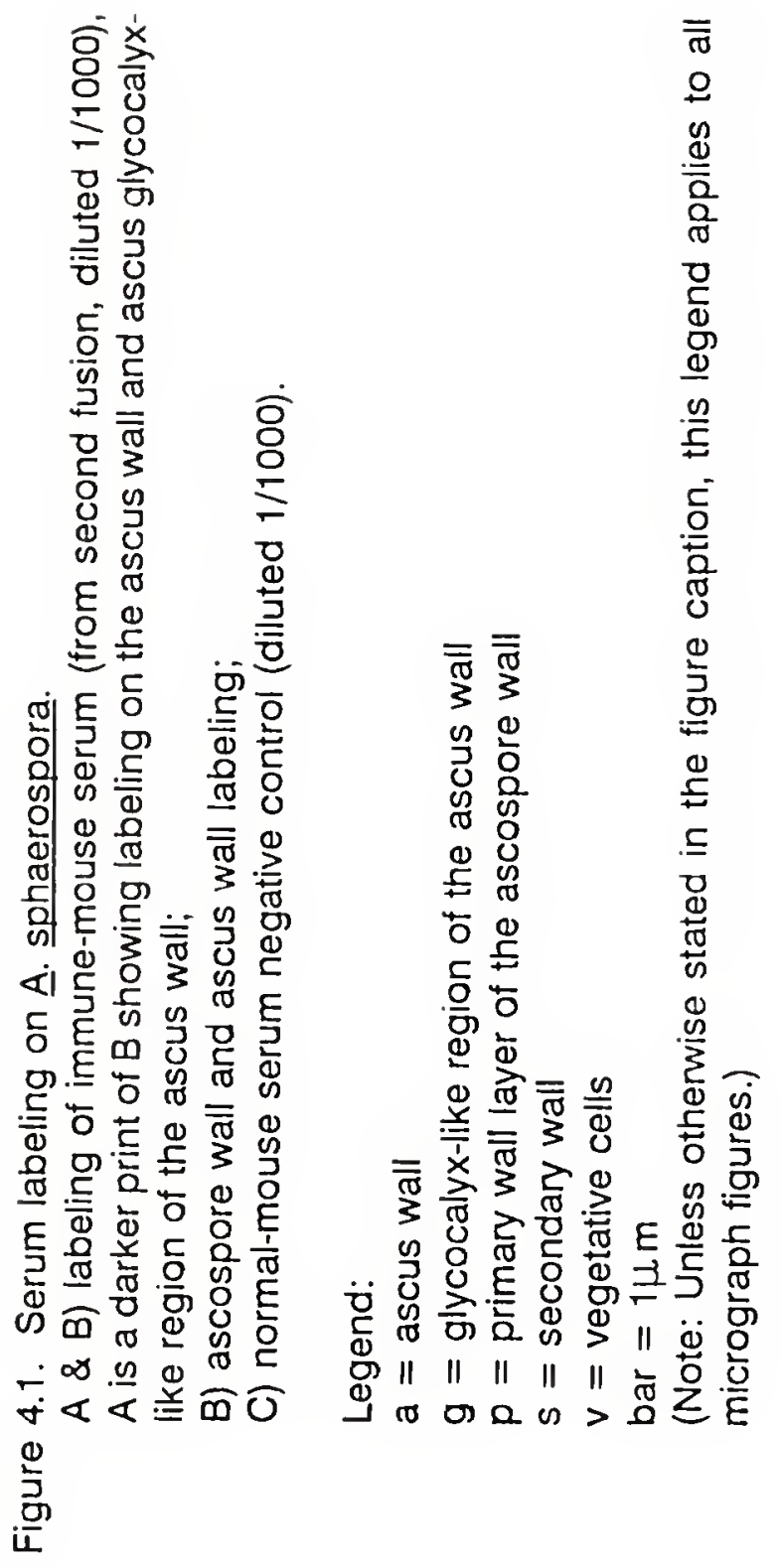



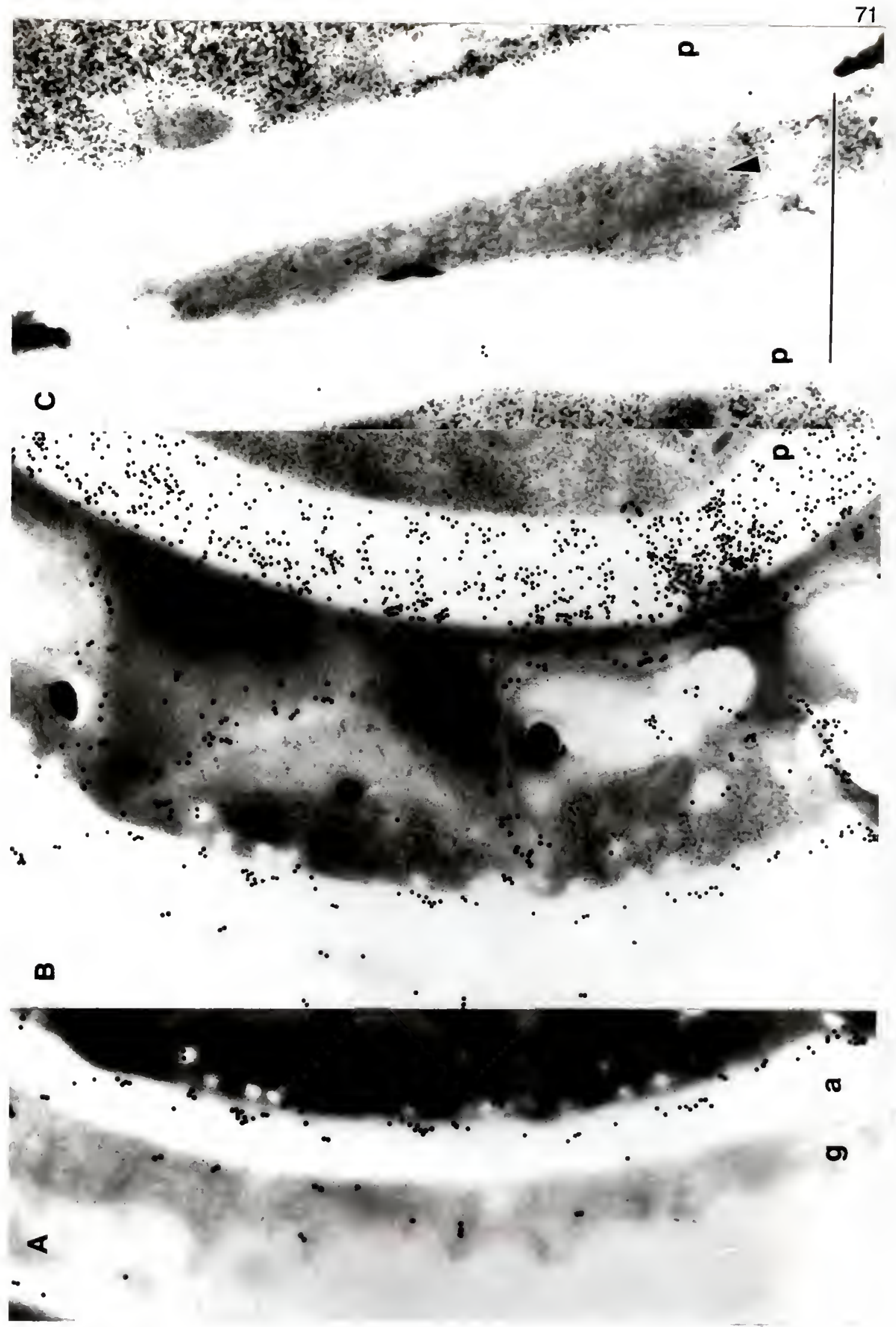


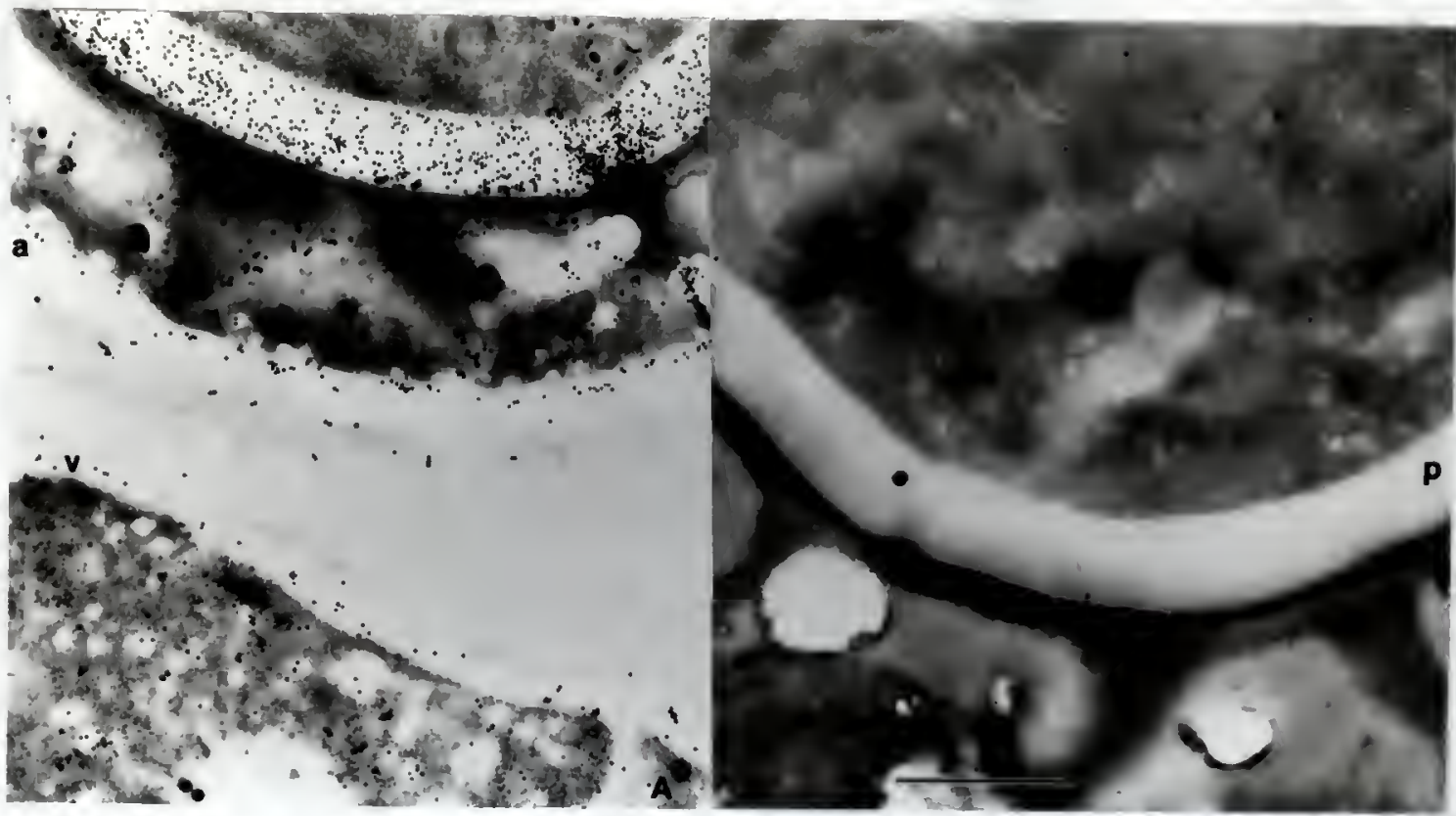

Figure 4.2. Serum labeling and buffer control on A. sphaerospora.

A) labeling of immune-mouse serum (from second fusion, diluted 1/1000);

B) buffer negative control.

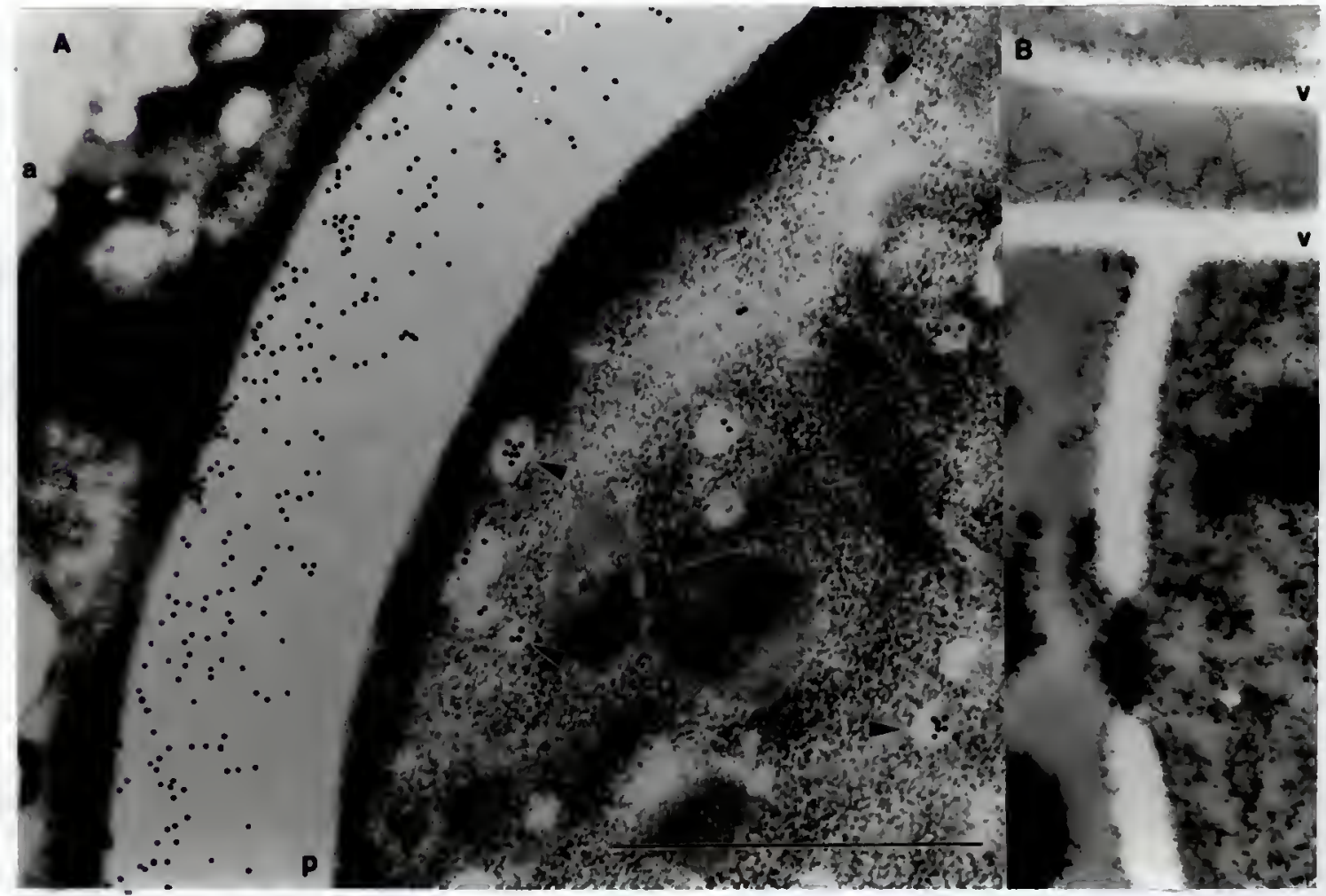

Figure 4.3. 8F11 culture supernatant labeling on A. sphaerospora.

A) Labeling on the ascospore wall and sporoplasmic vesicles (pointers);

B) Labeling on the vegetative wall, including septum. 


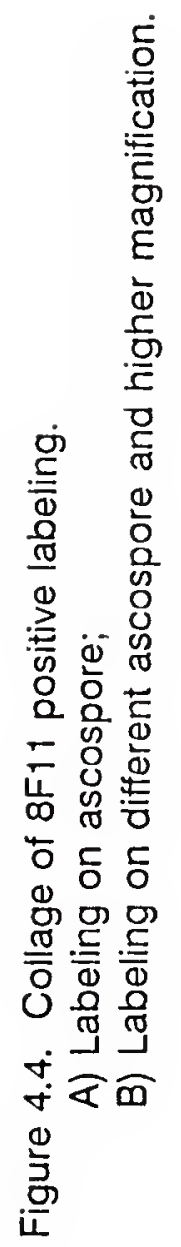




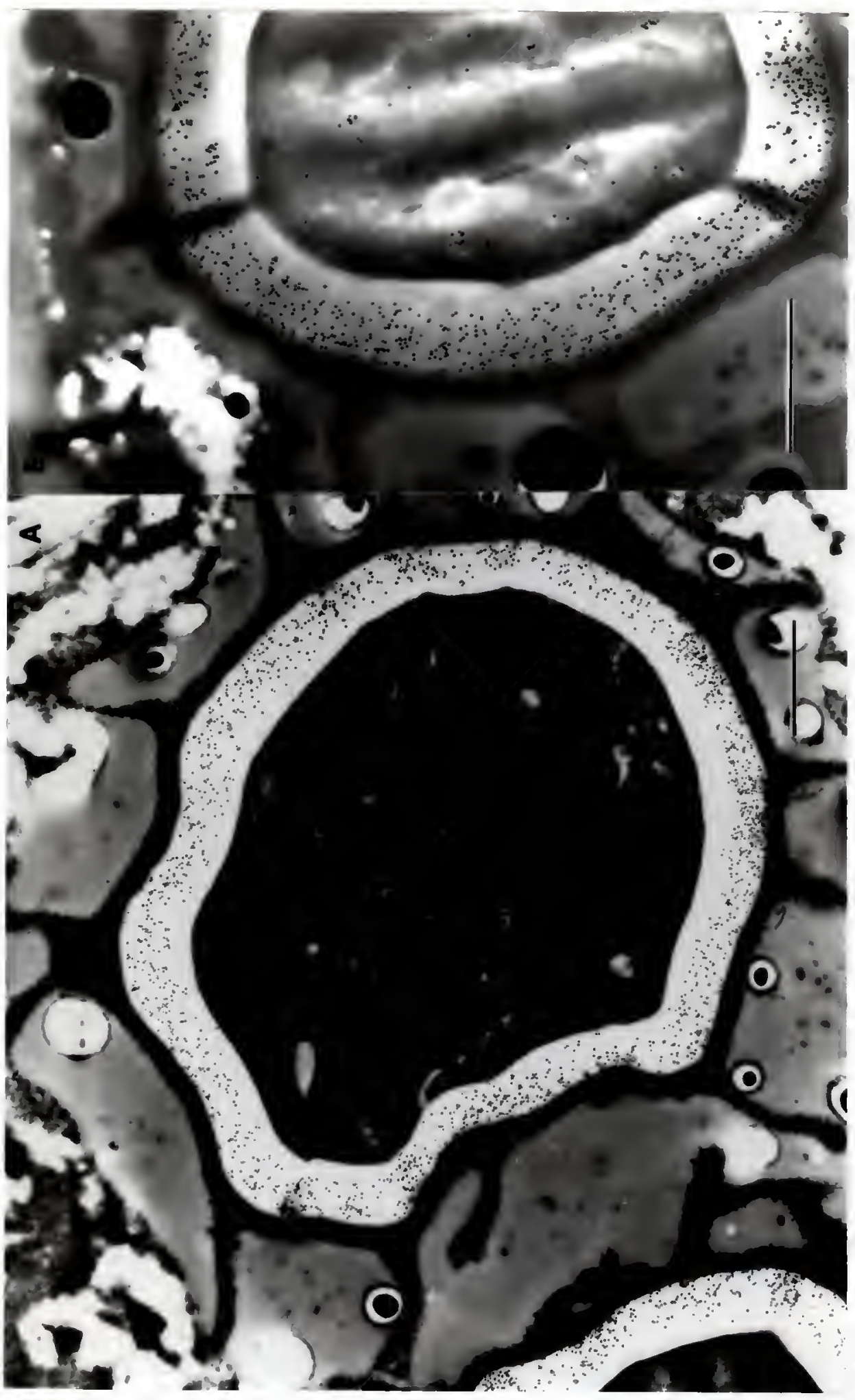




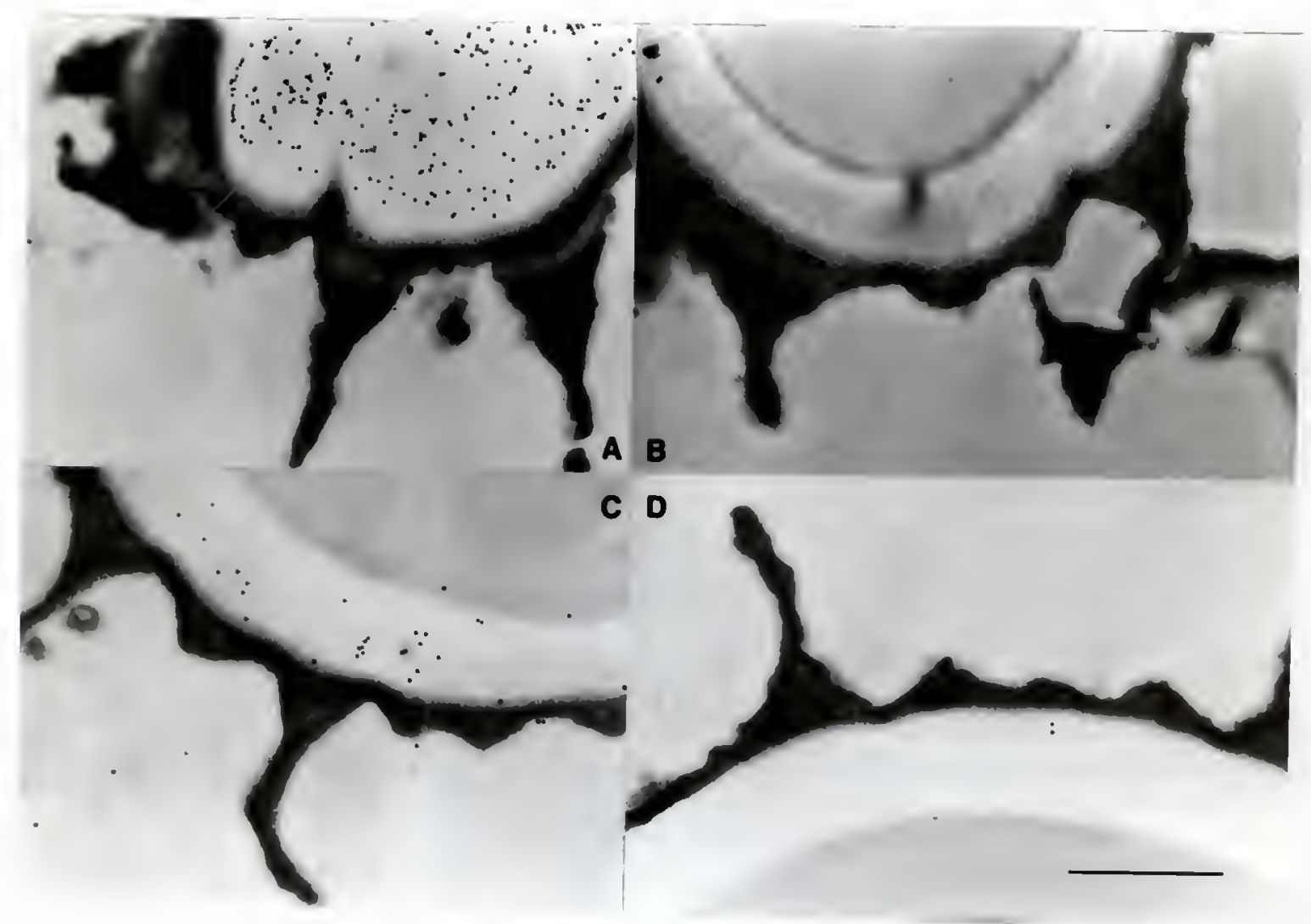

Figure 4.5. Determinant characterization for $8 \mathrm{~F} 11$.

A \& C) positive control, without pretreatment;

B) pretreated with periodate;

D) pretreated with pronase.

accomplished by competing off the anti-wall antibodies with clean wall preparation (such as that used for immunogen) prior to incubation of the section(s). This experiment was not preformed due to the limited quantity of this antibody preparation.

The antigenic determinant was both periodate and pronase sensitive (fig. 4.5), suggesting a glycoprotein antigen or conformational determinant, or release of the antigen from the sections. A conformational determinant, in this case, could occur 


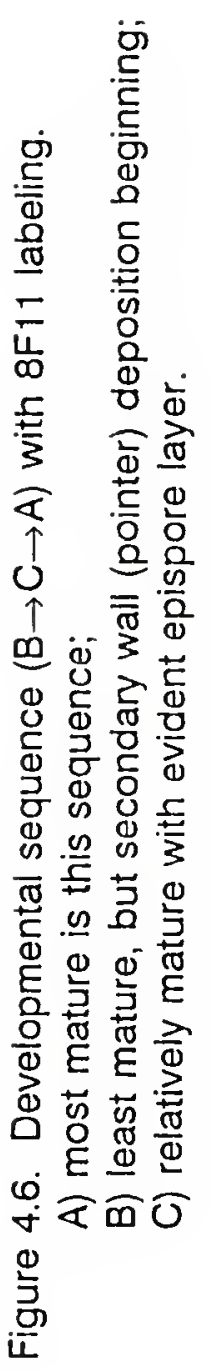




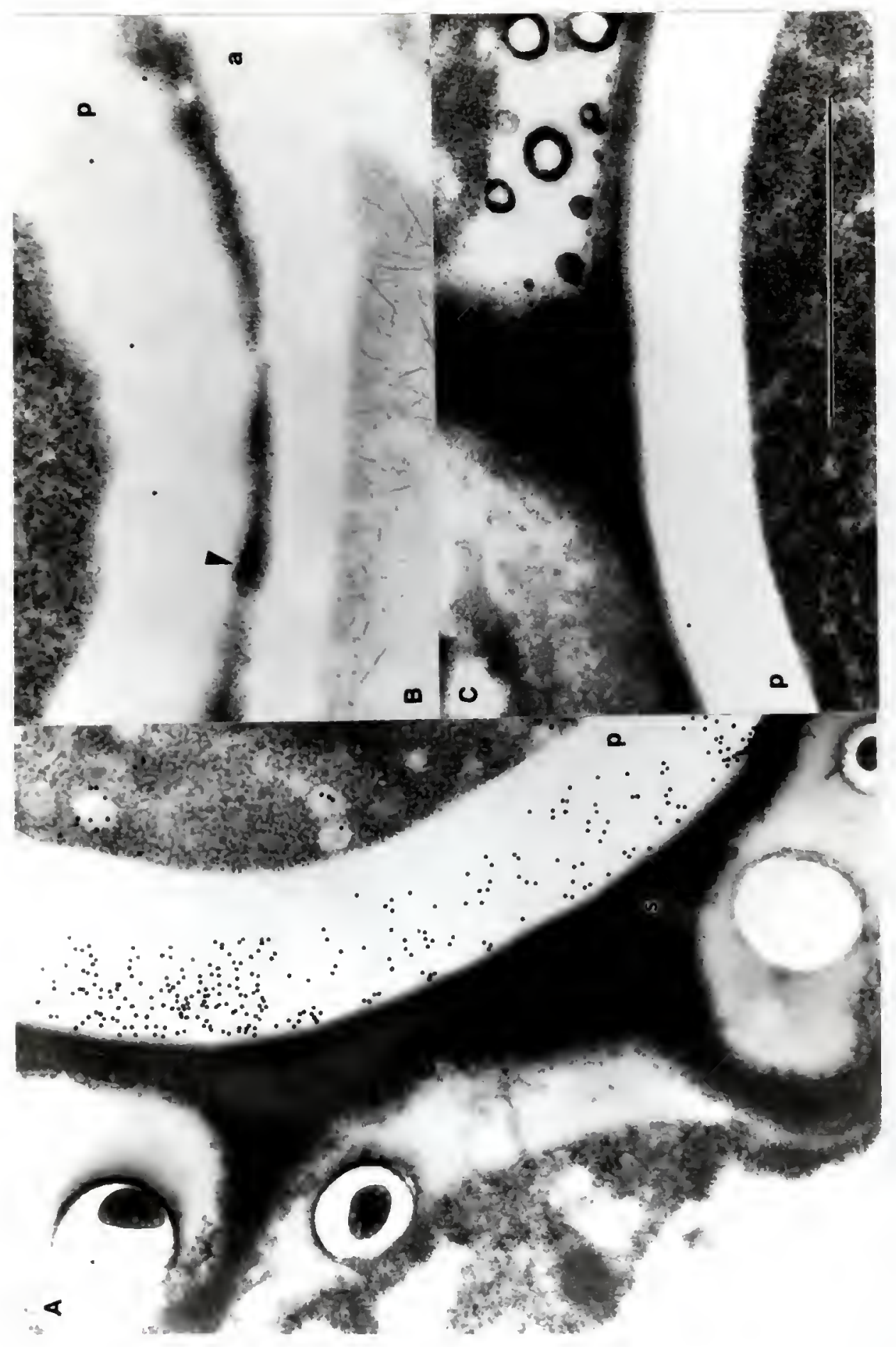




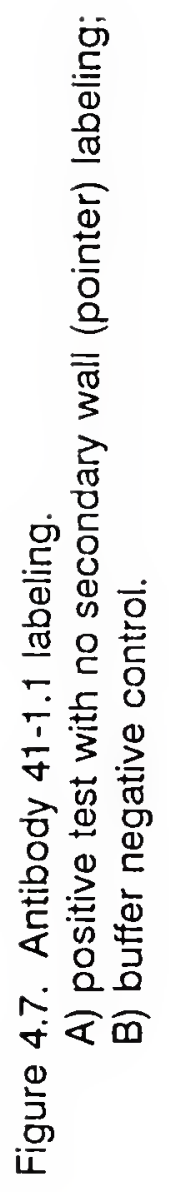




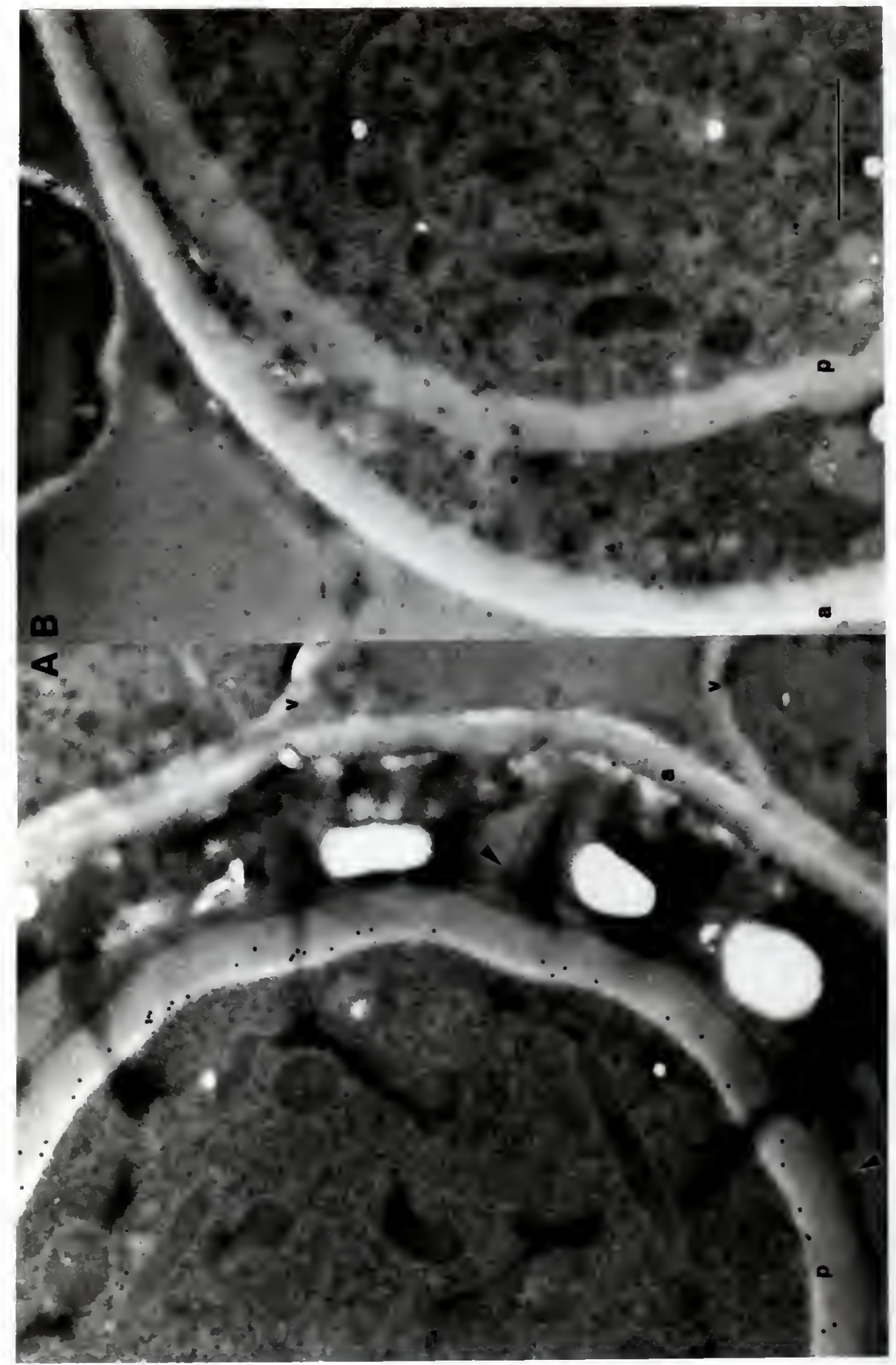


when a protein and carbohydrate were closely associated, but not covalently bound together. The antigenic determinant must be exposed in section, rather than buried in the wall as no pretreatment of the sections was required for labeling.

This antibody preparation labeled ascospores only in the late stages of the developmental sequence (fig. 4.6).

\section{Anitbody 41-1.1}

This monolonal antibody labeled an inner (sporoplasmic) layer of the primary ascospore wall (fig. 4.7). Labeling was evident in every developmental stage examined.

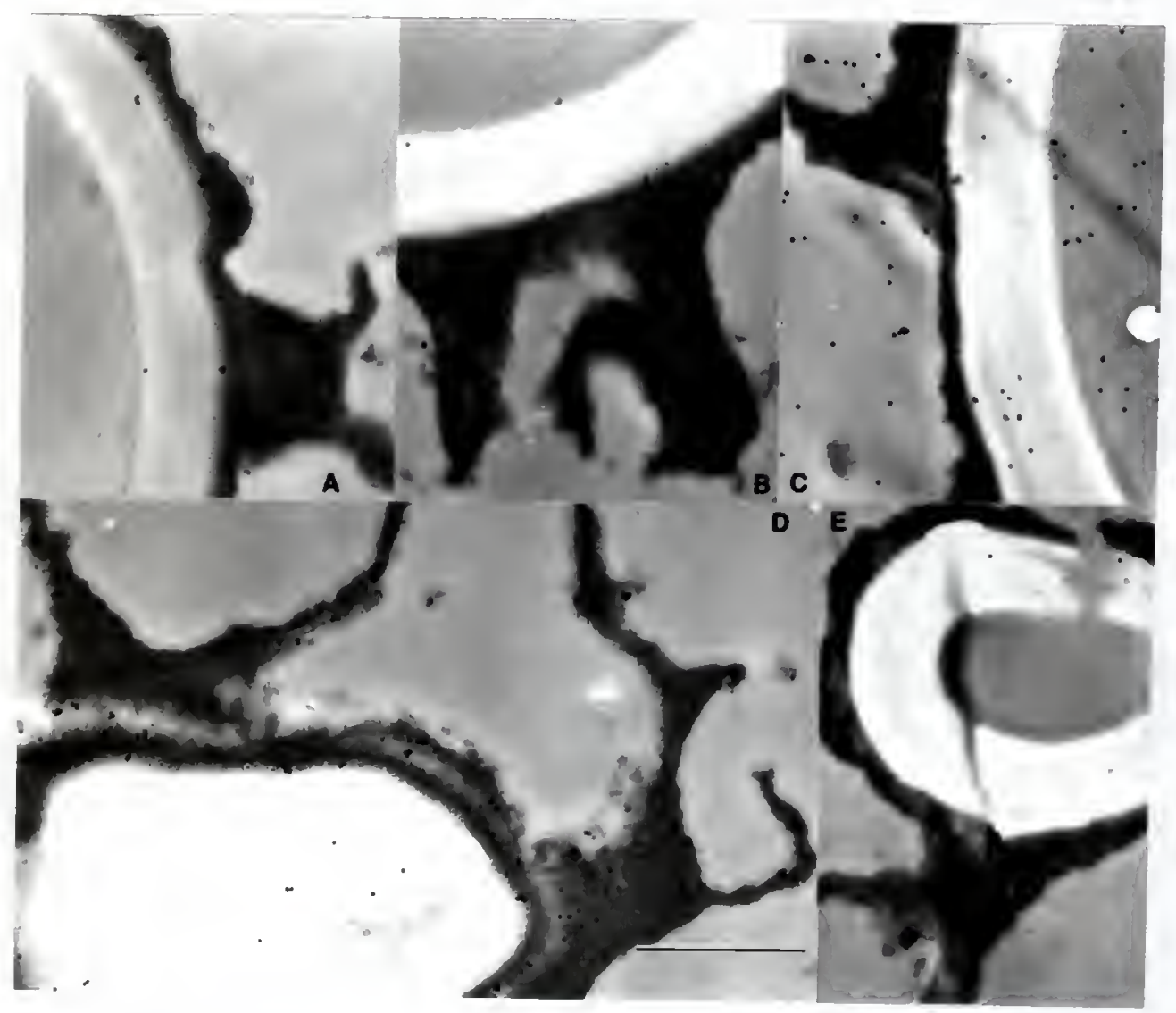

Figure 4.8. Pronase pretreatment with antibodies 12-2 and 41-1.1.
A) antibody $41-1.1$;
B) antibody 12-2;
C) buffer negative control with pronase pretreatment. 
The antigenic determinant is pronase sensitive (fig. 4.8A) and periodate (fig. 4.7A) insensitive. This suggests a protein, proteinecous hapten, or glycoprotein antigen. Notably, labeling of sections not treated with periodate was only seen on tangential sections through the primary wall. This suggests that the determinant was somehow buried in the section.

This antibody has been found to work well with tissue that has been fixed with $2 \%$ glutaraldehyde and post-fixed with osmium tetroxide.

\section{Antibody 12-2}

Monoclonal antibody $12-2$ specifically labeled the secondary wall and a sporoplasmic component (fig. 4.9). A complete developmental sequence was not present in sections thus far tested for labeling with this antibody.

The antigenic determinant was neither periodate nor pronase sensitive, and in fact both pretreatments improve labeling (fig 4.8B).

\section{Interspecies Cross-Reaction}

Antibodies 12-2 and 41-1.1 were tested for labeling on Pseudoplectania nigrella. These antibodies did cross-react with this species although they did not label the walls. Antibody 12-2 does not apparently label any part of the ascopore wall, but quite specifically labeled the sporoplasm as it does in Ascodesmis sphaerospora (fig. 4.10B). Antibody 41-1.1 specifically labeled a component within the perisporal sac, although this material does not seem to condense on the wall as there was no wall labeling (fig. 4.10A). P. nigrella is the only other species these antibodies have been tested on to date. 


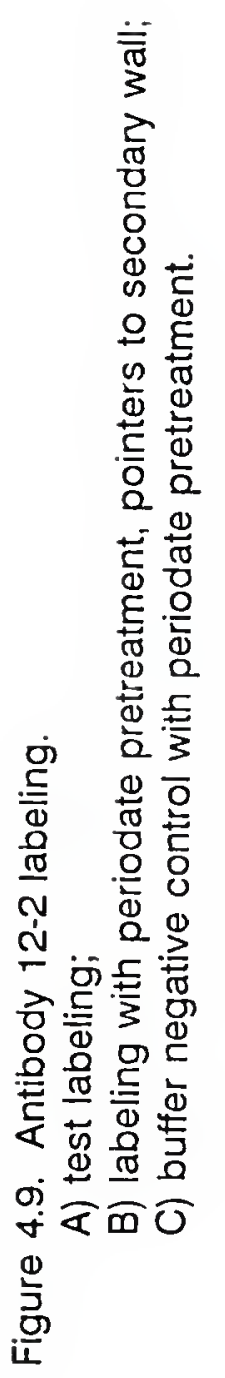




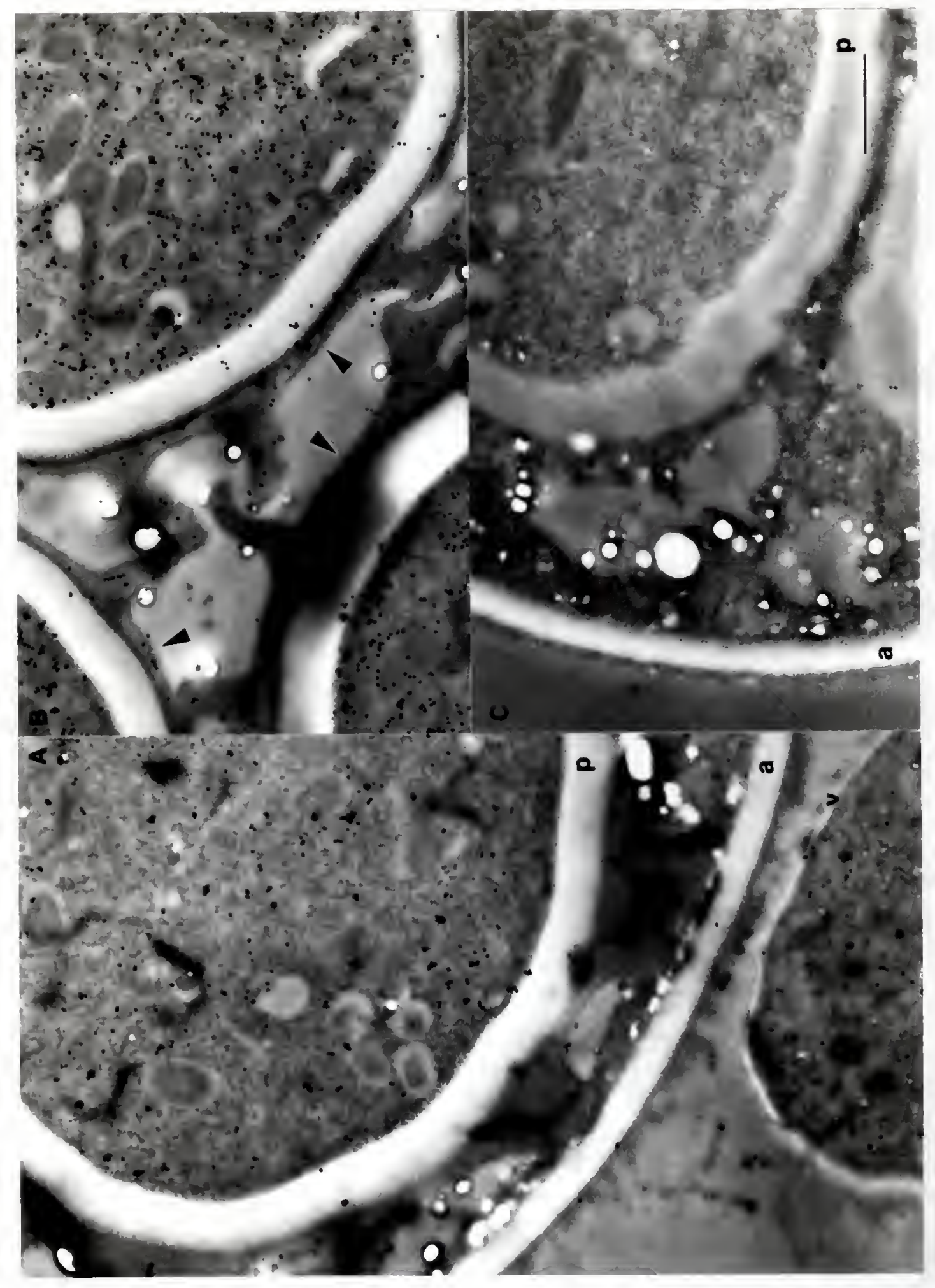




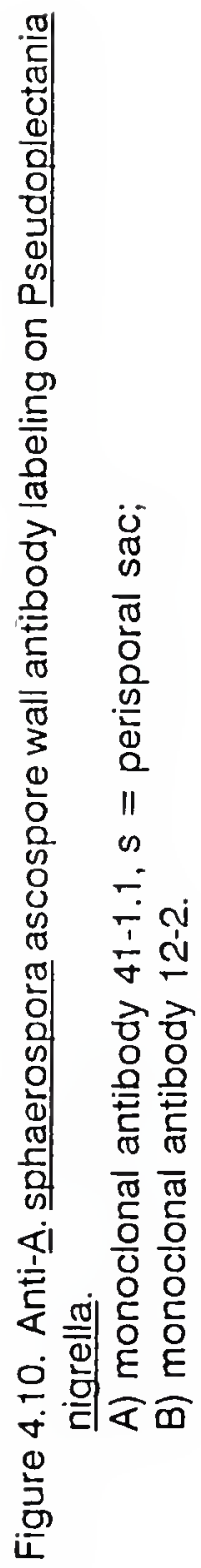




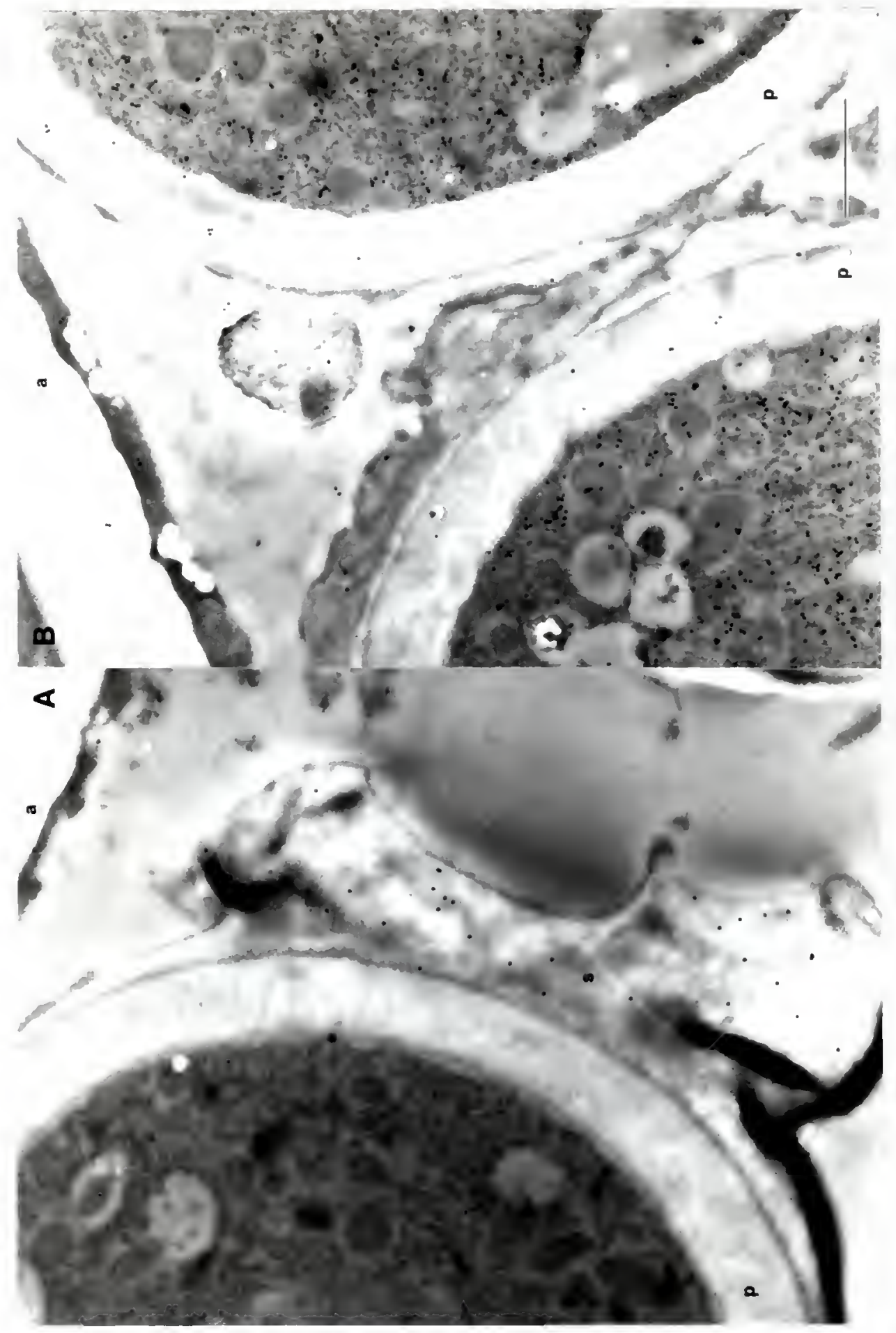




\section{Discussion}

\section{Serum Labeling}

Serum labeling is important because it demonstrates potential of the mouse Bcells and can demonstrate cross-reactivity with other wall systems. Labeling is evident on all areas of the ascospore wall. This indicates that either one immunodominant antigen occurs throughout the entire wall or that antibodies are being made to various antigens in every layer of the ascospore wall. The latter would appear to be the case, since antibody preparations 8F11, 12-2, and 41-1.1 all label different areas of the wall, and all

have different sensitivities to periodate and pronase.

Ascus and vegetative walls were labeled with immune serum. This would indicate cross-reactivity and common antigens (or at least determinants) in these wall systems if no vegetative wall contaminated the immunogen. It is quite possible that a very small amount of hyphal wall material from germinated spores was present in the immunogen. A conclusive statement of cross-reactivity cannot be made at this time for that reason.

\section{Antibody $8 \mathrm{~F} 11$}

Antibody 8F11 labeling definitively demonstrates a late maturation event in the ascospore primary wall layer. Interestingly, labeling did not built up through the developmental sequence, but appears quite suddenly. The vesicle labeling was concurrent with and as sudden as the wall labeling. Relative to the developmental process, the time that $8 \mathrm{~F} 11$ labeling appears coincides with the first appearance of fixation and infiltration artifacts in the sporoplasm. It seems quite possible that the appearance of this determinant at this time is either a result of a "sealing" process, or 
part of that process. While it is possible that the antigen is inaccessible during early development, such inaccessibility is in direct contrast with the sealing/protective function and seems unlikely.

There was no strong evidence suggesting how the $8 \mathrm{~F} 11$ determinant got into its position (outer $2 / 3$ to $3 / 4$ ) within the primary wall layer. The appearance of $8 \mathrm{~F} 11$ labeling at this late maturation stage could represent an addition to the wall or an in situ modification of the wall. If this is an addition to the wall, where are the synthesis enzymes and precursors situated? The labeling in the outer area of the primary wall layer with no apparent migration across the inner zone of the primary wall or across the secondary wall would suggest that the synthesis enzymes are in the wall. If the vesicle labeling was due to the same determinant, precursor packaging could be suggested, but the synthesis enzyme would also have to be present within the vesicle, since the labeling pattern was just as sudden for the vesicles as it was for the wall. If a wall constituent is enzymatically modified then enzymes would have to be in situ for both walls and vesicles. On the other hand, there could be a physical or physicochemical factor such as hydration/dehydration and/or incorporation of divalent cations responsible for modification. An in situ modification seems the more probable of these two suggested processes because of the suddenness of labeling and greater diversity of ways for a modification to occur.

\section{Antibody 41-1.1}

One of the most interesting aspects of labeling with antibody $41-1.1$ is that a pretreatment of sections with periodate is required for labeling in all but tangential sections. What the periodate did to the plastic or to the ascospore wall that resulted 
in improved labeling is the obvious question. At least on Epon resin, periodate does not appear to remove, or etch away the resin (Bendayan \& Zollinger, 1988). This tissue was not post-stained with osmium tetroxide, so this is not a question of unmasking determinants by removal of this fixative. Conversely, periodate is known to react with sensitive carbohydrates by opening up the pyranosyl units. Between these points, and the labeling of tangential sections through the primary wall, it seems most probable that the antigenic determinant was buried in wall carbohydrates. It would appear that the free path between wall molecules is a major influence on the outcome of this antibody's diffusion into the section. This is similar to Causton's (1984) description for epoxy resin crosslinking density.

\section{Antibody 8 F11 and 41-1.1}

It was obvious from the labeling patterns of these two antibodies, when taken together (figs. 4.4, 4.6A \& 4.7A), that there are distinct layers within the primary walls and that these layers have different constituents.

\section{Antibody 12-2}

It is very interesting that labeling was improved by both periodate and pronase pre-treatment of the sections. This may be the result of an alteration of the antigenci molecule before the mouse immunoglobulin responce ensued. The immune system's first response to a fungal invasion is a killer cell response and use of lytic enzymes (Reiss, 1986). It is possible that the mouse killer response slightly altered this molecule before the immune response proceeded to production of immunoglobulins and that periodate and pronase pretreatments of sections in some way mimicked that alteration. 
Work with this antibody did not get far into the morphological aspects. In one labeling test it appeared that the determinant might be sensitive to glutaraldehyde. Sections from block 15 ( $2 \%$ glutaraldehyde in the fixative) did not label as well as sections from block 4 ( $1 \%$ glutaraldehyde in the fixative), but conclusions can not be drawn as yet because the sections from block 15 were unsatisfactory. Until the morphology is improved it will not be possible to determine if this antibody is an appropriate probe for tracking precursors. It does label both epiplasm and sporoplasm components and thus shows potential for being such a probe.

Highly specific labeling of sporoplasmic components, but not wall components, was also demonstrated in Pseudoplectania nigrella. Further work with this antibody and analysis of cellular labeling patterns could provide both phylogenetic and biological information for large number of Pezizales. Generalization to the order is substantiated by the fact that Ascodesmis and Pseudoplectania are distantly related. They are members of different suborders within the Pezizales. Antibody 41-1.1 shows the same type of research potential, but perhaps slightly more limited as cytoplasmic components were not strongly labeled. 


\section{CHAPTER 5 \\ LECTIN CYTOCHEMISTRY}

\section{Introduction}

Lectins are carbohydrate-binding proteins (or glycoproteins) of non-immune origin which agglutinate cells and/or precipitate glycoconjugates (Goldstein et al., 1980). As of 1986 no purified lectin had been shown to exhibit enzymatic activity (Goldstein \& Poretz, 1986).

Lectins can be classified into carbohydrate binding groups (Goldstein \& Poretz, 1986; Benhamou, 1989b). These groups are: mannose/glucose binding, $\mathrm{N}$-acetylglucosamine binding, $\mathrm{N}$-acetyl-galactosamine/galactose binding, sialic acid binding, and L-fucose binding (Goldstein \& Poretz, 1986). Some workers have made a distinction between $\mathrm{N}$-acetyl-galactosamine and galactose binding groups (e.g., Benhamou, 1989b). With the exceptions of sialic acid and L-fucose, all of these carbohydrate groups are known to occur in fungi and were discussed in chapter 2.

The lectins within each of these categories differ markedly with respect to their anomeric specificity (Goldstein \& Poretz, 1986). Further, this specificity has been attributed to the sterochemical fit between complementary molecules (Sharon \& Lis, 1989). Carbohydrates are bound noncovalently by lectins (Sharon \& Lis, 1989). Each lectin differs with respect to its cross-reactivity with other sugars. Lectins further differ in number of glycosyl units their binding sites can accommodate. Some lectins appear 
to only bind one glycosyl unit while others, such as WGA, have an extended binding site capable of accommodating 2-5 residues (Goldstein \& Poretz, 1986).

For this study a lectin kit was purchased that had a representative lectin for each binding group. Additionally, GS-ll lectin was obtained as a gift from Dr. Katie Gropp. These lectins, their binding specificities, and previous uses in fungal research are reviewed below.

\section{Binding Specificities}

\section{WGA / GS $\|$}

WGA (wheat germ agglutinin; Triticum vulgare) and GS-II (Griffonia simplicifolia) lectins label $\mathrm{N}$-acetylglucosamine, although in totally different ways. Both of these lectins should detect chitin, but GS-II is not commonly used for this purpose. WGA has been used as a probe for chitin in several pulbications (e.g., Benhamou \& Ouellette, 1986; Benhamou, 1988; Simmons, 1989).

WGA is a dimeric carbohydrate-free protein (Goldstein \& Poretz, 1986). It apparently has a binding site which consists of 4 adjacent subsites (A-B-C-D; Allen et al., 1973). Allen and coworkers (1973) envisioned sites A, B, and C as accommodating $\mathrm{N}$-acetylglucosamine while the D site could accommodate other glycosides. The B site was further described as being able to handle a residue with a C-3 substitution, as in $\mathrm{N}$-acetylmuramic acid. This lectin has been shown to have an affinity for a number of various oligomers, but far and away its greatest affinity is for pentamers, tetramers, and trimers of N-acetylglucosamine (Goldstein \& Poretz, 1986). N-acetylglucosamine is the only simple sugar tested that binds to WGA (Allen et al., 1973). It has been suggested that the monomer binds to subsite $C$ (Allen et al., 1973). Neither glucosamine nor $B(1-4)$ 
polymers of glucosamine (chitosan) bind with WGA (Goldstein \& Poretz, 1986). WGA has been shown to have an affinity for sialic acids (Goldstein et al., 1975; Mandal \& Mandal, 1990) which appears to be due to the similarity in configuration of the sugars (Monsigny et al., 1980).

GS-II lectin is a tetramer of apparently identical subunits with one binding site each (Ebisu et al., 1986). It is a glycoprotein with aproximately $4 \%$ carbohydrate (Goldstein \& Poretz, 1986). This lectin binds best to N,N'-diacetylglucosamine and $N, N^{\prime}, N$ "-triacetylglucosamine, although it has also been shown to precipitate with rabbitliver glycogen and, to a lesser extent, with Saccharomyces cervisiae mannan (Ebisu et al., 1978). GS-II will bind both $\alpha$ and $B$ anomers (Ebisu et al., 1978). GS-Il lectin differs from WGA in that it does not bind to internal $B(1-4)$ linked $N$-acetylglucosamine and dces not appear to possess an extened binding site for contiguous $B(1-4)$ linked residues, Goldstein and Poretz (1986) described this lectin as being of particular interest because it is the only lectin that interacts with terminal nonreducing $\alpha-$ or $\mathrm{B}-\mathrm{N}$ acetylglucosamine.

Benhamou and Ouellette (1986) localized $\mathrm{N}$-acetylglucosamine in the walls of Ascocalyx abietina with WGA lectin. Cell wall labeling with this lectin was also found in both Ophiostoma ulmi and Verticillium albo-atrum (Benhamou,1988). Bonfante-Fasolo and coworkers (1990) used WGA lectin to localize chitin in vegetative cell walls and both WGA and chitinase-gold for localization in the spore walls of Glomus versiforme (Bonfante-Fasolo et al., 1986). Chitin in the bud scars of several yeasts was shown using WGA (Simmons, 1989). 


\section{LFA}

LFA lectin is derived from the slug Limax flavus. It is apparently a proteinaceous dimer (Goldstein \& Poretz, 1986). It is specific for sialic acids (Miller et al., 1982). Sialic acid binding lectins are ubiquitous among invertebrates (Mandal \& Mandal, 1990). The sialic acids are a family of about 30 derivatives of $\mathrm{N}$-acetyl or $\mathrm{N}$-glycolyl neuraminic acids (Mandal \& Mandal, 1990).

Using LFA lectin Benhamou and Ouellette (1986) found labeling of lipid bodies and a fibrillar network surrounding the fungal cells. In $\underline{V}$. albo-atrum this lectin was also found to label lipid bodies, but in $\underline{\mathrm{O}}$. ulmi there was intense labeling of the cytoplasm and weak labeling on organelles, plasma membrane, walls and septa (Benhamou, 1988).

\section{Con A}

Concanavalin A (Con A) is a carbohydrate-free metalloprotein with 4 subunits. Each subunit contains one $\mathrm{Ca}^{2+}$ and one $\mathrm{Mn}^{2+}$ ion (Goldstein \& Poretz, 1986).

Con A was first reported to precipitate with glycogen and yeast mannan by Sumner \& Howell (1936). Goldstein and coworkers (1965) found that a polysaccharide must have a minimum of approximately $10 \%-15 \%$ non-(1-6) linkages for Con A interact with it and form a precipitate. Even at high concentrations of Con A, linear polysaccharides were not found to precipitate (Goldstein et al., 1965). Yeast mannan had almost 5 times the turbidity of glycogen and Goldstein and coworkers (1965) suggested that this may be due to the extensive branching of the molecule $(34 \%)$. Manners and Wright (1962) reported an approximately linear relationship between the extent of branching of a glycogen-like polysaccharide and the resultant turbidity. In general, Con A can be described as binding to internal mannose (especially at 
branching points) and external glucose residues (Debray et al., 1981; Goldstein \& Poretz, 1986).

It is also noteworthy that the binding of Con A to sugar monomers, dimers or polysaccharides is dependent on the concentration of Con A in solution (Goldstein et al., 1965; Smith et al., 1968).

Con A was found to bind zoospores of Phytophthora cinnamomi and it was concluded via the localation of its binding that these zoospores have a glycocalyx is (Hardham, 1989), and further that binding of this lectin can induce encystment of the zoospores (Hardham \& Suzaki, 1986). This lectin has been shown to bind to the cell walls, electron-dense inclusions, and septal associated Woronin bodies of $\underline{\underline{O}}$. $\underline{\text { ulmi, }}$, and cytoplasm of $\underline{\mathrm{V}}$. albo-atrum (Benhamou, 1988).

\section{PNA}

Peanut lectin (PNA) is a tetrameric, carbohydrate-free protein. This lectin possesses an extended binding site which is specific for D-galactopyranosyl endgroups. In hemagglutination inhibition experiments this lectin was most effectively inhibited by Galß(1-3)NAcGal (Pereira et al., 1976; Goldstein \& Poretz, 1986). This disaccharide was found to be the most complementary to the binding site (Goldstein \& Poretz, 1986). PNA was also inhibited by GalB(1-6)Glc, GalB(1-4)Glc, galactosamine, and methyl $\alpha$-galactoside (Pereira et al., 1976).

To localize $\alpha$-D-galactose in $\underline{0}$. ulmi and $\underline{\mathrm{V}}$. albo-atrum Benhamou (1988) used the castor bean (Ricinus communis) lectin, RCA-I. RCA-I is capable of binding monomers and homodimers of D-galactose and lactose (Goldstein \& Poretz, 1986). Cell 
walls of $\underline{V}$ albo-atrum were specifically labeled while the walls of $\underline{\underline{O}}$. ulmi were unlabeled (Benhamou, 1988).

$\underline{D B A}$

This lectin is derived from Dolichos biflorus (horse gram). It is agglutinates blood group A specifically (Goldstein \& Poretz, 1986). It is a tetrameric glycoprotein (Carter \& Etzler, 1975) which has 2 binding sites per molecule (Etzler et al., 1981), and is dependent on divalent metal ions for carbohydrate-binding activity (Kocourek et al., 1977; Borrebaeck et al., 1981). In hemagglutination inhibition experiments NAcGal $\alpha$ (13)NAcGal $\alpha$ (1-3)Galß(1-4)Galß(1-4)Glc and NAcGalo $\alpha$ (1-3)NAcGal were found to be the most effective inhibitors (Baker et al., 1983). This lectin also binds the $\alpha$ anomers of $N$ acetylgalactosamine and galactose (Goldstein \& Poretz, 1986).

Benhamou and Ouellette (1986) used lectin from Helix pomatia (Roman snail), HPA, to localize $\alpha-\mathrm{N}_{-}$-acetylgalactosamine on Ascocalyx abietina. HPA has been described as binding to NAcGal $\alpha$ (1-3)NAcGal with greater affinity than $\alpha$-NAcGal, but also as a valuable probe for detection of terminal, nonreducing $\alpha$-NAcGal (Goldstein \& Poretz, 1986). The walls of this fungus were labeled, especially the external layer of old cells. Benhamou (1988) using that same lectin found walls of $\underline{\mathrm{V}}$. albo-atrum to be labeled but that $\underline{\mathrm{O}}$. ulmi walls were not labeled. $\underline{\mathrm{P}}$ cinnamomi cysts labeled with HPA, but zoospores were unlabeled (Hardham, 1989).

\section{UEA-I}

Ulex europaeus lectin, UEA-I, agglutinates O type blood (Goldstein \& Poretz, 1986). It appears to be a carbohydrate-free metalloprotein dimer (Horejsi \& Kocoure, 
1974). UEA-I binds $\alpha$-L-fucose monomer and terminal non-reducing $\alpha$-L-fucose (1-3) or (1-6) linked to N-acetylglucosamine (Goldstein \& Poretz, 1986; Benhamou \& Ouellette, 1986). Apparently this lectin can discriminate between trisaccharides that differ slightly in the nature of the penultimate residue due to an extended binding site (Goldstein \& Poretz, 1986).

In Ascocalyx abietina, Benhamou and Ouellette (1986) found lipid bodies to be strongly labeled while all other organelles and cytoplasm labeled very slightly with UEA-I lectin.

\section{Materials and Methods}

\section{Fungal Cultures and Other Fungi}

Details of fungal sources, culture and collection were given in Appendix A and chapter 4.

\section{Tissue Preparation for EM}

Tissue preparation and sectioning were explained in chapter 4 and appendices E \& F. Both lightly broken spores (block SP) and apothecial tissue (blocks 5 \& 15) were used. Additionally, Pseudoplectania nigrella fixed with $2 \%$ glutaraldehyde and $2 \%$ formaldehyde and embedded in LR White was tested for labeling with some of the lectins.

Blood of types $\mathrm{O}$ and $\mathrm{A}$ were fixed in $2 \%$ glutaraldehyde and $2 \%$ formaldehyde, for 30 minutes on ice, dehydrated through ethanol series to $95 \%$, and embedded in LR White resin. 


\section{Reagents and Cytochemical Labeling}

A lectin gold staining kit was obtained from EY Labortories (catalog \#LGS-01) which contained all the necessary components including lectins listed above, glycoprotein-gold, buffers and sugar inhibitors. GS-II lectin (EY Lab., catalog \#GP-2402) was also obtained. PBS $(0.15 \mathrm{M})$ with calcium chloride $(0.9 \mathrm{mM})$ buffer and $\mathrm{N}$ acetyglucosamine (EY Lab., \#LGS-01) sugar inhibitor were used with the GS-II lectin. An instruction manual with protocols and recommended dilutions was included in the kit. Those instructions were followed, although the dilutions of both lectin and glycoprotein-gold (where used) had to be adjusted for optimal labeling. The protocols provided by EY are similar to those given by Roth (1989).

In one of the GS-II experiments a pre-treatment with periodate was done to demonstrate sensitive sugars. The methodology is identical to that used with antibodies as described in appendix $\mathrm{G}$.

Table 5.1: List of lectins and labeling protocol information.

\begin{tabular}{llll}
\hline Lectin & $\frac{\text { Method }}{\text { indirect }}$ & $\frac{\text { Buffer }}{\text { PBS }}$ & $\frac{\text { Glycopro.-Gold }}{\text { ovomucoid-gold }}$ \\
GS-II & direct & PBS-CaCl$\cdot 2 \mathrm{H}_{2} \mathrm{O}$ & - \\
LFA & indirect & tris-saline & fetuin-gold \\
Con A & indirect & tris-saline & horse radish peroxidase-gold \\
PNA & direct & PBS & - \\
DBA & direct & PBS & - \\
UEA & direct & PBS & \\
\hline
\end{tabular}




\section{$\underline{\text { Results }}$}

\section{PNA, DBA and UEA-I}

PNA, DBA, and UEA-I did not label the fungi and bacteria tested. UEA-I and DBA did not label sections of the appropriate agglutinating blood type.

\section{WGA / GS-11}

Both WGA and GS-II lectins labeled the ascus wall but not the ascospore walls of Ascodesmis sphaerospora (figs. 5.1 \& 5.2). This same labeling pattern was apparent on Pseudoplectania nigrella for both lectins (figs $5.3 \& 5.4$ ). Both lectins labeled vegetative cell walls to some extent. Interestingly, GS-II did not label $\underline{\underline{P} \text { nigrella }}$

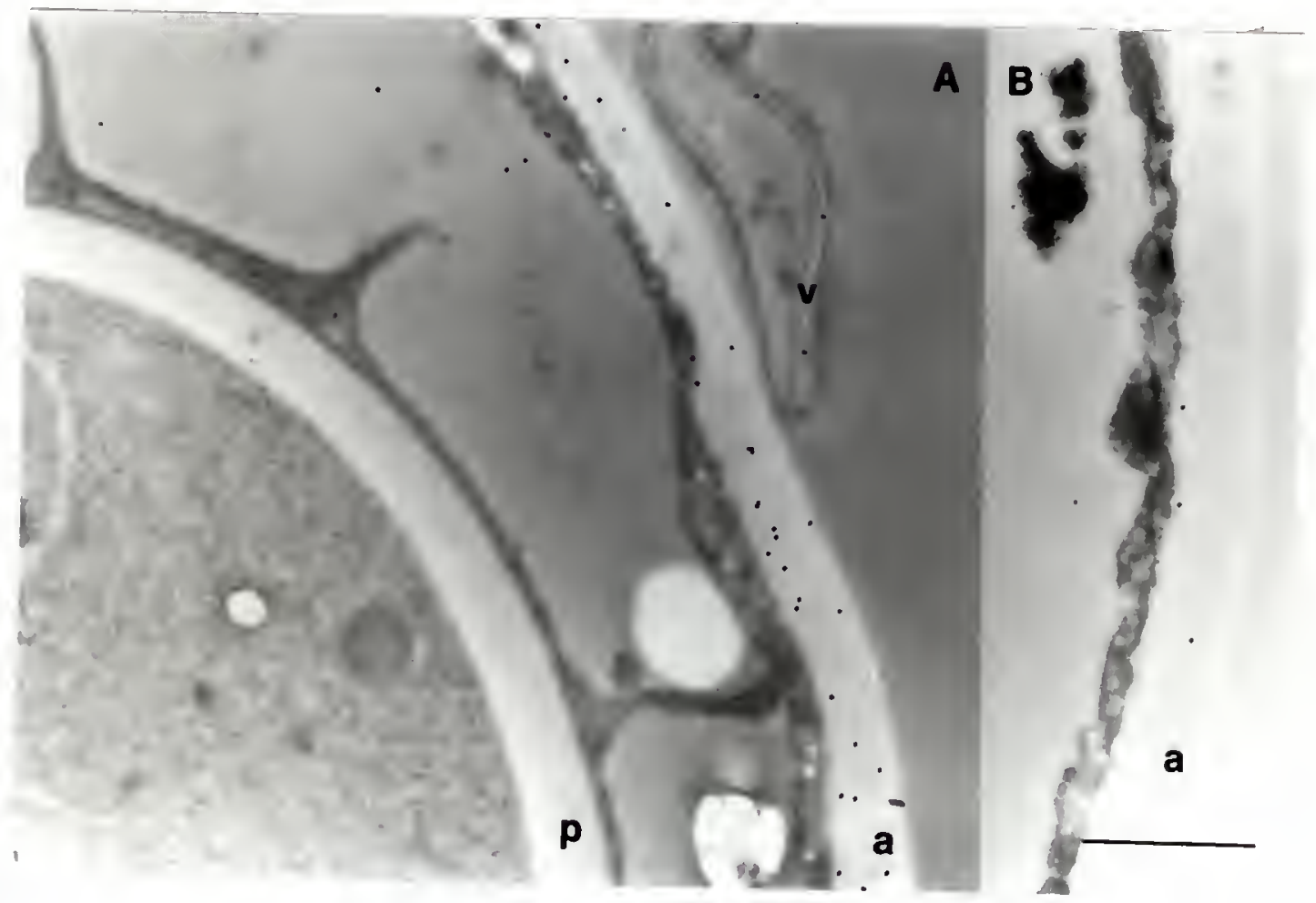

Figure 5.1. WGA labeling on $\underline{A}$. sphaerospora.
A) WGA test;
B) buffer negative control. 


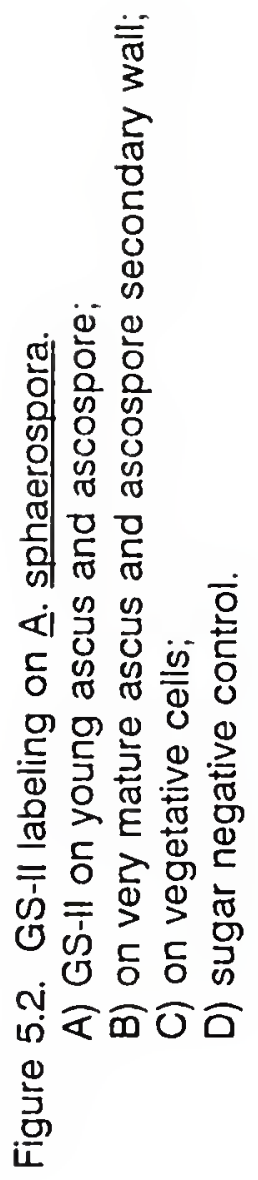




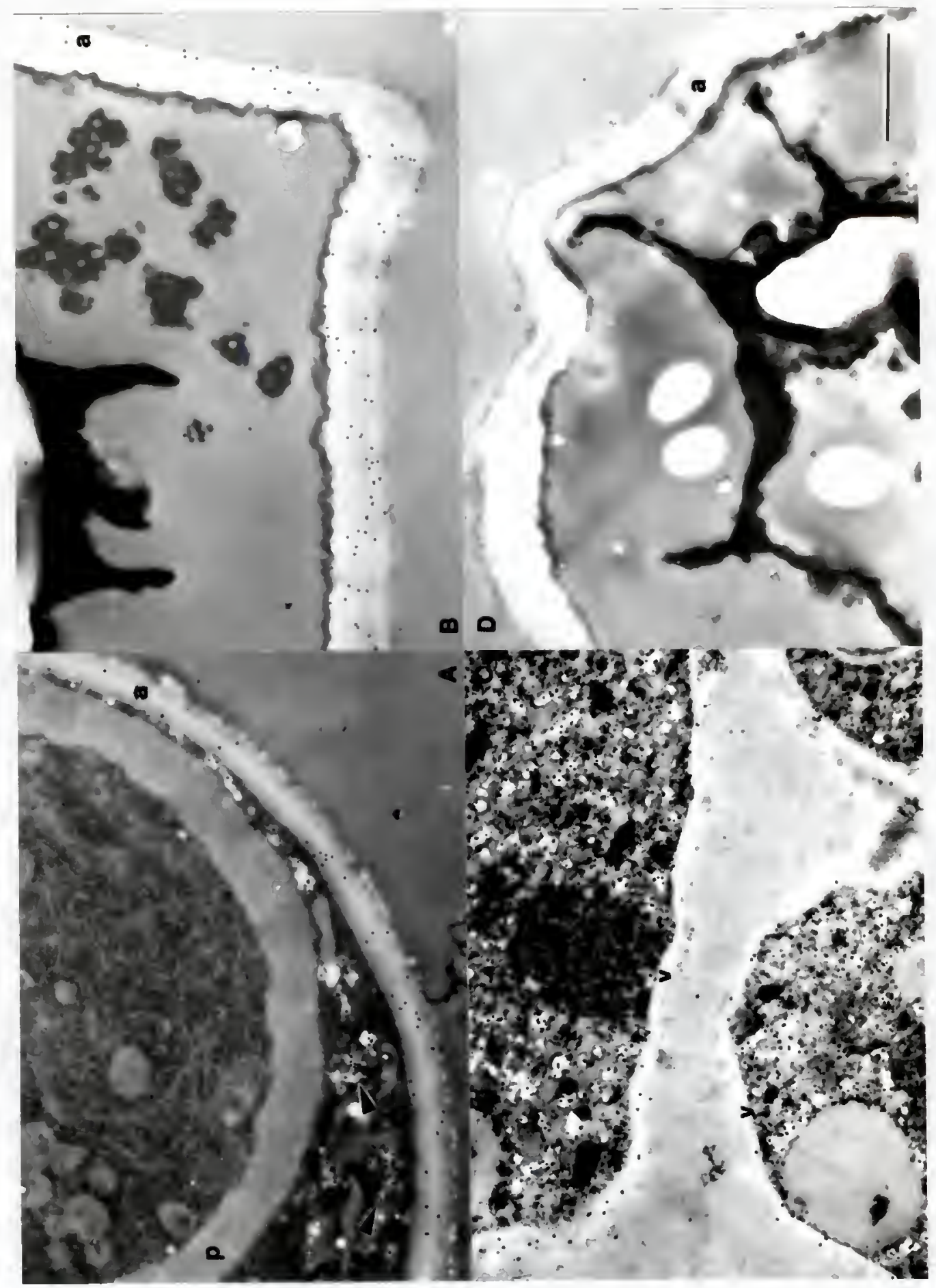




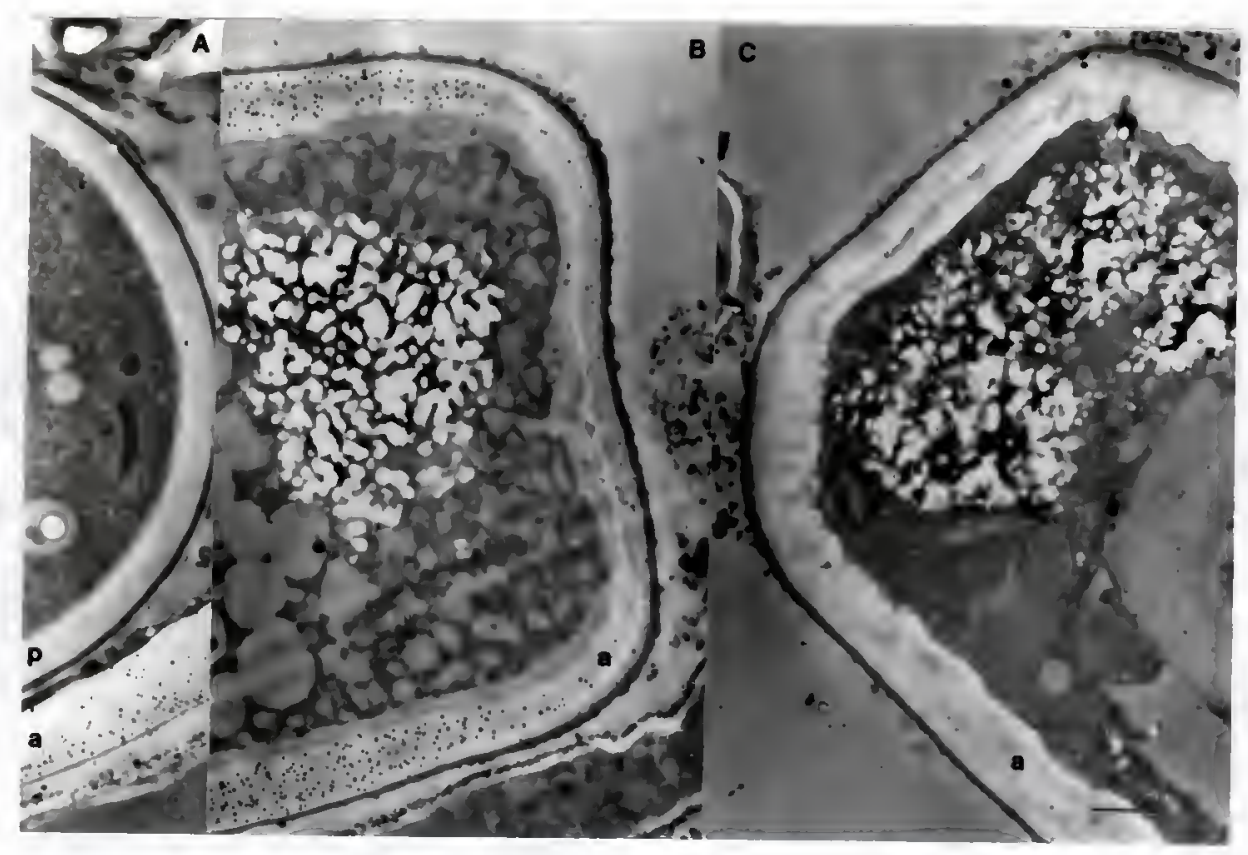

Figure 5.3. WGA labeling on $\underline{P}$. nigrella.
A) lower region of ascus with ascospore;
B) ascus apex;
C) buffer negative control.

paraphysis walls but did label vegetative cells in the excipular layers below the hypothecium (fig. 5.4A \& C). Paraphyses were not labeled with WGA either.

In both species the WGA labeling was increased with what should have been the sugar negative control (fig. 5-5). EY Labs provided $\mathrm{N}$-acetylglucosamine for this purpose. No other negative control was immediately available and therefore none was tried.

In addition to specific labeling of the ascus walls, GS-II lectin also specifically labeled electron transparent areas within both the ascus and vegetative cells (fig. 5.2). 


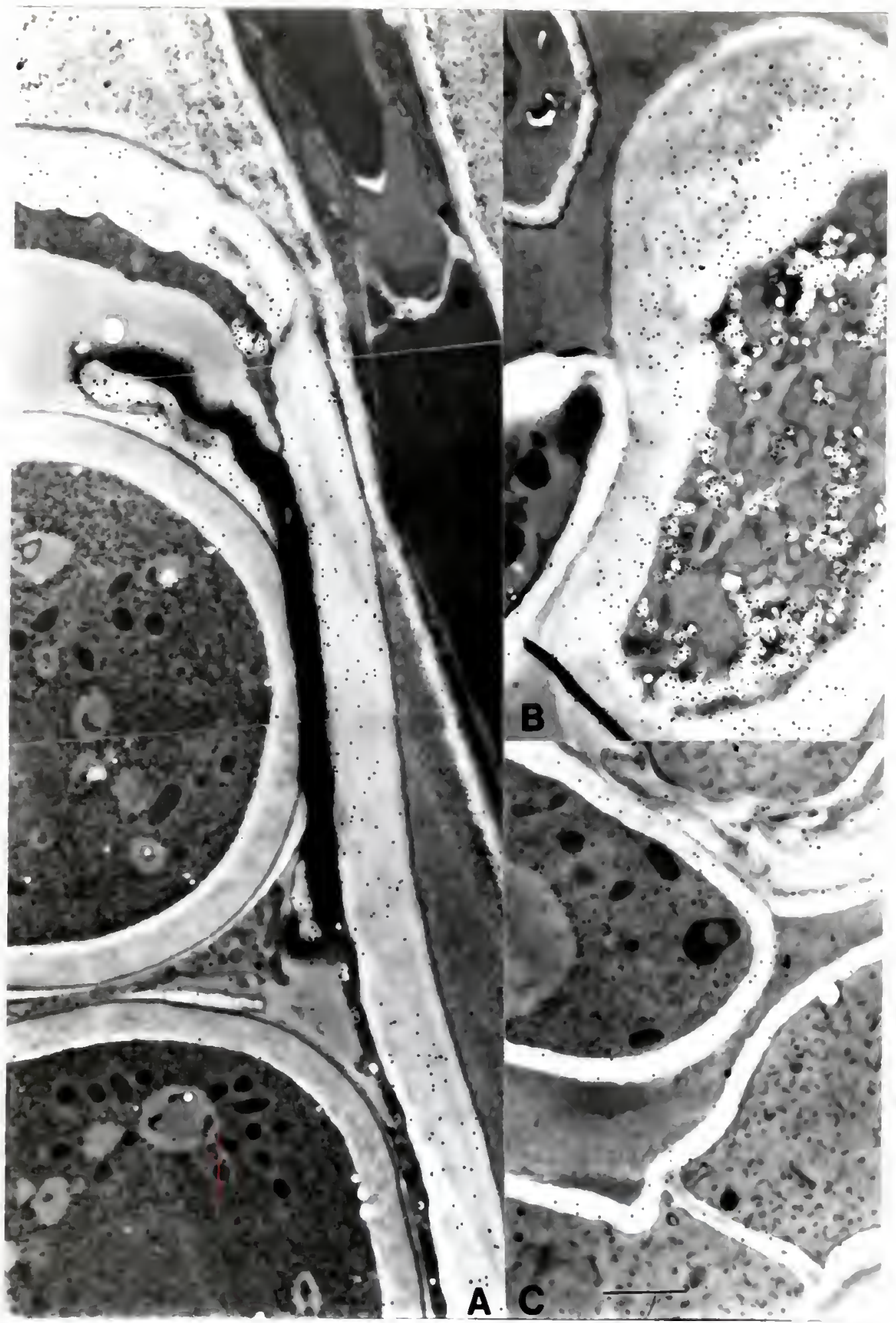

Figure 5.4. GS-Il labeling on $\underline{P}$. nigrella.

A) ascus, ascospore and paraphysis labeling;

$B$ ) cells of the excipular layer;

C) sugar negative control. 


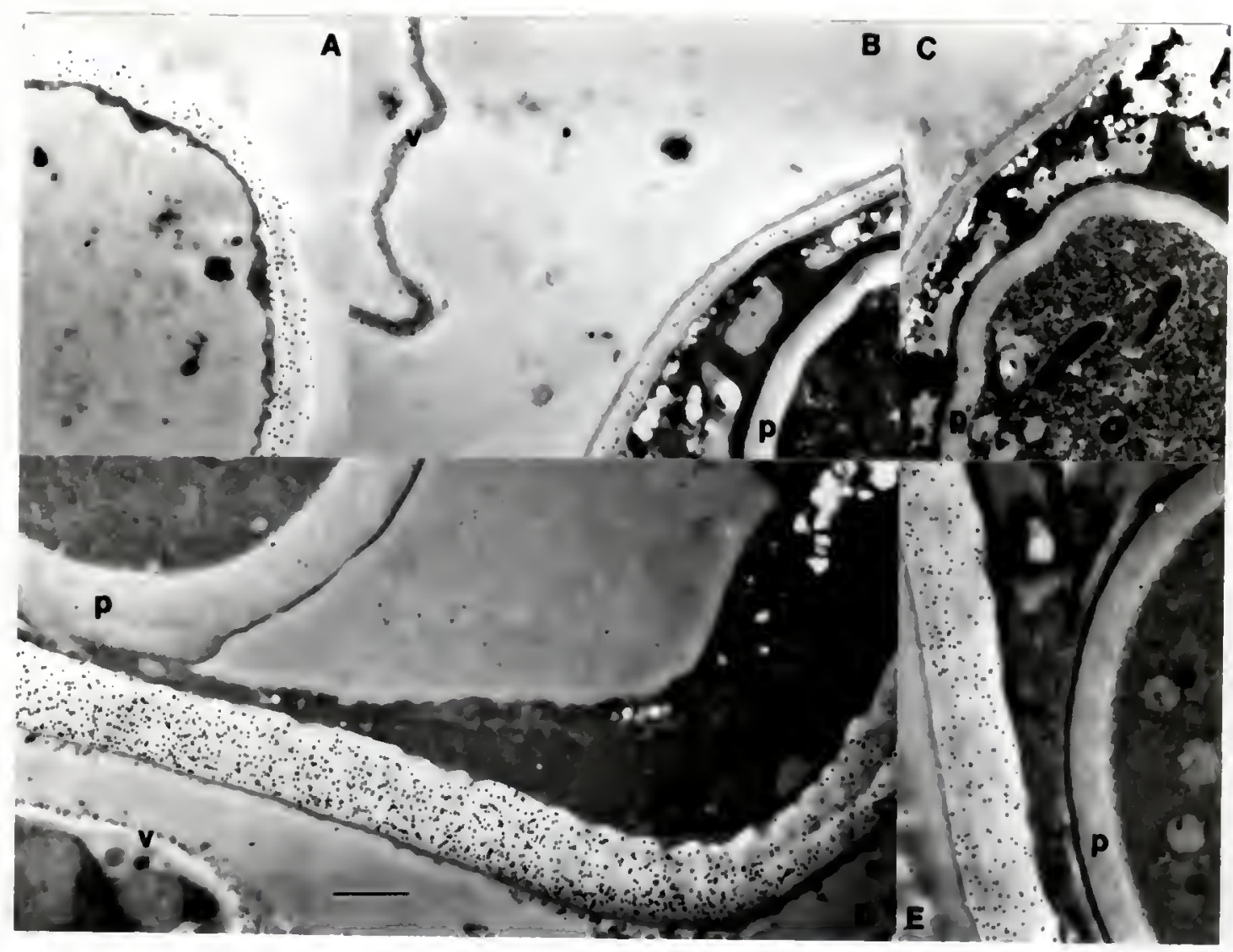

Figure 5.5. WGA labeling with sugar control.

A) sugar control on $\underline{A}$. sphaerospora;

B) sugar control on $\underline{A}$. sphaerospora;

C) WGA without sugar on $\underline{A}$. sphaerospora;

D) sugar control on $\underline{P}$. nigrella;

E) WGA without sugar on $\underline{P}$. nigrella.

$\underline{\text { LFA }}$

Labeling of LFA was evident over the cytoplasm of ascospores of $\underline{A}$. sphaerospora (figs. 5.6). This labeling did not appear to be specific. Specific labeling occurred in restricted areas around spent asci and on the outside of older cells (figs. 5.7). 


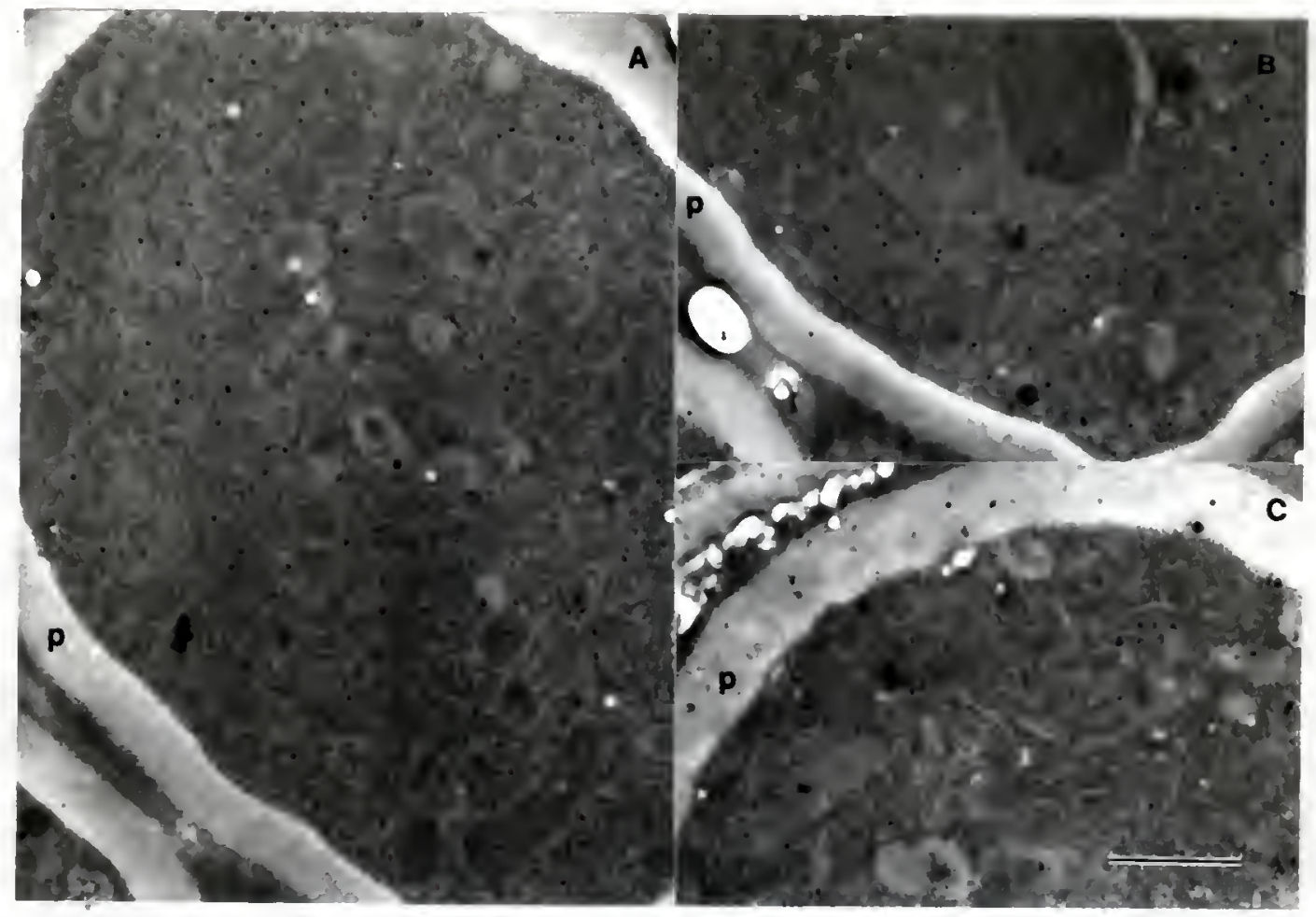

Figure 5.6. LFA labeling on $\underline{A}$. sphaerospora.
A) on an ascospore (1/80 lectin dilution);
B) on an ascospore (1/40 lectin dilution);
C) sugar negative control (1/80 lectin dilution) on an ascospore.

\section{Con A}

Con A labeling on $\underline{A}$. sphaerospora was different than for the previous lectins. In this case the lectin labeled the ascospore walls strongly (fig. $5.8 \mathrm{~A}-\mathrm{C}$ ) and an inner layer of vegetative cell walls or the plasma membrane of these cells (fig. 5.8D \& 5.10B) and a similar area on the ascus walls (fig. 5.11A), but nothing more on these later wall systems (figs. 5.8A \& D, and 5.11A \& B). Electron transparent areas within vegetative cells and asci were labeled when higher concentrations of the lectin were used (fig. 5.8D). 


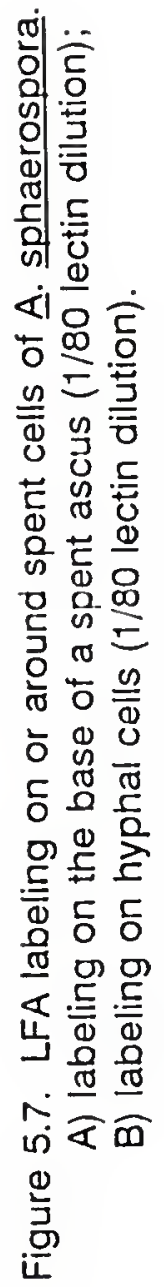




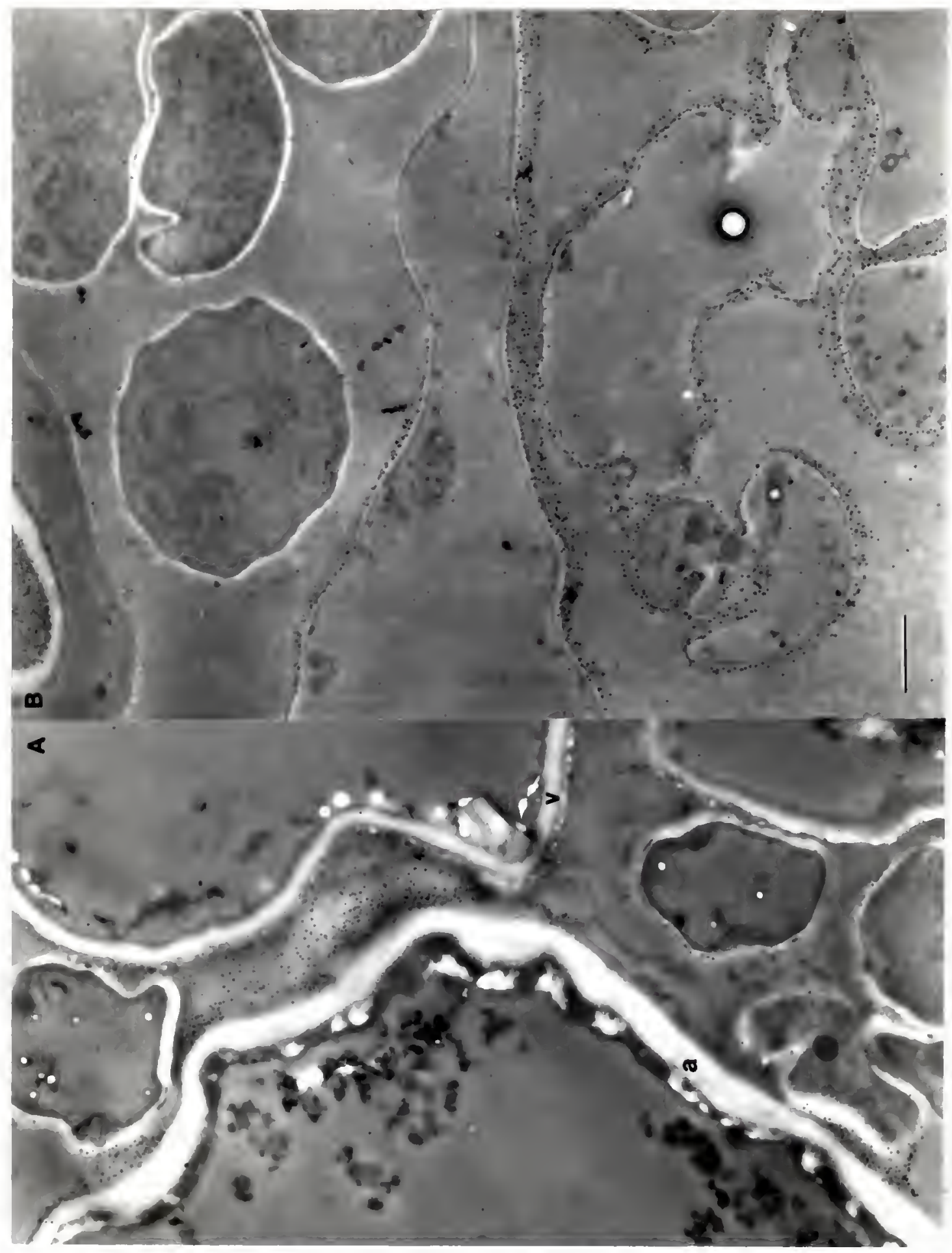


In contrast, Con A labeling on the ascospore walls of Pseudoplectania nigrella occured only in the secondary wall region (fig. 5.9A). Additionally, the outer layer of the ascus wall, or glycocalyx-like region, was specifically labeled (fig. 5.9A).

Ascospore secondary walls of Ascodesmis sphaerospora seem to label more and more strongly as the spore matures (fig. $5.8 \mathrm{C} \& 5.11 \mathrm{~A}$ vs $5.8 \mathrm{~A} \& \mathrm{~B}$ ). Interestingly, the ascospore secondary wall is strongly labeled on older spores which are still within the ascus, but not on those which have been expelled (such as on in the sections of lightly broken spores, see fig. 5.10).

The background seemed to be a slight problem using the dilutions of lectin and glycoconjugate recommended by the manufacture. In fact much better results, in terms of specific labeling without apparent background, were obtained using twice the recommended dilution (figs. $5.8 \mathrm{D}$ at $1 / 40 \& 5.11 \mathrm{~B}$ at $1 / 80$ ). At these higher dilutions the electron-transparent areas were not well labeled (fig. 5.11B). This change in labeling pattern might be expected because a similar concentration dependent pattern was found in precipitation studies (Manners \& Wright, 1962; Goldstein,1965).

In a digestion experiment with $\alpha$-mannosidase (Sigma \#M-1266) Con A was shown to be labeling $\alpha$-mannan in the ascospore walls of Ascodesmis sphaerospora. Figure 5.10A demonstrates the Con A positive control that received no pretreatment other than buffer washes. In comparing figure 5.10A with 5.10B, which demonstrates pretreatment with $\alpha$-mannosidase, there appears to be a slight decrease in labeling of the primary wall, and both figures appear to have background labeling on the plastic. To test for Con A recognition of any $\alpha$-mannosidase that may have not washed off in the rinses between these two treatments a pronase digestion to remove the $\alpha$ mannosidase was also preformed. Figure $5.10 \mathrm{C}$ demonstrates the pronase control (with 


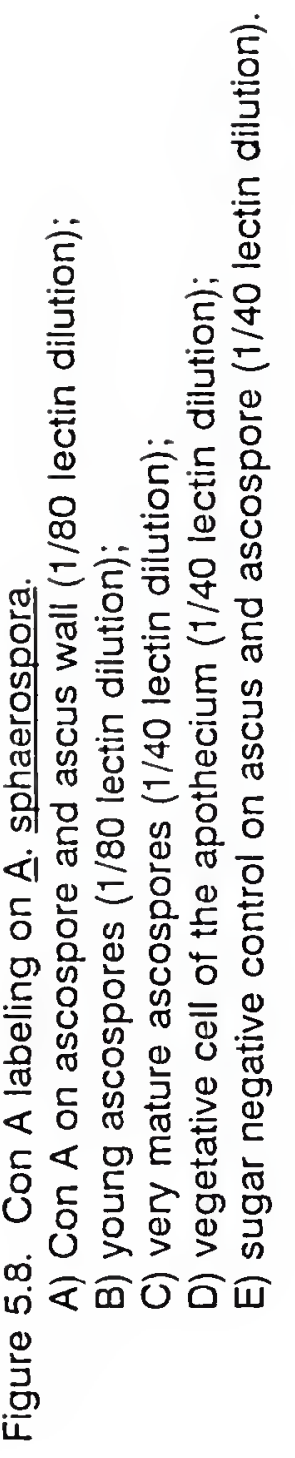




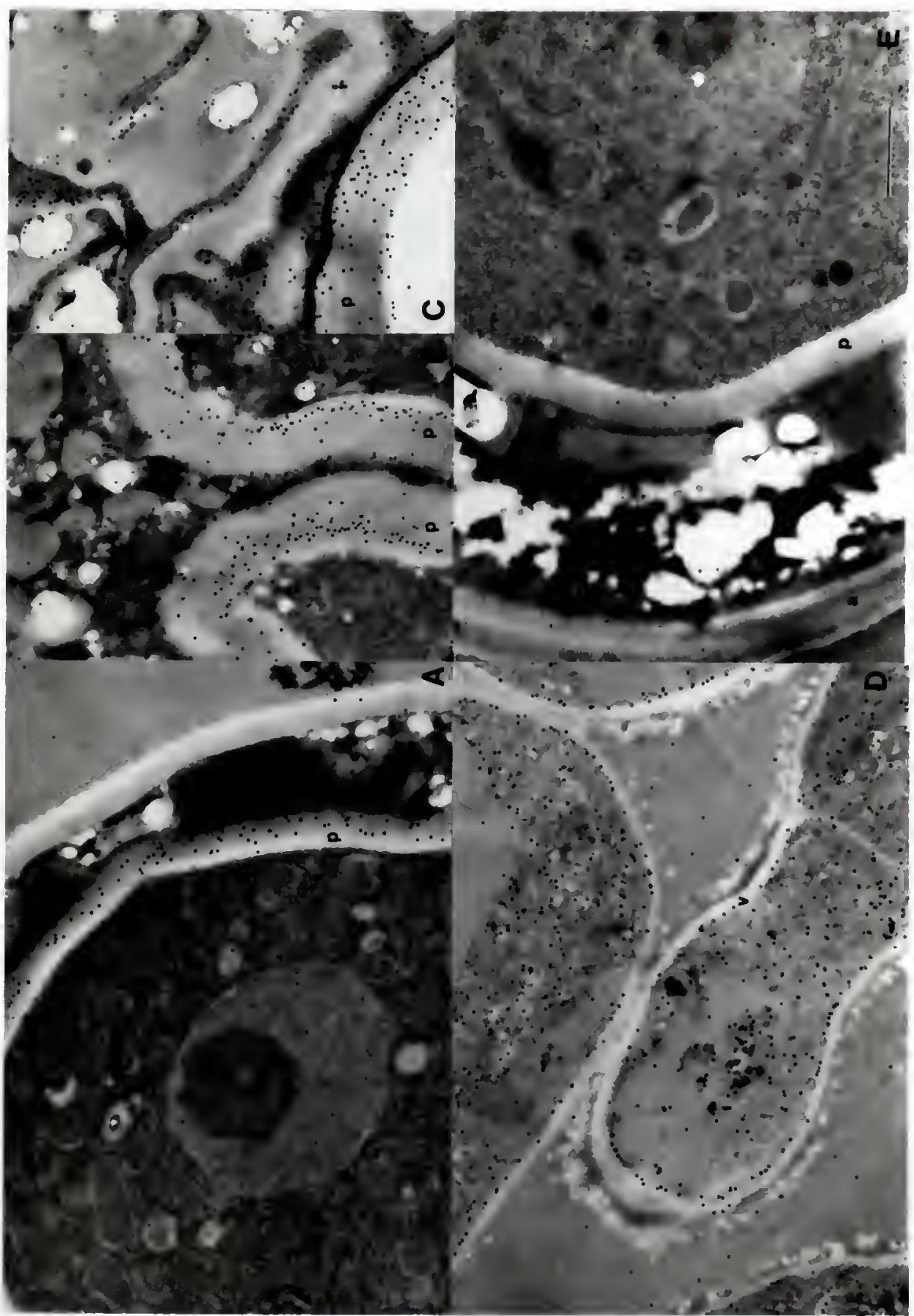




$$
\begin{aligned}
& \text { 产 } \\
& \text { 言壱 } \\
& \text { 윽 웅 } \\
& \text { 흐름 } \\
& \text { 등 } \\
& \text { 융 } \\
& \text { 百三岕正 }
\end{aligned}
$$

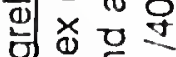

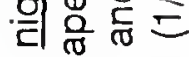

$$
\begin{aligned}
& \text { a) 约 } \\
& \text { 덩 앵 } \\
& \text { व }
\end{aligned}
$$

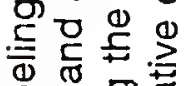

$$
\begin{aligned}
& \text { 유 } \\
& \approx \text { Ф } \\
& \text { 《 } \\
& \text { ㄷํㅇ ڤั ธั } \\
& \text { O } \\
& \text { ウi } \\
& \text { 高 }
\end{aligned}
$$




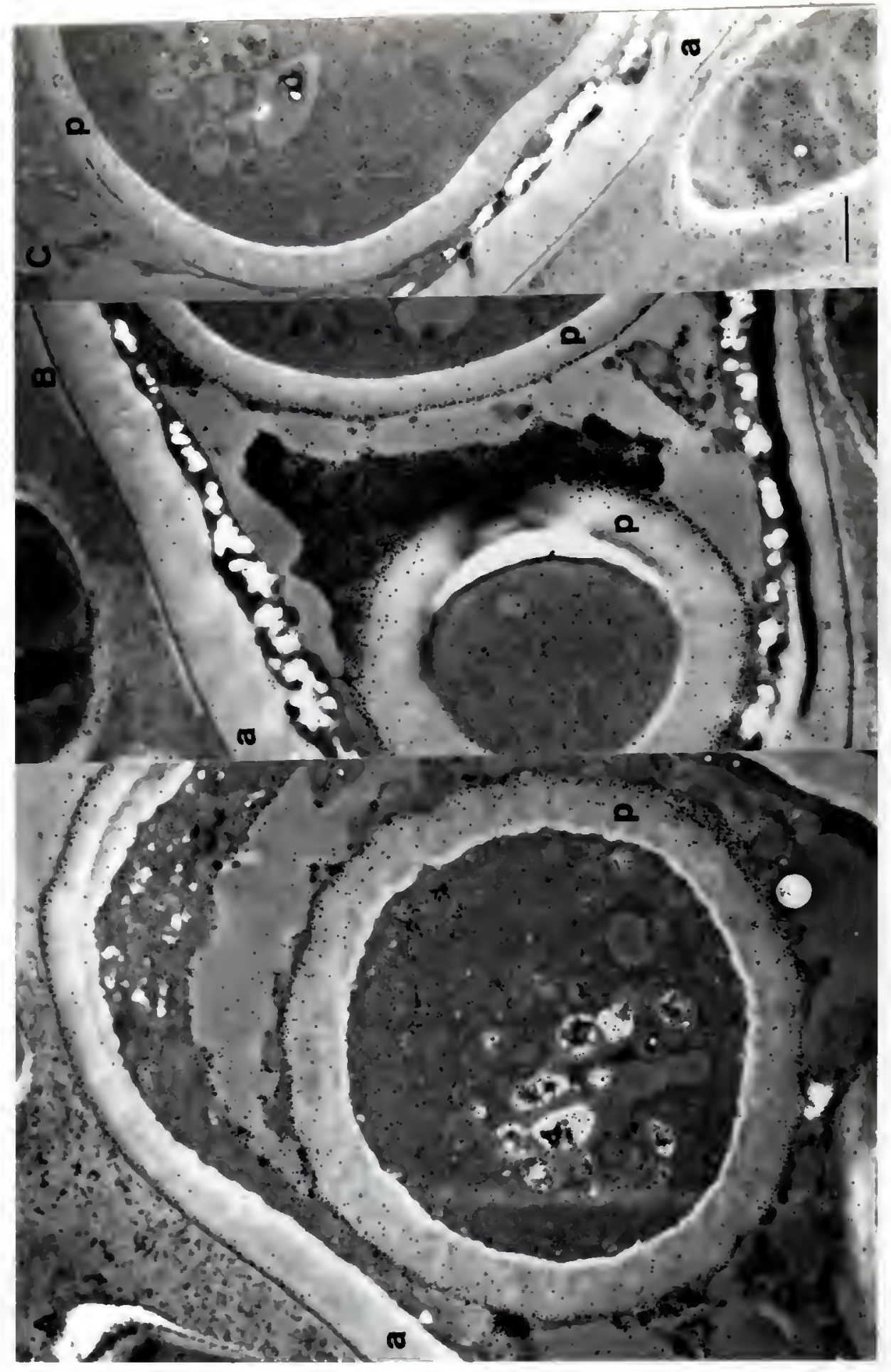




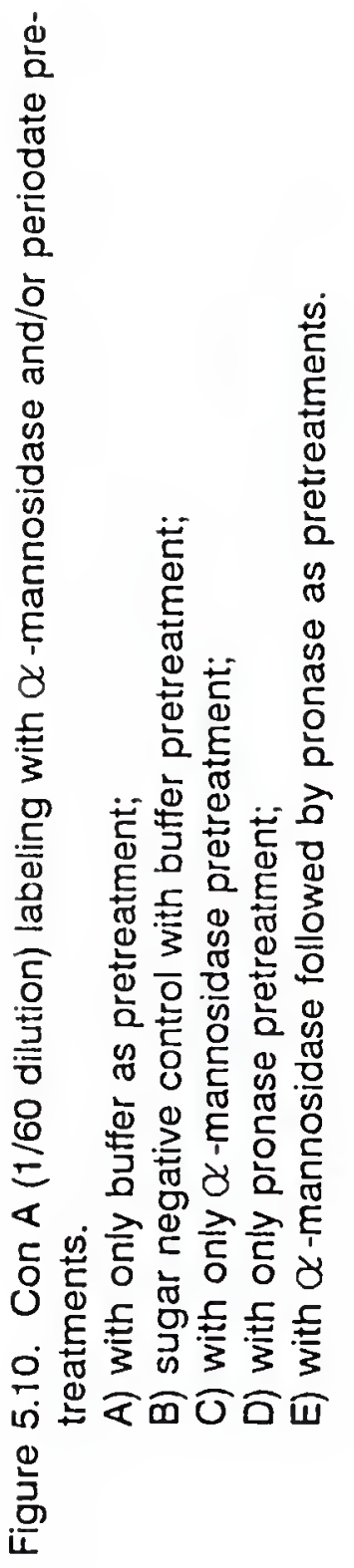




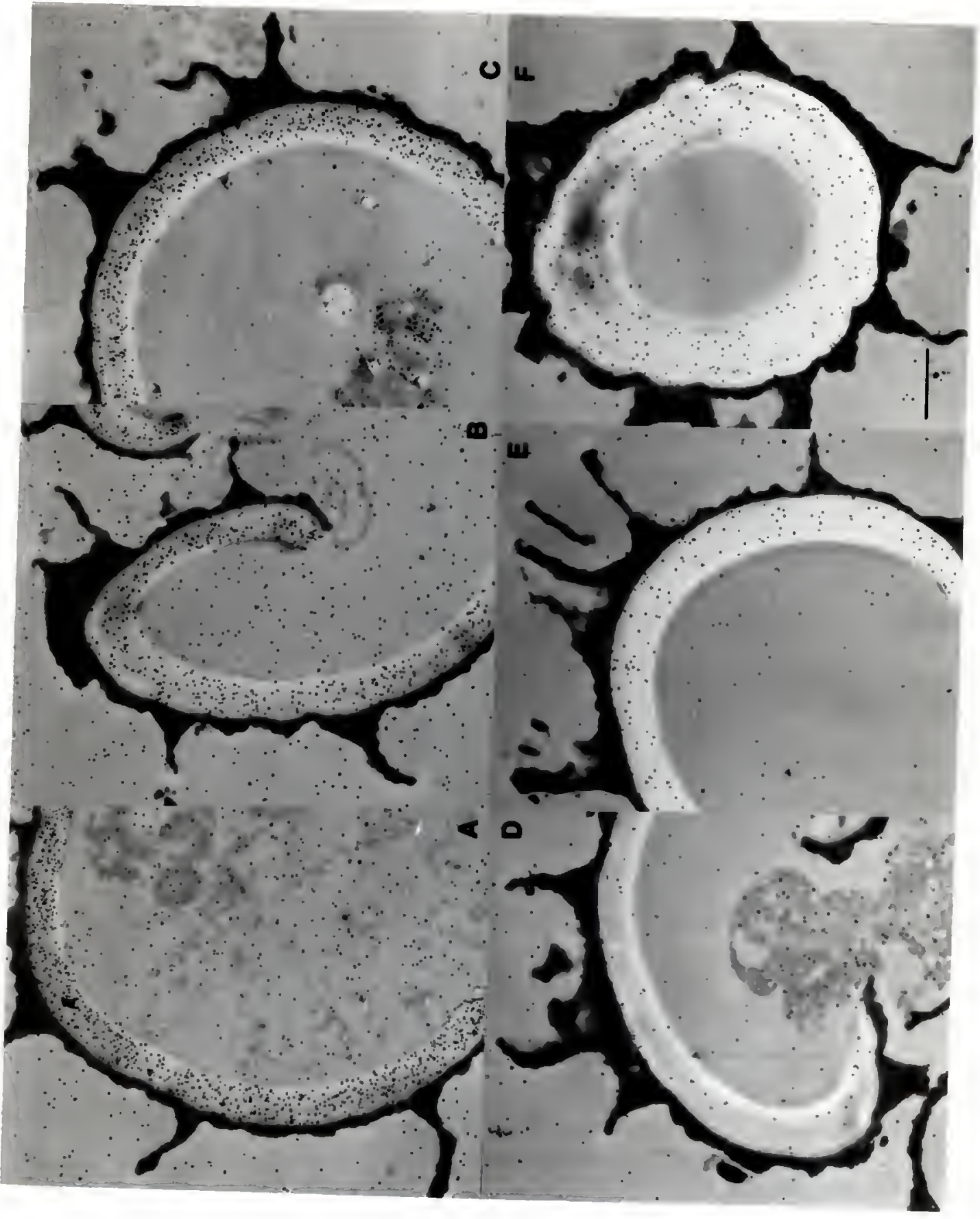




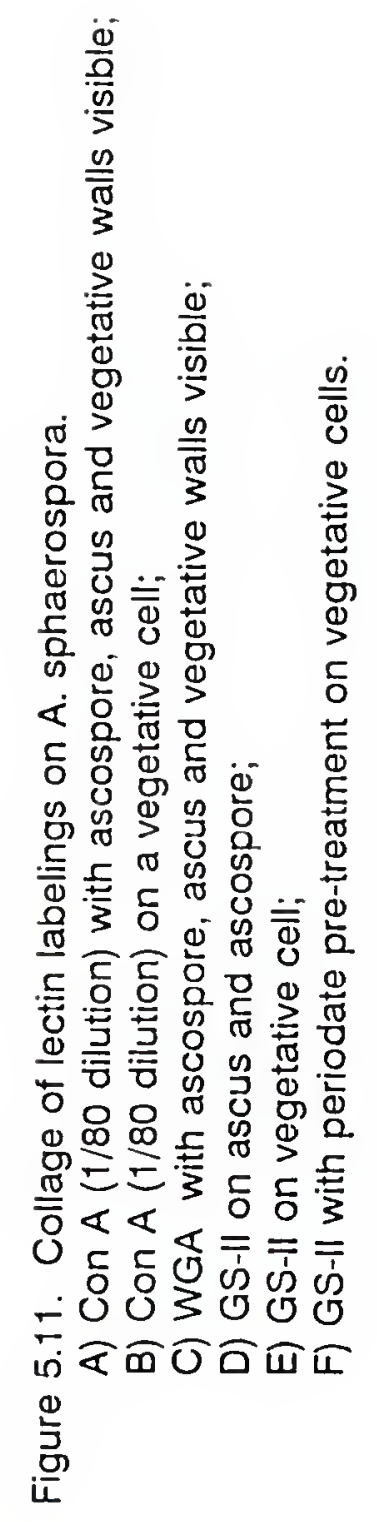




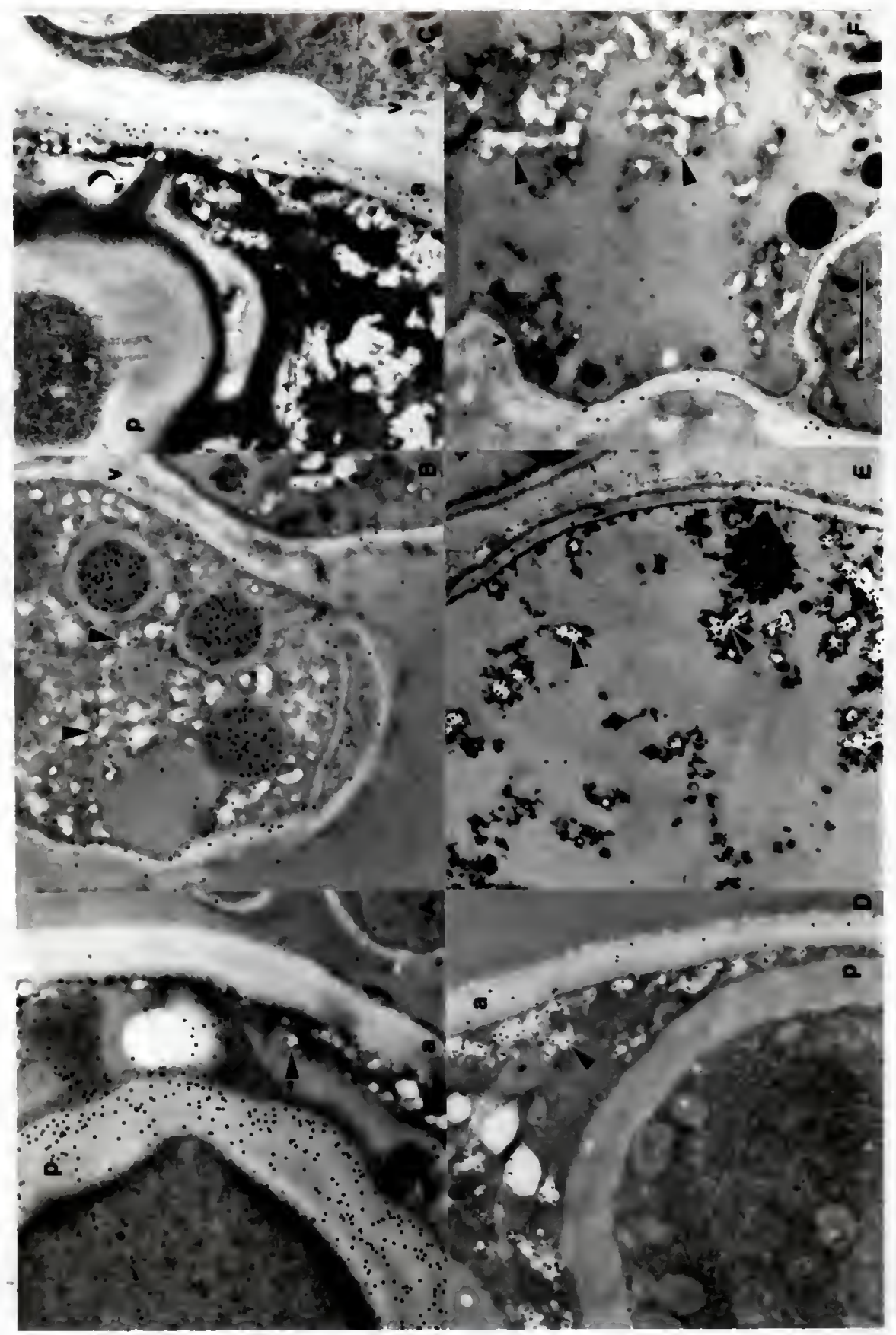


only the pronase pretreatment) and figures $5.10 \mathrm{E}$ and $\mathrm{F}$ demonstrate the results of the double digestion. The obvious, great reduction in labeling of the primary wall in the double digestion (figs. 5.10E \& F) in comparison with the Con A control (fig. 5.10A) and the single digestions (figs. $5.10 \mathrm{~B} \& \mathrm{C}$ ), indicates that Con A labeling primarily due to the presence of mannan in the wall.

\section{Discussion}

Wall Chemistry

The presence of chitin in the cell walls is one of the characteristics of Ascomycetes (Barknicki-Garcia, 1968). WGA has been used successfully in the past to localize chitin. In both Ascodesmis sphaerospora and Pseudoplectania nigrella ascus but not ascospore walls were labeled (figs. $5.1 \& 5.3$ ). This pattern was also observed with GS-II lectin in both these species (figs. $5.2 \& 5.4$ ). It is most probable that no part of the spore walls of these species contains chitin.

If chitin is absent from these ascospores walls then they must have some other structural polymer(s). Strong labeling of the primary wall with Con A (figs. 5.8A-C \& $5.11 \mathrm{~A})$ is suggestive of $\alpha$-mannan filling the structural role. The mannosidase digestion provides more definitive evidence for presence of $\alpha$-mannan within the wall (fig. 5.9). Some labeling is observed on the wall after digestion (fig. 5.9B) but this was expected as this enzyme is an exoenzyme incapable of degrading past branching points and Con A preferentially binds at branch points (Manner \& Wright, 1962; Goldstein, 1965). While an argument could be made for Con A labeling a glucose polymer in these spore walls, this now appears far less likely than mannan labeling. Additionally, if a glucose 
Table 5.2: $\quad$ Comparison of Con A and GS-ll labeling on Ascodesmis sphaerospora and binding specificities.

\begin{tabular}{|c|c|c|c|c|c|c|}
\hline & Spore & & Glycogen & & Gly- & \\
\hline Lectin & Wall & Ascus & Areas & Man. & cogen & $\underline{N \text {-AcGlc }}$ \\
\hline Con A & + & \pm & + & ++ & + & \pm \\
\hline GS-II & - & + & + & \pm & + & ++ \\
\hline
\end{tabular}

- , not labeled or bound

\pm , slightly labeled or bound

+ , specifically labeled, binding standard

++ , binding greater than standard

polymer was present one might expect to see GS-II labeling as well because of similar glycogen binding of these lectins (table 5.2).

\section{Glycogen Labeling}

Both Con A and GS-II lectins have been reported to bind glycogen (Con A, Sumner \& Howell, 1936; GS-II, Ebisu et al., 1978). Both of these lectins label electrontransparent areas within asci and vegetative cells (Con A, fig. 5.8D, \& GS-Il, figs. 5.2A \& $C, 5.11 \mathrm{~A} \& \mathrm{~B})$ that was initially thought to be an artifact of poor fixation. To further substantiate the chemistry of these electron-transparent areas, sections to be labeled with GS-II were pretreated with periodate (fig. $5.11 \mathrm{E}$ vs F). While cell walls continued to label as would be expected for $\mathrm{N}$-acetylglucosamine, the electron-transparent areas no longer labeled as would be expected for glycogen. Thus it is concluded that these electron-transparent areas are not artifacts but glycogen.

\section{Methods Notes}

It has been clearly shown that a lectin can label more than one carbohydrate type within the fungal cell (GS-II lectin; N-acetylglucoseamine in the walls, and glycogen 
within the cell; fig. 5.10D \& E vs F). The sugar negative control for this lectin was not labeled on either site. An unlabeled sugar negative control alone therefore can not be used to determine the particular carbohydrate being labeled when a lectin has multiple specificities.

It was pointed out in the results that the WGA labeling was increased by use of the supposed sugar negative control which was $\mathrm{N}$-acetylglucosamine. No other sugar control was readily available. Nevertheless it would appear that label continued to be specific as the overall pattern continued to be similar to that of GS-II and WGA without sugar. The fact that labeling increased while continuing to be specific suggests that the WGA was primed by the monomer. In inhibition studies (Goldstein et al., 1975) N,N',N"'triacetylchitotriose was found to be almost 30 times more effective than N,N'diacetylchitobiose. If the monomer does bind to subsite $\mathrm{C}$ as Allen and coworkers (1973) suggested it would seem that the lectin would be able to identify and bind available N,N'-diacetylchitobiose units in the A and B site up to 30 times more readily. Bonfonte-Fasolo and coworkers (1986) described an orientation of chitin fibrils within fungal cell walls. That varying orientation would lend itself to exposure of differing lengths of chitin fibril in section. If WGA is primed by the monomer an increase in labeling on exposed chitobiose, probably proportional to the amount exposed, would be expected. 


\section{CHAPTER 6}

CONCLUSIONS

\section{Evaluation of Experimental Methods}

\section{Tissue Preparation}

In general fixatives with less than $1 \%$ glutaraldehyde were not required, even with the antibodies. Fixative with $2 \%$ glutaraldehyde was most commonly used with the lectins, and worked quite well. Pelleting the apothecial was quite helpful in reducing the time required for block trimming and facing. Although scrapping the apothecia off the agar disrupted the older hyphal cells and mature asci, it was far more convenient than using unpelleted apothecia.

\section{Immunological}

Evaluation of immunological techniques were given at the end of Chapter 3 . In review, two main points were made. First, a hybridoma management plan was presented which would allow testing and work to proceed at a pace limited by the EM work rather than the needs of billions of hybridoma cells in log growth phase. Second, the ELISA test was found to be inadequate for this ascospore wall antigen because of background problems.

\section{Cytochemical}

The first priority was to try to examine and compare the chemistry of the 
ascospore walls with that of hyphal walls. Thus, the majority of experiments have been with lightly fixed tissues for optimal labeling conditions, even though good ultrastructural preservation was sacrificed. This was particularly necessary for working with unknown determinants of antibodies. Now that labeling has been proven with various probes, further work on both morphology and biological definition of the binding sites will be possible.

The antibodies have proven themselves finicky as to pretreatment of sections to obtain good labeling results and buffering systems required to reduce background labeling.

The lectins have proven themselves problematic in regard to background labeling, not labeling even on positive controls, apparent lectin priming resulting in increased labeling with the sugar negative control, and labeling more than one type of sugar on the sections. To an extent, problems with background and lack of labeling have been resolved by altering the dilutions of the primary probe and/or glycoproteingold (indirect method). It appears that increasing the dilution of Con A lectin reduces specific labeling on the electron transparent areas, which are presumably glycogen, without greatly reducing ascospore wall labeling. This is not an unexpected result as similar results have been found in precipitation and inhibition studies.

Evaluation of labeling was qualitative rather than quantitative. This type of evaluation has been sufficient for this study. From qualitative analysis there appears to be some linearity to the labeling patterns of antibody $8 \mathrm{~F} 11$ (fig. $4.4 \& 4.6 \mathrm{~A}$ ). Quantitative analysis using morphometric techniques must be done to make a well-founded statement about such labeling patterns. Although detailed analysis of labeling patterns was not a goal of this study, it can be done at some point in the future with micrographs taken for this study. 


\section{Ascospore Wall Chemistry}

Any hypothesis regarding a generalized chemical similarity has been disproven with every specific probe used in this study (table 6.1). Immune-sera showed some cross-reactivity but the possibility of immunogen contamination renders that data unacceptable as proof of chemical similarity. From the information gained in this study it appears that the various wall systems in fungi are chemically distinct. The correlation of structure and function seems to once again be reinforced by experimental data.

Table 6.1: Comparision of wall labeling patterns.

\begin{tabular}{|c|c|c|c|c|c|c|c|c|}
\hline \multirow[b]{3}{*}{ Trtm. } & \multicolumn{4}{|c|}{ A. sphaerospora } & \multicolumn{4}{|c|}{$\underline{P}$. nigrella } \\
\hline & \multicolumn{4}{|c|}{ Ascospore } & \multicolumn{4}{|c|}{ Ascospore } \\
\hline & $\underline{1}^{\circ}$ & $\underline{2}^{\circ}$ & Ascus & Veg. & $1^{\circ}$ & $\underline{2}^{\circ}$ & Ascus & Veg. \\
\hline Serum & + & + & + & + & 0 & 0 & 0 & 0 \\
\hline $8 F 11$ & + & - & - & - & 0 & 0 & 0 & 0 \\
\hline $41.1-3$ & + & - & - & - & - & - & - & - \\
\hline $12-2$ & - & + & - & - & - & - & - & - \\
\hline WGA & - & - & + & + & - & - & + & + \\
\hline GS-II & - & - & + & + & - & - & + & + \\
\hline Con A & + & + & - & \pm & - & + & + & - \\
\hline LFA & - & - & \pm & \pm & 0 & 0 & 0 & 0 \\
\hline $\begin{array}{l}, \text { no labelir } \\
+, \text { specific } \\
\pm \text {, labeling } \\
\text { 0, not teste }\end{array}$ & 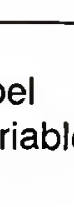 & & nable & & & & & \\
\hline
\end{tabular}


In the proposal it was hypothesized that skeletal elements of the ascospore wall would be chitin or $B(1-3)$ glucan, or possibly mannan. WGA and GS-II lectin labeling (figs. 5.1, 5.3, 5.2 \& 5.4) demonstrate chitin in the ascus wall and a lack of detectable quantities of chitin in the ascospore wall of both Ascodesmis sphaerospora and Pseudoplectania nigrella. Con A labeling, especially in combination with $\propto$-mannosidase digestion (figs. 5.11), on $\underline{A}$. sphaerospora suggests a mannan structural polymer, but does not exclude B-glucan playing such a role solely or in combination with mannan. Conversely, $\underline{P}$. nigrella ascospore walls were only labeled in the secondary wall layer, and thus mannan would not appear to be the structural polymer in the primary wall of this species. By elimination, it would appear in this case that a glucan or glucans are the skeletal elements in this case, but a strong statement to that effect can not be made until there is positive evidence. Such an apparent chemical difference between these two species is not unexpected considering the distant relationship of these fungi.

\section{Precursor Tracking}

In the proposal it was hypothesized that given the appropriate probe it should be possible to track wall materials not synthesized in situ. Antibody 12-2 has shown promise of being such a probe, but poor morphology has interfered with proving it. Further work towards this goal would be worthwhile.

\section{Maturation of the Ascospore Wall}

Antibody $8 \mathrm{~F} 11$ has definitively shown a maturation event in the primary wall. Labeling with this antibody does not occur until the ascospore is apparently complete and relatively mature (fig. $4.4 \& 4.6$ ). 
A further point can be made concerning the literature on ascosporogenesis. The use of the word "mature" has been used in at least two different contexts in regard to the primary wall. Gibson and Kimbrough (1988) describe the time of primary wall maturity as when the outer delimiting membrane moves away from the primary wall. Later in that same paper they discuss a change in silver proteinate staining over time and stated that the staining change indicated a change in the primary wall chemistry. It would appear that they have inadvertently contradicted themselves if "mature" is considered a final product rather than termination of a obvious deposition process. Labeling by antibody $8 \mathrm{~F} 11$ strongly supports the hypothesis of continued chemical changes in the primary wall after the termination of obvious deposition and apparent morphological maturity. Thus, the primary wall has been shown not to be in final, or fully mature form, until very late in the process of ascosporogenesis. 
APPENDIX A

FUNGAL CULTURE

\section{Fungus}

Ascodesmis sphaerospora stock culture (\# 260) was obtained as a gift from Dr. Kimbrough.

\section{Corn Meal Malt Yeast Medium (CMMY)}

$8.5 \mathrm{~g}$ corn meal agar (BBL, 11132)

4.0g bacto-agar (Difco, 0140-01)

$0.5 \mathrm{~g}$ yeast extract (BBL, 11929)

$0.5 \mathrm{~g}$ malt extract (Difco, 0186-02-4)

$500 \mathrm{ml}$ deionized $\mathrm{H}_{2} \mathrm{O}$

\section{Protocol}

1. Ingredients are placed in a $1000 \mathrm{ml}$ flask.

2. Cover flask with aluminum foil and sterilize.

(autoclave for 20 minutes)

3. Pour sterile medium about $3 \mathrm{~mm}-5 \mathrm{~mm}$ deep in $100 \mathrm{~mm} \times 15 \mathrm{~mm}$ sterile plastic petri dishes (Fisher, 8-757-13).

4. Let sit overnight.

5. Inoculate plates with about a $0.5 \mathrm{~cm}-1 \mathrm{~cm}$ square from a previous culture.

6. Seal plates with parafilm.

7. Grow at room temperature with a source of natural light. 


\section{APPENDIX B \\ ISOLATION OF ASCOSPORE WALLS}

\section{For Immunization and EM}

1. Inoculate plates of CMMY agar with Ascodesmis sphaerospora.

2. Grow up for 2-3 weeks in natural light.

3. Collect spores off lids with rubber policeman and $\mathrm{dH}_{2} \mathrm{O}$ and place in flask or other suitable clean storage container.

4. Break spores in Braun homogenizer.

a. Fill jar about $1 / 3$ full of beads.

Beads: Potters Co. \#P-008 (about $0.17 \mathrm{~mm}$ )

b. Add spore suspension to about $1 / 2$ full.

c. Add 3 drops of tributyl phosphate (antifoam agent).

d. Stop the jar, and put a little glycerin on jar body.

e. Place in homogenizer, adjust $\mathrm{CO}_{2}$, and shake for 2-3 minutes.

f. Filter off homogenate and wash the beads with $\mathrm{dH}_{2} \mathrm{O}$.

5. Centrifuge at $10,000 \mathrm{rpm}(15,890 \mathrm{~g})$ for 10 minutes over a $10 \%$ over $25 \%$ over $50 \%$ sucrose step gradient. Sucrose is dissolved in $\mathrm{dH}_{2} \mathrm{O}$. (Centrifuge: Beckman model J2-21)

6. Remove and discard supernatant.

7. Resuspend pellet in $\mathrm{dH}_{2} \mathrm{O}$.

8. Centrifuge at $5,000 \mathrm{rpm}(3,970 \mathrm{~g})$, for 5 minutes.

9. Repeat steps $6,7 \& 8$ at least once more, the last time in $0.1 \mathrm{M}$ cacodylate buffer.

10. Suspend the pellet in $0.5 \%$ glutaraldehyde and $1 \%$ paraformaldehyde in $0.1 \mathrm{M}$ cacodylate buffer. Fix for 30 minutes on ice. 
11. Centrifuge at $2,000 \mathrm{rpm}$, for 5 minutes. (Centrifuge: Damon Clinical model $\mathrm{CL}$ )

12. Remove and discard supernatant. For preparation of immunogen proceed to step 13 of this protocol. For embedding proceed to Appendix C, step 13.

13. Resuspend pellet in $0.1 \mathrm{M}$ cacodylate buffer, and let stand for 15 minutes.

14a. For immunogen, repeat steps $11,12, \& 13$ at least twice more using sterile PBS buffer (0.15M, pH 7.0-7.4).

14b. For ELISA and EM, repeat steps 11 through 13 once or twice more using $\mathrm{dH}_{2} \mathrm{O}$.

15a. Suspend in PBS buffer.

15b. For ELISA, suspend in $\mathrm{dH}_{2} \mathrm{O}$.

15c. For EM, precede to Appendix D step 15.

16. Store at $4^{\circ} \mathrm{C}$.

17. Estimate concentration of wall fragment suspension by the hemacytometer counting method. (America Optical, bright line hemacytometer) 


\section{APPENDIX C \\ PROTOCOLS FOR HYBRIDOMA CONSTRUCTION \\ AND CLONING}

\section{Mouse immunization}

1. Young, healthy, female, Balb-c mice were selected from the stock collection.

2. Inoculations were made every 2 weeks for a minimum of 2 months.

a. The first 2 immunizations were sub-cutaneous in the neck region with $0.1 \mathrm{ml}$ of 50\% Freund's (SIGMA, St. Louis, MO.) complete adjuvant and 50\% resuspended broken spore-wall stock suspension (4.5-7 $\times 10^{8}$ parts per $\mathrm{ml}$ ).

b. All further immunizations were intra-peritoneal with $1 \mathrm{ml}$ of $50 \%$ Freund's incomplete adjuvant and $50 \%$ resuspended broken spore-wall stock.

3. A final pre-fusion boost (as in $2 \mathrm{~B}$ above) 2-3 days prior to sacrifice.

\section{Cell fusion}

1. Grow SP2-O myeloma cells to log phase in a $75 \mathrm{ml}$ culture flask. This usually takes about 2-3 days in $75 \mathrm{ml}$ culture flask.

2. Sacrifice mouse, and save blood for serum.

3. Dissect out spleen.

4. Break up spleen cells by one of the following methods:

Method 1:

a. Mash spleen through a sterile screen into DME media.

b. Pull cells into syringe through an 18 gauge needle and expel through a 21 gauge needle.

c. Pull cells into syringe through an 18 gauge needle and expel through a 23 gauge needle. 
d. Pull cells into syringe through an 18 gauge needle and expel through a 25 or 26 gauge needle into centrifuge tube.

Method 2:

a. Set spleen on sterile screen above a sterile beaker.

b. Clip a small piece of tissue off the larger end with sterile scissors.

c. Place 18 gauge needle on a syringe and fill it with DME media.

d. While holding the spleen with forceps, insert the needle in the uncut end and force the media through the spleen.

e. Repeat steps $c$ and $d$ until the spleen in more or less empty of cells.

f. Transfer cells from beaker to a centrifuge tube.

5. Transfer SP2-O cells to centrifuge tubes.

6. Balance all centrifuge tubes (those with spleen and SP2-O cells) and centrifuge them at about 10,000 rpm for 10 minutes. Discard spleen cell supernatant and save the SP2-O cell supernatant ( $=$ conditioned media).

7. Resuspend spleen and SP2-O each in $5 \mathrm{ml}$ of DME media.

8. Count live cells of each suspension, determine concentration of live cells.

9. In a sterile centrifuge tube mix cells at a rate of 10/1 live spleen/live SP2-O cells.

10. Add $1 \mathrm{ml}$ PEG dropwise over 1 minute period.

11. One minute later add $1 \mathrm{ml}$ DME slowly while gently swirling.

12. One minute later add $2 \mathrm{ml}$ DME slowly while gently swirling.

13. Two minutes later add $4 \mathrm{ml} \mathrm{DME} \mathrm{slowly} \mathrm{while} \mathrm{gently} \mathrm{swirling.}$

14. Four minutes later add $10 \mathrm{ml}$ DME slowly while gently swirling.

15. Centrifuge at $10,000 \mathrm{rpm}$ for 10 minutes. Discard supernatant.

16. Resuspend cells in DME with $10 \%-25 \%$ horse serum (or non-serum substitute such as CPSR).

17. Count cells and dilute further with that medium as needed to obtain 100-200 cells per well (see step 18). 
18. Place 50 or $100 \mu$ cell suspension per well into 96 well culture plates.

19. Place in a controlled environment $\left(37^{\circ} \mathrm{C}\right.$, and $5 \%$ humidity) incubator.

\section{Cell selection}

1. Twelve to eighteen hours after plating the fusion cells feed them an equal amount (50 or $100 \mu \mathrm{l})$ of $2 \mathrm{X}$ HAT media.

2. Feed approximately every 5 days thereafter. The first 2 of these feedings with $1 X$ HAT in 55\% DME / $20 \%$ horse serum (or CSPR) / 25\% SP2-O conditioned media, and thereafter with same media minus the HAT.

\section{Cloning}

Method 1:

1. Grow cells up into large volume.

2. Count cells and dilute to approximately $1 \times 10^{6}$ cells per $\mathrm{ml}$ media.

3. Prepare 2 - 96 well plates by placing $100 \mu$ I media in each well.

4. Place $100 \mathrm{H}$ l cell suspension in each well of the first column on the first plate.

5. Place $100 \mathrm{\mu l}$ from wells of the first column into the wells of the second column, etc., until serial dilutions have been made across all the wells of both plates.

6. Monitor for growth of single colonies per well.

\section{Method 2:}

1. Prepare plates as in step 3 above.

2. Transfer $100 \mu \mathrm{l}$ of cell suspension from a target well (of 96 or 24 well plate) to a well in the first column of the first cloning plate.

3. Proceed to step 5 above. 


\section{APPENDIX D \\ FREEZING AND THAWING HYBRIDOMA OR SP2-O CELLS}

\section{Freezing Media}

$10 \% \mathrm{v} / \mathrm{v}$ horse serum or CSPR

$10 \%$ DMSO

balance feed medium (eg. DME with 5\%-20\% horse serum or CSPR and $0 \%-25 \%$ conditioned medium)

\section{Freezing Protocol}

1. Prepare cryovials.

2. Spin down cells at low speed (Dynac centrifuge, speed setting 5, for 8-10 minutes).

3. Remove medium and save if needed.

4. Add $1 \mathrm{ml}-2 \mathrm{ml}$ of freeze media for each $5 \mathrm{ml}-15 \mathrm{ml}$ of media removed. (This is not terribly critical.)

5. Place immediately in a freezer $\left(-80^{\circ} \mathrm{C}\right.$ ) or liquid nitrogen. (If immediately placed in a $-20^{\circ} \mathrm{C}$ freezer transfer to $-80^{\circ} \mathrm{C}$ or liquid nitrogen as soon as possible and not more than $30-60$ minutes.)

\section{Thawing Protocol}

1. Thaw cells as quickly as possible (at about $37^{\circ} \mathrm{C}$ ).

2. Add to a centrifuge tube with $10 \mathrm{ml}-15 \mathrm{ml}$ of DME.

3. Centrifuge as in step 2 above.

4. Remove DME from cell pellet and discard.

5a. Repeat steps 2-4 of desired. 
5b. Suspend pellet in $10 \mathrm{ml}-15 \mathrm{ml}$ of feed medium.

6. Grow up in a small cell culture flask (e.g., $25 \mathrm{ml}$ ) under typical conditions (Appendix C). 


\section{APPENDIX E \\ LIGHT BREAK OF ASCOSPORES}

\section{Fixative}

$0.5 \%$ glutaraldehyde

$2 \%$ paraformaldehyde

in cacodylate buffer (approx. 0.1M)

\section{Protocol}

1. Collect spores, suspend in $\mathrm{dH}_{2} \mathrm{O}$ and place in a microfuge tube.

2. Centrifuge at $1,000 \mathrm{~g}$ for 3 minutes. (Fisher Centrifuge, model 59)

3. Remove and discard supernatant.

4. Resuspend pellet in fix, and place on ice for 15 minutes.

5. Centrifuge at $1,000 \mathrm{~g}$ for 3 minutes.

6. Remove and discard excess fix.

7. Add glass beads to approximately $1: 5, v: v$, spores:beads, then gently mix.

8. Add additional fix until all beads are just moist, and vortex for 100-120 seconds (setting 9).

9. Add additional fix so that liquid level is well above the beads and gently suspend the spores.

10. Once the beads have settled, use Pasteur pipet to remove the spore suspension, being careful not to pick up any beads.

11. Place spore suspension on ice for 15 minutes. (Total fix time is about 45 minutes.)

12. Centrifuge at $1,000 \mathrm{~g}$ for 1 minute.

13. Resuspend in $0.1 \mathrm{M}$ cacodylate buffer, and let stand at room temperature for 15 minutes.

14. Repeat steps 12 and 13 twice more, the last time resuspending in $\mathrm{dH}_{2} \mathrm{O}$. 
15. Dehydrate in ethanol series to $95 \% \mathrm{EtOH}$.

16. Infiltrate with, and embed in LR White resin.

Ref.: Olson, L.W. 1978. Preparation of "difficult" spores, and sporangia for electron microscopy. In: M.S. Fuller.(ed.), Lower Fungi In The Laboratory, Dept. of Botany, Univ. of Georgia, publisher. 


\section{APPENDIX F \\ FIXATION PROTOCOL}

\section{Fixative}

The various combination of glutaraldehyde/formaldehyde concentrations are given in table 4.1. In all cases the final concentration of cacodylate buffer used was $0.1 \mathrm{M}$.

\section{Protocol}

1. Cut out pieces of agar with greatest density of apothecia, trimming off excess depth, so that final dimensions are $0.5 \mathrm{~cm} \times 1 \mathrm{~cm}-2 \mathrm{~cm} \times 0.25 \mathrm{~cm}-0.5 \mathrm{~cm}$.

2a. Place pieces of agar in fixative solution.

2b. Alternatively, skip step 1 and flood plates with fixative.

3. Fix for 30-60 minutes on ice.

4. Wash for 30 minutes using 3 changes of $0.1 \mathrm{M}$ cacodylate buffer.

5. Wash for 10 minutes in $\mathrm{dH}_{2} \mathrm{O}$ (optional).

6a. Dehydrate through ethanol series to $95 \%$ for LR White Resin.

6b. Dehydrate through ethanol series through $100 \%$ and acetone for Spurr's resin.

7. Infiltrate with, and embed in the appropriate resin increasing the resin concentration in $25 \% \mathrm{v} / \mathrm{v}$ increments.

8. Polymerize resin at $50-60^{\circ} \mathrm{C}$ for $12-24$ hours. 
APPENDIX G

ANTIBODY LABELLING

\section{Protocol}

0. Pretreatment (see below).

1. Block, $5 \%$ milk, with or without $1 \%$ sodium azide, in PBS. (Carnation Co.)

2. Wash, briefly in PBS, and/or blot.

3. Primary antibody, 1 hour at room temperature, diluted in PBS or Tris/high salt/tween 20 (THST).

4. Washes, about 5 times for total of 50 minutes in buffer (PBS, or first wash in THST, then PBS. Blot.

5. Gold-conjugated secondary antibody, 1 hour at room temperature. (EY Labs, goatanti-mouse $\mathrm{IgG} / \mathrm{lgM}, 15 \mathrm{~nm}$ gold, diluted to $1.25 \mu \mathrm{g} / \mathrm{ml}$.)

6. Washes, about 5 times for total of 50 minutes in PBS. Blot.

7. Washes, 2 or 3 times for total of 30 minutes in $\mathrm{dH}_{2} \mathrm{O}$. Blot, and view, post-stain, or store.

\section{Pre-treatment experiments}

1. Sodium meta-periodate etching:

a. Float grids on saturated $\mathrm{NaIO}_{4}$ in $\mathrm{dH}_{2} \mathrm{O}$, at room temperature for 1 hour. (Fisher Scientific Co., lot 716131.)

b. Washes, 3 times for total of 30 minutes in $\mathrm{dH}_{2} \mathrm{O}$. Blot.

c. Begin above labelling protocol, or proceed with Pronase digest.

2. Pronase digest:

a. Float grids on $1 \% \mathrm{w} / \mathrm{v}$ solution of Pronase in PBS buffer, for 1 hour at $37^{\circ} \mathrm{C}$. (Calbiochem, B grade, 45,000 PUK units/gm.) 
b. Washes, 3 times for total of 30 minutes in PBS. Blot.

c. Begin labelling protocol. 


\section{Literature Cited}

Aldrich, H.C., and W.J. "Todd. 1986. Ultrastructure Techniques for Microorganisms. Plenum Press. New York.

Allen, A.K., A. Neuberger and N. Sharon. 1973. The purification, composition and pecificity of wheat-germ agglutinin. Biochem. J. 131:155-162.

Araki, Y. and E. Ito. 1975. A pathway of chitosan formation in Mucor rouxii, enzymatic deacetylation of chitin. Eur. J. Biochem. 55:71-78.

Aronson, J.M. 1965. The cell wall. In: G.C. Ainsworth and A.S. Sussman (eds.). The Fungi: An Advanced Treatise, volume I. Academic Press, New York, pp. 49-76.

Aronson, J.M. 1981. Cell wall chemistry, ultrastructure, and metabolism. In: G.T. Cole and B. Kendrick (eds.). Biology of Conidial Fungi. Academic Press, New York 2: 459-507.

Baker, C.A., S. Sugii, E.A. Kabat, R.M. Ratcliffe, P. Hermentin, and R.U. Lemieux. 1983. Immunochemical studies on the combining sites of Forssman reactive hemagglutanins from Dolichos biflorus, Helix pomatia and Wistaria floribanda. Biochemistry 22:2741-2750.

Banowetz, G.M., E.J. Tirone, and B.B. Krygier. 1984. Immunological comparisons of teliospores of two wheat bunt fungi, Tilletia species, using monoclonal antibodies and antisera. Mycologia, 76:51-62.

Bartnicki-Garcia, S. 1968. Cell wall chemistry, morphogenesis, and taxonomy of fungi. Annu. Rev. Microbiol. 22:87-108.

Bastin, J.M., J. Kirkley, and A.J. McMicheal. 1982. Production of monoclonal antibodies. In: A.J. McMichael and J.W. Fabre (eds.). Monoclonal antibodies in clinical medicine. Academic Press Inc., New York, pp. 503517.

Beckett, A. 1981. Ascospore formation. In: G. Turina \& H.R. Hoh (eds.). The Fungal Spore: Morphogenetic Controls. Academic Press, New York pp. 107-129. 
Beesley, J.E. 1989. Immunocytochemistry of microbiological organisms: A survey of techniques and applications. Tech. Immunocytochem. 4 :6793.

Bellemere, A. and L.-M. Melendez-Howell. 1976. Etude ultrastructure comparee des l'ornamentation, externe de la paroi des ascospores de deux Pezizales: Peziza fortinii n. sp., recoltee qu Mexique, et Aleuria aurantia (Oed. ex Fr.) Fuckel. Revue Mycol. 40:3-19.

Bendayan, M. 1981. Ultrastructural localization of nucleic acids by means of nuclease-gold complexes. J. Histochem. Cytochem. 29:531-541.

1982. Double immunocytochemical labeling applying the protein A-gold technique. J. Histochem. Cytochem. 30:81-85.

1984a. Protein A-gold electron microscopic immunocytochemistry: Methods, applications and limitations. J. Electron Microsc. Tech. 1:243-258.

. 1984b. Enzyme-gold electron microscopic cytochemistry: A new affinity approach for the ultrastructural localization of macromolecules. J. Electron Microsc. Tech. 1:349-372.

- 1989a. Protein A-gold and protein G-gold postembedding immunoelectron microscopy. In: H.A. Hayat (ed.) Colloidal gold: Principles, methods, and applications, volume 1. Academic Press, New York, pp. 33-94.

. 1989b. The enzyme-gold cytochemical approach: A review. In: (M.A.Hayat, ed.) Colloidal gold: Principles, methods, and applications, Vol. 2. Academic Press, New York, pp. 117-147.

Bendayan, M. and M. Zollinger. 1983. Ultrastructural localization of antigenic sites on osmium-fixed tissues applying the protein A-gold technique. J. Histochem. Cytochem. 31(1):101-109.

Benhamou, N. 1988. Ultrastructural localization of carbohydrates in the cell walls of two pathogenic fungi: A comparative study. Mycologia 80(3):324-337.

. 1989a. Ultrastructural study of galacturonic acid distribution in some pathogenic fungi using gold-complexed Aplysia depilans gonad lectin. Can. J. Microbiol. 35:349-358.

1989b. Preparation and application of lectin-gold complexes. In: M.A.Hayat (ed.). Colloidal gold: Principles, methods, and applications, Vol. 1. Academic Press, New York, pp. 95-143. 
Benhamou, N., and G.B. Ouellette. 1986. Ultrastructural localization of glycoconjugates in the fungus Ascocalyx abietina, the scleroderris canker agent of conifers, using lectin-gold complexes. J. Histochem. Cytochem. 43(7):855-867.

Blackwell, J. 1982. The macromolecular organization of cellulose and chitin. In: R.M. Brown, Jr. (ed.). Cellulose and Other Natural Polymer Systems: Biogenesis, Structure, and Degradation. Plenum Press, New York, pp. 403-428.

Bonfante-Fasolo, P., A. Faccio, S. Perotto, and A. Schubert. 1990. Correlation between chitin distribution and cell wall morphology in the mycorrhizal fungus Glomus versiforme. Mycol. Res. 94(2):157-165.

Bonfante-Fasolo, P., B. Vian, and B. Testa. 1986. Ultrastructural localization of chitin in the cell wall of a fungal spore. Biol. Cell $\underline{57}: 265-270$.

Borrebaeck, A.C.K., B. Lonnerdal, and M.E. Etzler. 1981. Metal ion content of Dolichos biflorus lectin and effect of divalent cations on lectin activity. Biochemistry 20:4119-4122.

Borrebaeck, A.C.K., and S.A. Moller. 1986. In vitro immunization. Effect of growth and differentiation factors on antigen-specific $B$ cell activation and production of monoclonal antibodies to autologous antigens and weak immunogens. J. Immunol. 136(10):3710-3715.

Boyde, A., E. Bailey, S.J. Jones, and A. Tamarin. 1977. Dimensional changes during specimen preparation for SEM. SEM/ITRI 1:507-508.

Brams, P., D.E. Pettijohn, M. Brown, and L. Olsson. 1987. In vitro B-lymphocyte antigen priming against both non-immunogenic and immumogenic molecules requiring low amounts of antigen and applicable in hybridoma technology. J. Immunol. Methods 98:11-22.

Brawner, D.L., and J.E. Cutler. 1986a. Ultrastructural and biochemical studies of two dynamically expressed cell surface determinants on Candida albicans. Infect. Immun. 51(1):327-336.

1986b. Variability in expression of cell surface antigens of Candida albicans during morphogenesis. Infect. Immun. 51(1):337-343.

Briza, P., G. Winkler, H. Kalchhauser, and M. Breitenbach. 1986. Dityrosine is a prominent component of yeast ascospore wall. J. Biol. Chem. 261(9):4288-4294.

Briza. P., G. Winkler, and M. Breitenbach. 1988. Chemical composition of the yeast ascospore wall. J. Biol. Chem. 263(23):11569-11574. 
Burnett, J.H. 1979. Aspects of the structure and growth of hyphal walls. In: J.H. Burnett, and A.P.J. Trinci (eds.). Fungal Walls and Hyphal Growth. Cambridge University Press, Cambridge, pp. 1-26.

Cabib, E., B. Bowers, and R.L. Roberts. 1983. Vectorial synthesis of a polysaccharide by isolated plasma membranes. Proc. Natl. Acac. Sci. USA 80:3318-3321.

Cabib, E., S.J. Silverman, A. Sburlati, and M.L. Slater. 1990. Chitin synthesis in Yeast (Saccharomyces cervisiae). In: P.J. Kuhn, A.P.J. Trinci, M.J. Jung, M.W. Goosey, and L.G. Copping (eds.). Biochemistry of cell walls and membranes in fungi. Springer-Verlag, New York, pp. 31-42.

Carlemalm, E., R.M. Garavito, and W. Villiger. 1982. Resin development for electron microscopy and an analysis of embedding at low temperature. J. Microsc. 126:123-143.

Carroll, G.C. 1967. The Ultrastructure of ascospore delimitation in Saccobolus karverni. Jour. Cell Bio. $\underline{33}: 218-224$.

Carter, W.G., and M.E. Etzler. 1975a. Isolation and characterization of subunits from the predominant form of Dolichos biflorus lectin. Biochemistry 14:2685-2689.

. 1975b. Isolation, characterization, and subunit structures of multiple forms of Dolichos biflorus lectin. J. Biol. Chem. 250(7):2756-2762.

Causton, B.E. 1984. The choice of resins for electron immunocytochemistry. In: J.M. Polak and I.M. Varndell (eds.) Immunolabelling for electron microscopy. Elsevier Science, New York, pp. 29-36.

Cole, G.T., and H.C. Aldrich. 1971. Ultrastructure of conidogenesis in scopulariopsis brevicaulis. Can. J. Bot. 49:745-755.

Coons, A.H., H.J. Creech, and R.N. Jones. 1941. Immunological properties of an antibody containing a fluorescent group. Proc. Soc. Exp. Biol. 47:200-202.

Craig, S. and D.J. Goodchild. 1982. Post-embedding immunolabelling. Some effects of tissue preparation on the antigenicity of plant proteins. Eur. J. Cell Biol., 28:251-256.

Dae, M.W., M.A. Heymann, and A.L. Jones. 1982. A new technique for perfusion fixation and contrast enhancement of foetal lamb myocardium for electron microscopy. J. Microsc. 127:301-305. 
Daniel, G., T. Nilsson, and B. Pettersson. 1989. Intra- and extracellular localization of lignin peroxidase during the degradation of solid wood and wood fragments by Phanerochaete chrysosporium by using transmission electron microscopy and immuno-gold labeling. Appl. Envir. Microbiol. 55(4):871-881.

Davis, L.L. and S. Bartnicki-Garcia. 1984. Chitosan synthesis by the tandem action of chitin synthetase and chitin deacetylase from Mucor rouxii. Biochem. 23:1065-1073.

Debray, H., D. Decout, G. Strecker, G. Spik, and J. Montreuil. 1981. Specificity of twelve lectins towars oligosaccharides and glycoproteins related to $\mathrm{N}$ glycosylproteins. Eur. J. Biochem. 117:41-55.

DeWaele, M., J. DeMey, M. Moeremans, M. DeBrabander, and B. VanCamp. 1983. Immunogold staining method for the detection of cell surface antigens with monoclonal antibodies. Immunochemistry 2:1-23.

Dox, A.W., and R.E. Neidig. 1914. The soluble polysaccharides of lower fungi. I. Mycodextran, a new polysaccharide in Penicillium expansum. J. Biol. Chem. 18:167-175.

Duran A., B. Bowers, and E. Cabib. 1975. Chitin synthetase zymogen is attached to the yeast plasma membranes. Proc Natl. Acad. Sci., USA 르:3952-3955.

Dute, R.R., J.D. Weete, and A.E. Rushing. 1989. Ultrastructure of dormant and germinating conidia of Aspergillus ochraceus. Mycologia 81(5):772-782.

Dyby, S.D. and J.W. Kimbrough. 1987. A comparative ultrastructural study of ascospore ontogeny in selected species of Peziza (Pezizales; Ascomycetes). Bot. Gaz. 148(3):283-296.

Ebisu, S., P.N.S. Iyer, and I.J. Goldstein. 1978. Equalibrium dialysis and carbohydrate binding studies on the 2-acetamido-2-deoxy-Dglycopyranosyl-binding lectin from Bandeiraea simplicifolia seeds. Carb. Res. 61:129-138.

Edwards, P.A.W. 1981. Some properties and applications of monoclonal antibodies. Biochem. J. 200:1-10.

Eldred, W.D., C. Zucker, H.J. Karten, and S. Yazulla. 1983. Comparison of fixation and penetration enhancement techniques for use in ultrastructural immunocytochemistry. J. Histochem. Cytochem., 31:285-292.

Erdos, G.W. and D. Whitaker. 1983. Failure to detect immunocytochemically reactive endogenous lectin on the cell surface of Dictyostelium discoideum. J. Cell Biol. 97:993-1000. 
Etzler, M.E., S. Gupta, and C.A.K. Borrebaeck. 1981. Carbohydrate binding properties of the Dolichos biflorus lectin and its subunits. J. Biol. Chem. 256(5):2367-2370.

Faulk, W.P. and G.M. Taylor. 1971. An immunocolloid method for the electron microscope. Immunochemistry $\underline{8}: 1081-1083$.

Farkas, V. 1979. Biosynthesis of cell walls of fungi. Microbio. Rev. 43(2):117144.

Fevre, M. 1984. Action of nucleotides on membrane bound and solubilized Bglucan syntheases from Saprolegnia monoica. In: C. Nombela (ed.). Microbial cell wall synthesis and autolysis. Elsevier Scientific, Amsterdam, p. 131.

Fevre, M., V. Girard, and P. Nodet. 1990. Cellulose and B-glucan synthesis in Saprolegnia. In: P.J. Kuhn, A.P.J. Trinci, M.J. Jung, M.W. Goosey, and L.G. Copping (eds.). Biochemistry of cell walls and membranes in fungi. Springer-Verlag, New York, pp. 97-108.

Gander, J.E. 1974. Fungal cell wall glycoproteins and peptido-polysaccharides. Annu. Rev. Microbiol. 28:103-119.

Geoghegan, K.F., J.L. Dallas, and R.E. Feeney. 1980. Periodate inactivation of ovotransferrin and human serum transferrin. J. Biol. Chem. 255:1142911434.

Gibson, J.L. and J.W. Kimbrough. 1988a. Ultrastructural observations on Helvellaceae (Pezizales). Ascosporogenesis of selected species of Helvella. Can. J. Bot. $\underline{66}: 771-783$.

1988b. Ultrastructural observations on Helvellaceae (Pezizales). II. Ascosporogenesis of Gyromitra exculenta. Can. J. Bot. 66:1743-1749.

Glaser, L. and D.H. Brown. 1957. The synthesis of chitin in cell free extracts of Neurospora crassa. J. Biol. Chem. 228:729-742.

Goding. 1986. Monoclonal antibodies: Principles and practice (2nd edition). Academic Press, N.Y.

Goldstein, I.J., S. Hammarstrom, and G. Sundblad. 1975. Precipitation and carbohydrate binding specificity studies on wheat germ agglutinin. Biochim. Biophys. Acta $\underline{405}: 53-61$.

Goldstein, I.J., C.E. Hollerman, and J.M. Merrick. 1965. Protein-carbohydrate interaction I. The interaction of polysaccharides with concanavalin $A$. Biochim. Biophys. Acta 97:68-76. 
Goldstein, I.J., R.C. Hughes, M. Monsigny, T. Osawa, and N. Sharon. 1980. What should be called a lectin? Nature (London), 285:66.

Goldstein I.J., and R.D. Poretz. 1986. Isolation, Physicochemical characterization, and carbohydrate-binding specificity of lectins. In: (I.E. Liener, N. Sharon, and I.J. Goldstein, eds.) The lectins: Properties, functions, and applications in biology and medicine. Academic Press, Inc., New York, pp. 33-247.

Gorin, P.A. 1985. Structural diversity of D-galacto-D-mannan components isolated from lichens having ascomycetous mycosymbionts. Carbohydrate Research 142:253-267.

Gorin, P.A.J. and M. lacomini. 1984. Polysaccharides of the lichens Cetraria islandica and Ramarlina usnea. Carbohydrate Res. 128:119-132.

Gorin, P.A.J., and J.F.T. Spencer. 1968. Structural chemistry of fungal polysaccharides. Adv. Carbohydr. Chem. 23:367-417.

Green, J.H., W.K. Harrell, J.E. Johnson, and R. Benson. 1980. Isolation of an antigen from Blastomyces detmatitidis that is specific for the diagnosis of blastomycosis. Curr. Microbiol. 4:293-296.

Guber, F. and A.R. Hardham. 1988. Secretion of adhesive material during encystment of Phytophthora cinnamomi zoospores, characterized by immunogold labelling with monoclonal antibodies to components of peripheral vesicles. J. Cell Sci. 90:225-235.

Hardham, A.R. 1985. Studies on the cell surface of zoospores and cysts of the fungus Phytophthora cinnamomi: The influence of fixation on patterns of lectin binding. J. Histochem. Cytochem., 33(2):110-118.

1989. Lectin and antibody labelling of surface components of spores of Phytophthora cinnamomi. Aust. J. Plant Physiol. 16:19-32.

Hardham, A.R. and E. Suzaki. 1986. Encystment of zoospores of the fungus, Phytophthora cinnamomi, is induced by specific lectin and monoclonal antibody binding to the cell surface. Protoplasma 133:165-173.

Hardham, A.R., E. Suzaki, and J.L. Perkin. 1985. The detection of monoclonal antibodies specific for surface components on zoospores and cysts of Phytophthora cinnamomi. Exp. Myclo. 9:264-268.

1986. Monoclonal antibodies to isolate-, species-, and genus-specific components on the surface of zoospores and cysts of the fungus Phytophthora cinnamomi. Can. J. Bot. 64:311-321. 
Harper, R.A. 1897. Kerntheilung und zellbildung im ascus. Jahrbuch fur wissenschaftliche Botanik 30:249-284.

Hashimoto, T., C.D. Wu-Yuan, and H.J. Blumenthal. 1976. Isolation and characterization of the rodlet layer of Trichophyton mentagrophytes microconidial wall. J. Bacteriol. 127:1543-1549.

Hayat, M.A. 1981. Fixation for electron microscopy. Academic Press, New York.

1986. Basic techniques for transmission electron microscopy. Academic Press, New York, pp. 411.

Hearn, V.M., B.L. Griffins, and P.A. Gorin. 1989. Structural analysis of watersoluble fractions obtained from Aspergillus fumigatus mycelium. Glycoconjugate J. 6:85-100.

Hixson, D.C., J.M. Yep, J.R. Glenney, T. Hayes, and E.F. Walborg. 1981. Evaluation of periodate/lysine/paraformaldehyde fixation as a method for cross-linking plasma membrane glycoproteins. J. Histochem. Cytochem. 29:561-566.

Hohl, H.R., \& W. Streit. 1975. Ultrastructure of ascus, ascospore, and ascocarp in Neurospora lineolata. Mycologia 67:367-381.

Hopwood, V., D. Poulain, B. Fortier, G. Evans, and A. Vernes. 1986. A monoclonal antibody to a cell wall component of Candida albicans. Infect. Immun. 54(1):222-227.

Horejsi, V. \& J. Kocourek. 1974. Studies on phytohemagglutinins. XVII. Some properties of the anti-H specific phytohemagglutinin of the Furze seeds (Ulex europaeus L.). Biochem. Biophys. Acta 336:329-337.

Horikoshi, K., and S. lida. 1964. Studies of the spore coats of fungi I. Isolation and composition of the spore coats of Aspergillus oryzae. Biochim. Biophys. Acta 83:197-203.

Hospenthal D.R., A.L. Rogers, and G.L. Mills. 1988. Development of amphotericin B lipsomes bearing antibody specific to Candida albicans. Mycopathologia 101:37-45.

Hrmova, M., C.S. Taft, and C.P. Selitrennikoff. 1989. 1,3-B-D-Glucan synthase of Neurospora crassa: Partial purification and characterization of solubilized enzyme activity. Exp. Mycol. 13:129-139.

Hunsley, D., and J.H. Burnett. 1970. The ultrastructural architecture of the walls of some hyphal fungi. J. Gen. Microbiol. 62:203-218. 
Johnston, I.R. 1965. The composition of the cell wall of Aspergillus niger. Biochem. J. 96:651-658.

Kang, M.S., J. Au-Young, and E. Cabib. 1985. Modification of yeast plasma membrane density by Concanavalin A attachment. Application to study of chitin synthetase distribution. J. Biol. Chem. 260:12680-12684.

Kellenberger, E., M Durrenberger, W. Villiger, E. Carlemalm, and M. Wurtz. 1987. The efficiency of immunolabel on Lowicryl sections compared to theoretical predictions. J. Histochem. Cytochem. 35(9):959-969.

Khardori, N. 1989. Host-parasite interaction in fungal infections. Eur. J. Clin. Microbiol. Infect. Dis. 8(4):331-351.

Kimbrough, J.W., and J.L. Gibson. 1990. Geopyxis carbonaria. Ultrastructural and cytological observations of apothecial tissues of Geopyxis carbonaria (Pezizales, Ascomycetes). Can. J. Bot. 68:243-257.

Kimbrough, J.W., C.G. Wu, and J.L. Gibson. 1990. Ultrastructural observation on Helvellaceae (Pezizales, Ascomycetes). IV. Ascospore ontogeny in selected species of Gyromitra subgenus Discina. Can. J. Bot. 68:317328.

Kocourek. J., G.A. Jamieson, T. Votruba, and V. Horejsi. 1977. Studies on phytohemagglutinins. I. Some properties of the lectins of horse gram seeds (Dolichos biflorus L.). Biochem. Biophys. Acta 500:344-360.

Kohler, G. and C. Milstein. 1975. Continuous cultures of fused cells secreting antibody of predefined specificity. Nature 256:495-497.

Kuhn, P.J. and A.P.J. Trinci. 1990. Cell walls and membranes in fungi - an introduction. In: Kuhn, P.J., A.P.J. Trinci, M.J. Jung, M.W. Goosey, and L.G. Copping (eds). 1990. Biochemistry of cell walls and membranes in fungi. Springer-Verlag, New York, pp. 1-4.

Kuhn, P.J., A.P.J. Trinci, M.J. Jung, M.W. Goosey, and L.G. Copping (eds). 1990. Biochemistry of cell walls and membranes in fungi. SpringerVerlag, New York.

Leduc, E.H. and W. Bernhard. 1962. Water-soluble embedding media for ultrastructural cytochemistry. In: R.J.C. Harris (ed). The interpretation of ultrastructure. Academic Press, New York, pp. 21-45.

LeGal, M. 1947. Recherches sur les ornamentations sporales des Discomycetes opercules. Ann. Sci. Nat. 11 ser. Bot. 7:73-297. - 1951. Les Discomycetes de Madagascar. Paris. 
Lenard, J. and S.J. Singer. 1968. Alterations of the conformation of proteins in red blood cell membranes and in solution by fixatives used in electron microscopy. J. Cell Biol. 37:117-121.

Leung, H. and P.H. Williams. 1987. Nuclear division and chromosome behavior during meiosis and ascosporogenesis in Pyricularia oryzae. Can. J. Bot. 65:112-123.

Mahadevan, P.R., and E.L. Tatum. 1965. Relationship of the major constituents of the Neurospora crassa cell wall to wild-type and colonial morphology. J. Bact. 90(4):1073-1081.

- 1967. Localization of structural polymers in the cell wall of Neurospora crassa. J. Cell Biol. 35:295-302.

Mandal, C. and C. Mandal. 1990. Sialic acid binding lectins. Experimentia 46:433-441.

Manners, D.J., and A. Wright. 1962. $(\chi-1,4-$ glucosans. XIV. The interaction of Concanavalin-A with glycogens. J. Chem. Soc. 1962(4):4592-4600.

Mason, D.Y., J.L. Cordell and K.A.F. Pulford. 1983. Production of monoclonal antibodies for immunocytochemical use. Immunocytochemistry 2:175216.

Mauseth, J.D. 1988. Plant anatomy. Benjamin Cummings Pub. Co., Menlo Park, CA.

McLean, I.W. and P.K. Nakane. 1974. Periodate-lysine-paraformaldehyde fixative: A new fixative for immunoelectron microscopy. J. Histochem. Cytochem. 22:1077-1083.

McMichael, A.J. and J.W. Fabre (eds.). 1982. Monoclonal antibodies in clinical medicine. Academic Press, New York.

Merkus, E. 1973. Ultrastructure of the ascospore wall in Pezizales (Ascomycetes) - I. Ascodesmis microscopica (Crouan) Seaver and A. Nigricans van Tiegh. Persoonia $\underline{7(3): 351-366 .}$

1974. Ultrastructure of the ascospore wall in Pezizales (Ascomycetes - II. Pyronemataceae sensu Eckblad. Persoonia 8(1):1-22.

1975. Ultrastructure of the ascospore wall in Pezizales (Ascomycetes) - III. Otideaceae and Pezizaceae. Persoonia 8(3):227247. 
1976. Ultrastructure of the ascospore wall in Pezizales (Ascomycetes) - IV. Morchella Helvellaceae, Rhizinzceae, Thelebolaceae, and Sarcoscyphaceae. General discussion. Persoonia 9(1):1-38.

Miller, R.L., J.F. Collawn, and W.W. Fish. 1982. Purification and macromolecular properties of a sialic acid-specific lectin from the slug Limax flavus. J. Biol. Chem. 257:7574-7580.

Mims, C.W., E.A. Richardson, and J.W. Kimbrough. 1990. Ultrastructure of ascospore delimitation in freeze substituted samples of Ascodesmis nigricans (Pezizales). Protoplasma 156:94-102.

Mishell, R.I., and R.W. Dutton. 1966. Immunization of normal mouse spleen cell suspensions in vitro. Science, 153:1004-1006.

Miyazaki, T., T. Yadomae, H. Yamada, O. Hayachi, I Suzuki, and Y. Ohshima. 1980. Immunochemical examination of the polysaccharides of mucorales. In: P.A. Sandford, and K. Matsuda (eds.). Fungal Polysaccharides. American Chemical Society, Washington D.C., pp. 8194.

Mol, P.C. and J.G.H. Wessels. 1987. Linkages between glucosamino-glycan and glucan determine alkali-insolubility of the glycan in walls of Saccharomyces cervisiae. FEMS Microbiology Letters 41(1):95-99.

Monsigny, M., A.-C. Poche, C. Sene. R. Maget-Dana, and F. Delmotte. 1980. Sugar-lectin interactions: How does wheat-germ agglutinin bind sialoglycoconjugates? Eur. J. Biochem. 104:147-153.

Morre, D.J., H.H. Mollenhauer, and C.E. Bracker. 1971. Origin and continuity of golgi apparatus. In: J. Reinert, and H. Ursprung (eds.). Results and problems in cell differentiation: Origin and cell continuity of cell organelles. Springer-Verlag, New York, 2:82-126.

Nakane, P.K. and G.B. Pierce. 1966. Enzyme-labeled antibodies: Preparation and application for the localization of antigens. J. Histochem. Cytochem. 14:929-931.

Nawaz, M.S. and W.M. Hess. 1987. Ultrastructure of Neovossia horrida teliospores. Mycologia 79(2):173-179.

Neville, A.C. 1975. Biology of the arthropod cuticle. Springer-Verlag, New York.

Newman, G.R. 1987. Use and abuse of LR White. Histochem. J. 19:118-120.

Newman, G.R. and J.A. Hobot. 1987. Modern acrylics for post-embedding immunostaining techniques. J. Histochem. Cytochem. 35(9):971-981. 
Newman, G.R. and B. Jasani. 1984. Post-embedding immunoenzyme techniques. In: J.M. Polak and I.M. Varndell (eds.). Immunolabelling for electron microscopy. Elsevier Science, New York, pp. 53-70.

Niyo, K.A., H.S. McNabb Jr., and L.H. Tiffany. 1986. Ultrastructure of athe ascocarps, asci, and ascospores of Mycosphaerella populorum. Mycologia 78(2):202-212.

Notario, V., T.G. Villa, and J.R. Villaneuva. 1979. Cell wall associated 1,4-betaD-xylanase in Cryptococcus albidus var. aerius: in situ characterization of the activity. J. Gen. Microbiol. 114:415-422.

Novaes-Ledieu, M. and C.G. Mendoza. 1981. The cell walls of Agaricus bisporus and Agaricus campestris fruiting body hyphae. Can. J. Microbiol. 27(8):779-787.

Pardue, R.L., R.C. Brady, G.W. Perry, and J.R. Dedman. 1983. Production of monoclonal antibodies against calmodulin by in vitro immunization of spleen cells. J. Cell Biol. 96:1149-1154.

Peberdy, J.F. 1990. Fungal cell walls - A review. In: P.J. Kuhn, A.P.J. Trinci, M.J. Jung, M.W. Goosey, and L.G. Copping (eds.). Biochemistry of cell walls and membranes in fungi. Springer-Verlag, New York, pp. 5-30.

Pereira, M.E.A., E.A. Kabat, R. Lotan, and N Sharon. 1976. Immunochemical studies on the specificity of the peanus (Arachis hypogaea) agglutinin. Carbohydr. Res. 51:107-118.

Pollard, K., D. Lunny, C.S. Holgate, P. Jackson, and C.C. Gird. 1987. Fixation, processing, and immunochemical reagent effects on preservation of $T$ lymphocyte surface membrane antigens in paraffin-embedded tissue. J. Histochem. Cytochem 35(11):1329-1338.

Prabhakar, B.S., M.V. Haspel, and A.L. Notkins. 1984. Monoclonal antibody techniques applied to viruses. In: $\mathrm{K}$. Maramorosah and $\mathrm{H}$. Koprowski (eds.). Methods in virology, volume VII. Academic Press Inc., New York, pp. 1-18.

Preston, J.F. and J.E. Gander. 1968. Isolation and partial characterization of the extracellular polysaccharides of Penicillium charlesii. I. Occurrence of galactofuranose in high molecular weight polymers. Arch. Biochem. Biophys. 124:504-512.

Raspail, F.V. 1830. Essai de chime microcopique appliquee a la physiologie. Paris.

Rees, D.A. 1977. Polysaccharide shapes. Chapman and Hall, London. 
Reeves, F, Jr. 1967. Ascospore formation in Pyronema domesticum. Mycologia 59:1018-1033.

Reiss, E. 1986. Molecular immunology of mycotic and actinomycotic infections. Elsevier Scientific, New York.

Reiss, E., J.B. Knowles, S.L. Bragg, and L. Kaufman. 1986a. Monocional Antibodies against the M-protein and carbohydrate antiges of histoplasmin characterized by the enzyme-linked immunoelectrotransfer blot method. Infect. Immun. 53(3):540-546.

Reiss, E., L. DeRepentigny, R.J. Kuykendall, A.W Carter, R. Galindo, P.Auger, S.L. Bragg, and L. Kaufman. 1986b. Monoclonal antibodies against Candida tropicalis Mannan: Antigen detection by enzyme immunoassay and immunofluorescence. J. Clin. Microbiol. 24(5):796-802.

Romano, E.L., C. Stolinski, and N.C. Hughes-Jones. 1974. An antiglobulin reagent labelled with colloidal gold for use in electron microscopy. Immunochemistry, 17:521.

Rosenburger, R.F. 1976. The cell wall. In: J.E. Smith and D.R. Berry (eds.), The filamentous fungi, volume 2. Wiley, New York, pp. 328-344.

Rosing, W.C. 1982. Ultrastructure of Ascus and ascospore development in Chaetomium brasiliense. Mycologia 74(6):960-974.

. 1985. Fine structure of cleistothecia, asci, and ascospores of Myxotrichum deflexum. Mycologia 77(6):920-926.

Roth, J. 1983. Application of lectin-gold complexes for electron microscopic localization of glyconjugates on thin sections. J. Histochem. Cytochem. 31:987-999.

. 1989. Postembedding labeling on lowicryl K4M tissue sections: Detection and modification of cellular components. Methods Cell Biol. 31:513-551.

Rudall, K.M. 1969. Chitin and its association with other molecules. J. Polymer Sci. $\underline{\mathrm{C} 28}: 83-102$.

Salt, S.D. and J.D. Gander. 1985. Variations in phosphoryl substituents in extracellular peptidophosphogalacto-mannans from Penicillium charlesii G. Smith. Exp. Mycol. 9:9-19.

Schutzbach, J.S. and H. Ankel. 1972. Mannosyltransferases from Cryptococcus laurentii. Methods in Enzymology 28:553-560. 
Sercarz, E., B. Bonavida, A. Miller, R.J. Scibiendki, and J.A. Stratton. 1974. Immune response to Lysozyme: Limited heterogeneity caused by restricted T cells. In: E.F. Osserman, R.E. Canfield, and S. Beychok (eds.). Lysozyme. Academic Press, New York, pp. 143-152.

Sharon, N. and H. Lis. 1989. Lectins as cell recognition molecules. Science 246:227-234.

Simmons, R.B. 1989. Comparison of chitin localization in Saccharomyces cerevisiae and Cryptococcus neoformans, and Malassezia spp. Mycol. Res. 93(4):551-553.

Singer, S.J. 1959. Preparation of an electron dense antibody conjugate. Nature (London) 183:1523-1524.

Smith, E.E., Z.H.G. Smith and I.J. Goldstein. 1968. A turbidimetric study of the interaction of concanavalin $A$ with amylopectin and glycogen and some of their enzymic and chemical degradation products. Biochem. J. 107:715-724.

Stagg, C.M. and M.S. Feather. 1973. The characterization of a chitin-associated D-glucan from the cell walls of Aspergillus niger. Biochim. Biophys. Acta 320:64-72.

Stefanini, M., C. DeMartino, and L. Zamboni. 1967. Fization of ejaculated spermatozoa for electron microscopy. Nature 216:173-174.

Ste-Marie, L., S. Senechal, M. Boushira, S. Garzon, H. Strykowski, L. Pedneault, and L. DeRepentigny. 1990. Production and characterization of monoclonal antibodies to cell wall antigen of Aspergillus fumigatus. Infection and Immunity, 58(7):2105-2114.

Sternberger, L.A. 1986. Immunocytochemistry. Churchill Livingstone. New York.

Stirling, J.W. 1989. Ultrastructural localization of lysozyme in human colon eosinophils using the protein A-gold technique: Effects of tissue processing on probe distribution. J. Histochem. Cytochem. 37(5):709714.

1990. Immuno- and affinity probes for electron microscopy: A review of labeling and preparation techniques. J. Histochem. Cytochem., 38(2): 145-157.

Sumner J.B. and S.F. Howell. 1936. The identification of the hemagglutinin of the jack bean with concanavalin A. J. Bacteriol. 32:227-237. 
Tanner, W. 1990. Synthesis and function of glycosylated proteins in Saccharomyces cerevisiae. In: P.J. Kuhn, A.P.J. Trinci, M.J. Jung, M.W. Goosey, and L.G. Copping (eds.), Biochemistry of cell walls and membranes in fungi. Springer-Verlag, New York, pp. 109-118.

Tolson, N.D., B. Boothroyd, vand C.R. Hopkins. 1981. Cell surface labelling with colloidal gold particulates: The use of avidin and staphylococcal protein A-coated gold in conjunction with biotin and Fc-bearing ligands. J. Micorsc. 123:215-220.

Voller, A., and D.E. Bidwell. The enzyme linked immunosorbent assay, volume 2: A review of recent developments with abstracts of microplate applications. MicroSystems, Guernsey, U.K.

Weibull, C., A. Christiansson, and E. Carlemalm. 1983. Extraction of membrane lipids during fixation, dehydration and embedding of Acholeplasma laidlawii - cells for electron microscopy. J. Microsc. 129:201-207.

Wessels, J.G.H. 1979. Wall structure and growth in Schizophyllum commune. In: J.H. Wessels \& A.P.J. Trinci (eds.). Fungal walls and hyphal growth pp. 27-48.

. 1986. Cell wall synthesis in apical hyphal growth. International Review of Cytology 104:37-79.

Wu, C.G. and J.W. Kimbrough. 1991a. Ultrastructural studies on ascosporogenesis in Ascobolus stictoideus (Pezizales, Ascomycetes). Can. J. Bot. (in press).

1991b. Ultrastructural studies on ascosporogenesis in Ascobolus immersus (Pezizales, Ascomycetes). Mycologia (in press).

Yamasaki, F.B., D.T. and R.E. Feeney. 1982. Periodate oxidation of methionine in proteins. Anal. Biochem. 125:183-189.

Young, K.D. and H.W. Larsh. 1982. Production and characterization of a hybridoma-derived antibody to Blastomyces dermatitidis. J. Clin. Microbiol. 15:204-207.

Zickler, D. and J.-M. Simonet. 1980. Identification of gene-controlled steps of ascospore development in Podospora anserina. Exp. Mycol. 4:191-206.

Zonneveld, B.J.M. 1971. Biochemical analysis of the cell wall of Aspergillus nidulans. Biochim. Biophysi. Acta 249:506-514. 
1972. Morphogenesis in Aspergillus nidulans: the significance of $\alpha-1,3$ glucanase for cleistothecium development. Biochim. Biophys. Acta 273:174-187.

1973. Inhibitory effect of 2-deoxyglucose on cell wall $\alpha-1,3$ glucan synthesis and cleistothecium development in Aspergillus nidulans. Developmental Biology 34:1-8. 


\section{BIOGRAPHICAL SKETCH}

My given name is Demaris Ellen Lusk, but most people know me as "Dee." I was born in Eugene, Oregon on 19 June 1957. I grew up on a small family farm near Eugene. There I learned to garden, can, cook, and raise both dairy and beef stock. I spent many hours walking in the neighboring woods and valleys. During these walks I gained a appreciation for the land and its many plant and animal residents.

I graduated from Winston Churchill High School in 1975. A year after graduation I enrolled at Lane Community College. While attending this college I decided on a program in plant sciences. After two years of basic course work at Lane Community College I transferred to Oregon State University in Corvallis, Oregon. There I earned a Bachelor of Science degree and a Master of Science degree, both in Botany. My masters thesis work was in the area of fungal systematics. I came to the University of Florida to continue my studies of fungi and their biology. Additionally, I had hoped to learn techniques of electron microscopy. I have achieved these goals and more here at the University of Florida and I am grateful for the outstanding training I have received. 
I certify that I have read this study and that in my opinion it conforms to acceptable standards of scholarly presentation and is fully adequate, in scope and quality, as a dissertation for the degree of Doctor of Philosophy.

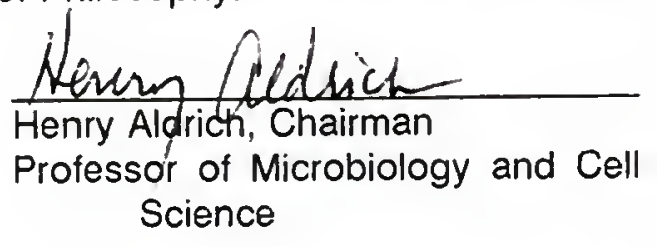

I certify that $I$ have read this study and that in my opinion it conforms to acceptable standards of scholarly presentation and is fully adequate, in scope and quality, as a dissertation for the degree of Doctor of Rhilosophy.
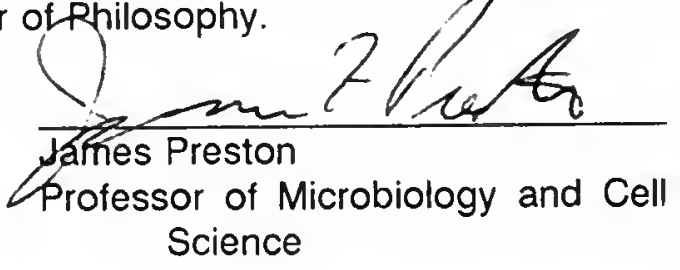

I certify that I have read this study and that in my opinion it conforms to acceptable standards of scholarly presentation and is fully adequate, in scope and quality, as a dissertation for the degree of Doctor of Philosophy.

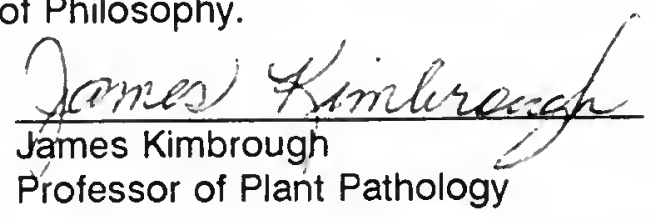

I certify that I have read this study and that in my opinion it conforms to acceptable standards of scholarly presentation and is fully adequate, in scope and quality, as a dissertation for the degree of Doctor of Philosophy,

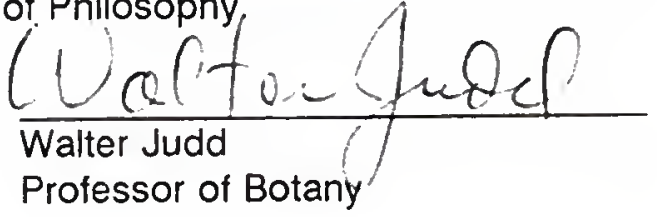

I certify that I have read this study and that in my opinion it conforms to acceptable standards of scholarly presentation and is fully adequate, in scope and quality, as a dissertation for the degree of Doctor of Philosophy'.

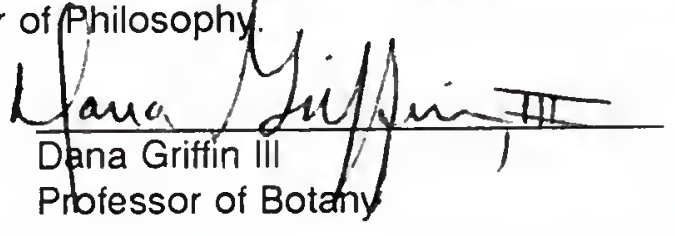

This dissertation was submitted to the Graduate Faculty of the Department of English in the College of Liberal Arts and Sciences and to the Graduate School and was accepted as partial fulfillment of the requirements for the degree of Doctor of Philosophy.

August 1991

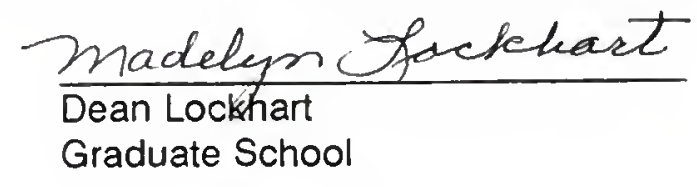


UNIVERSITY OF FLORIDA

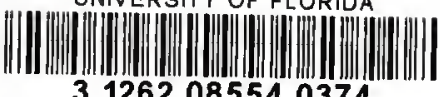

31262085540374 